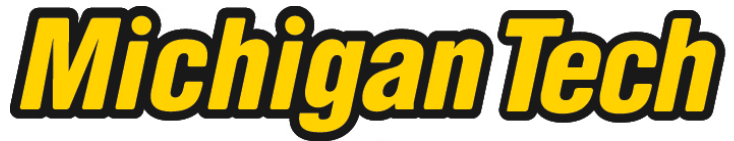 \\ Michigan Technological University Create the Future Digital Commons @ Michigan Tech
}

Dissertations, Master's Theses and Master's Reports - Open

Dissertations, Master's Theses and Master's

Reports

2014

\section{REVIEW OF FACTORS AFFECTING SUSTAINABILITY IN THE UNIVERSITIES}

Hosna Ajilian

Michigan Technological University

Follow this and additional works at: https://digitalcommons.mtu.edu/etds

Part of the Natural Resources Management and Policy Commons, and the Oil, Gas, and Energy Commons

Copyright 2014 Hosna Ajilian

\section{Recommended Citation}

Ajilian, Hosna, "REVIEW OF FACTORS AFFECTING SUSTAINABILITY IN THE UNIVERSITIES", Master's Thesis, Michigan Technological University, 2014.

https://doi.org/10.37099/mtu.dc.etds/867

Follow this and additional works at: https://digitalcommons.mtu.edu/etds

Part of the Natural Resources Management and Policy Commons, and the Oil, Gas, and Energy Commons 


\title{
REVIEW OF FACTORS AFFECTING SUSTAINABILITY IN THE UNIVERSITIES
}

\author{
By
}

Hosna Ajilian

\begin{abstract}
A THESIS
Submitted in partial fulfillment of the requirements for the degree of MASTER OF SCIENCE

In Applied Natural Resource Economics
\end{abstract}

\section{MICHIGAN TECHNOLOGICAL UNIVERSITY}

2014

(C) 2014 Hosna Ajilian 
This thesis has been approved in partial fulfillment of the requirements for the Degree of MASTER OF SCIENCE in Applied Natural Resource Economics.

School of Business and Economics

Thesis Advisor: Becky Lafrancois

Committee Member: $\quad$ Mark C Roberts

Committee Member: $\quad$ Patricia Bennett

School Dean: Eugene Klippel 


\section{Table of Contents}

\section{Contents}

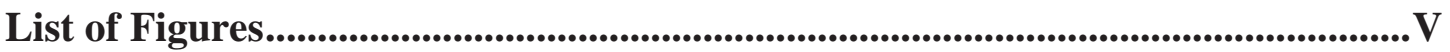

List of Tables ................................................................................................

Acknowledgments ................................................................................................................... VIII

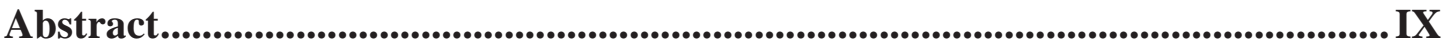

1. Introduction...................................................................................................................1

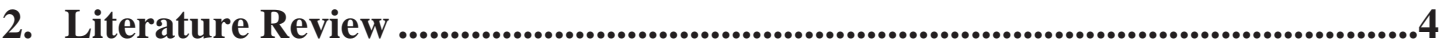

2-1- A General Review of Campus Sustainability Literature in Higher Education

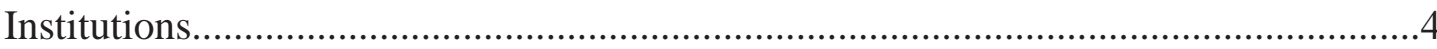

2-2- A Deeper Look into an Empirical Analysis: Stafford's Case Study ...............13

3. Research Approach and Methodology .....................................................................21

3-1- Description of the Ordered Probit Model.....................................................23

3-2- The Econometrics Model in the Current Research .........................................24

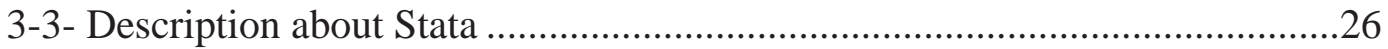

3-4- Explanatory Variables ..............................................................................29

3-5- Explanation of the Explanatory Variables in the Model ....................................31

3-5-1- Carnegie Classification ..........................................................................3

3-5-2- Geographical Zone..........................................................................

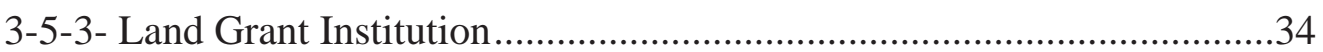

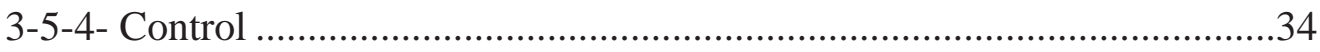

3-5-5- Top 50 Liberal Art ...........................................................................

3-5-6- Renewable Portfolio Standard (RPS)....................................................

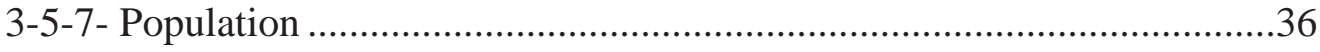

3-5-8- Share of Total Degrees at Bachelor's Level............................................36

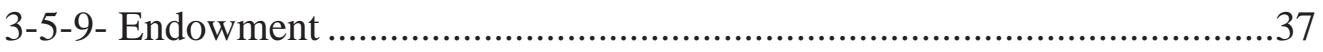

3-5-10- Average Amount of Federal Grants ..........................................................37

3-5-11- Political Point of View of the State.....................................................38

3-5-12- Research and Related Expenses........................................................38 
3-5-13- Net Tuition

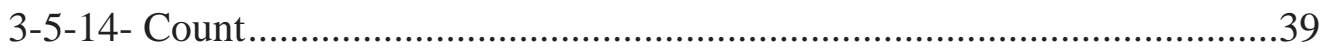

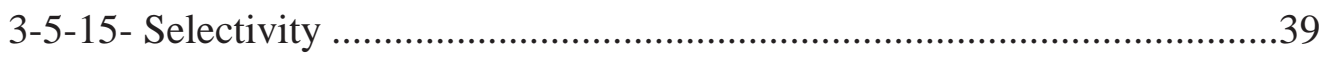

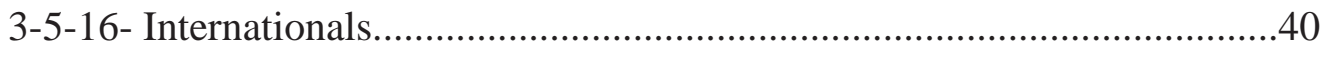

3-6- Test for Multicollinearity ......................................................................40

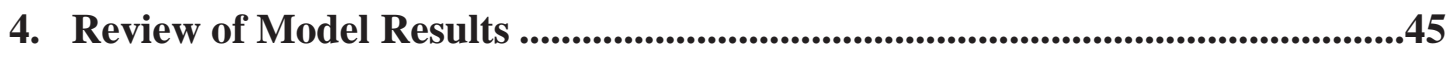

4-1- Four Part Specification Test over Dummy Variables ................................46

4-2- "Four Parts Specification Test" over Categorical Variables ..........................56

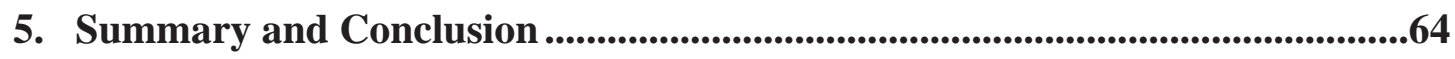

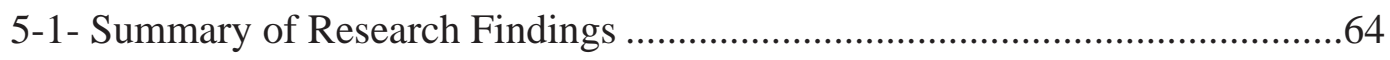

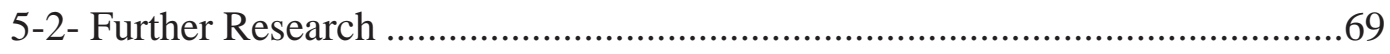

Appendix 1- The College Sustainability Report Card ...........................................70

Appendix 2- List of Universities Used in the Research (Extracted from Report

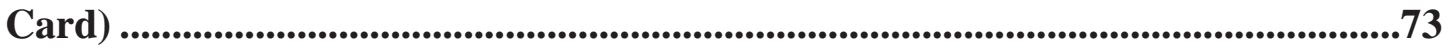

Appendix 3-Testing Equality Constraints in the Model.........................................87

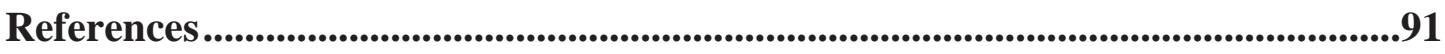




\section{List of Figures}

Figure 2-1- Integrated approach toward campus sustainability [4] ......................... 10

Figure 3-1- Sustainability grades distribution among the IHEs............................... 22

Figure 3-2- Letter grades and their equivalent numerical grades with their percentage

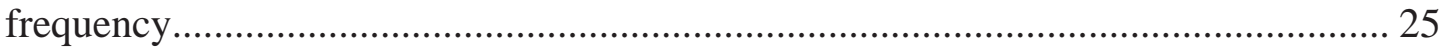

Figure 3-3- Statistical summary of variables used in the STATA............................ 31

Figure 3-4- Correlation matrix of all the (non-dummy) variables against each other 41

Figure 3-5- Variance inflation factor (VIF) to check for multicollinearity ............... 43

Figure 4-1- Snapshot of STATA results excluding the "Dummy Variables" ............ 45

Figure 4-2- STATA results excluding "Education and related expenses" and "Total

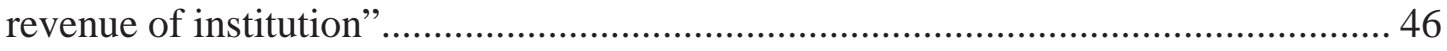

Figure 4-3- Population indicators used in the STATA model .................................. 47

Figure 4-4- Snapshot of F-test for "Populsmall" and "Populbig" variables, derived

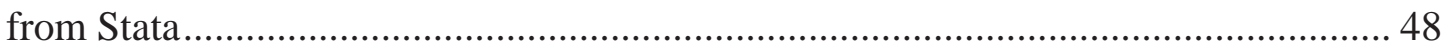

Figure 4-5- Snapshot of F-test for "RPS" variable, derived from Stata ..................... 49

Figure 4-6- Snapshot of F-test for "Top50LA" variable, derived from Stata.............. 50

Figure 4-7- Snapshot of F-test for "Controlprivate" variable, derived from Stata ..... 51

Figure 4-8- Snapshot of F-test for "Landgrant01" variable, derived from Stata ........ 52

Figure 4-9- Snapshot of F-test for "Geography zone" variables, derived from Stata. 53

Figure 4-10- The research activity indicators used in the STATA model .................. 54

Figure 4-11- Snapshot of F-test for "Carnegiebach" and "Carnegiedoc", derived from

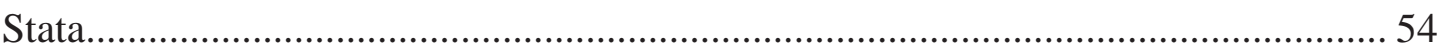

Figure 4-12- Snapshot of STATA variables including the "dummy variables"......... 55

Figure 4-13- Snapshot of F-test for "Bach_deg_share_of_tot_deg” variable, derived

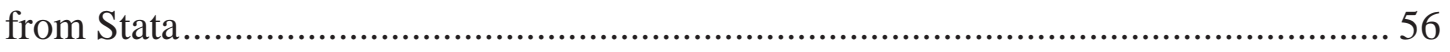

Figure 4-14- Snapshot of F-test for "Endowment" variable, derived from Stata ....... 57

Figure 4-15-Snapshot of F-test for "Fed_grant_avg_amount" variable, derived from

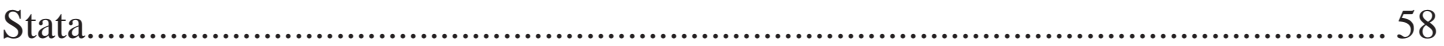

Figure 4-16- Snapshot of F-test for "Obama08_share” variable, derived from Stata 59

Figure 4-17- Snapshot of F-test for "Research_related_cost" variable, derived from

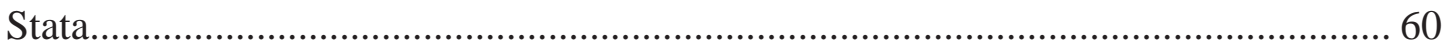

Figure 4-18- Snapshot of F-test for "Nettuition01" variable, derived from Stata ...... 61

Figure 4-19- Snapshot of F-test for "Count" variable, derived from Stata.................. 62

Figure 4-20- Snapshot of F-test for "Select" variable, derived from Stata................. 62

Figure 4-21- Snapshot of F-test for "International" variable, derived from Stata ...... 63

Figure 4-22- Snapshot of STATA variables after dropping the variable "Count" ..... 64 
Figure A-1- Snapshot of testing equality constraint in a regression through Stata .... 87

Figure A-2- The result of test command in Stata ................................................. 88

Figure A-3- Unconstrained model extracted from Stata........................................ 89

Figure A-4- Constrained model extracted from Stata............................................ 90

Figure A-5-The result of "ftest" unconstrained against constrained ........................ 90 


\section{List of Tables}

Table 2-1- The Barriers, Motivators and Benefits of green buildings for IHE [11] ... 11

Table 3-1- Different categories of letter grades ..................................................... 26

Table 3-2- List of Explanatory Variables used in the Model..................................... 32

Table 3-3- Table of correlation status between all non-dummy variables of the model

Table 5-1- Classification of the variables which have the most impact on sustainability 68

Table A-1- List of Universities Used in the Research (Extracted from Report Card) [15]. 


\section{Acknowledgments}

I would like to thank some wonderful people who helped me to finish my master thesis. First, I am very thankful to have had the opportunity to work with my advisor Dr. Becky Lafrancois. Her great advice and assistance during all courses which I had with her as well as the current research helped me a lot in keeping my progress on schedule. In addition, I would like to express my very great appreciation to Dr. Mark Roberts, my research committee member and my professor in Econometrics, for his valuable contribution through this research including all technical comments and feedback I received from him regarding my research approach and methodology. I also need to thank Dr. Patricia Bennett, another committee member of my master thesis, who was always willing to help and give her best suggestions and support either when I was working with her, or through my research work.

Besides that I should show my appreciation toward Dr. Gary Campbell for his great support throughout the period I was involved with the Applied Natural Resource program. I learnt many things from his lectures and courses I attended. Also, special thanks to Dr. Thomas Merz, Professor at the School of Business and Economics, for all his academic support and motivation through the program.

I would also like to thank Mr. Mark Orlowski, Founder \& Executive Director of Sustainable Endowments Institute, who supported my research by giving his approval for using the data.

In addition, special thanks go to Mr. David Taivalkoski, director of Energy Management and Sustainability at Michigan Tech, who spent his time to answer my questions about campus building energy management system.

Finally, I would like to thank my family for their love, and encouragement throughout my study. My parents and my sisters always cheering me up and my husband stood by me with his great support at all times.

To My Little Lovely Daughter: Lillian Pouryousef 


\section{Abstract}

Purpose - The focus of this research is to find out a meaningful relationship between adopting sustainability practices and some of the characteristics of institutions of higher education (IHE). IHE can be considered as the best place to promote sustainability and develop the culture of sustainability in society. Thus, this research is conducted to help developing sustainability in IHE which have significant direct and indirect impact on society and the environment.

Design/methodology/approach - First, the sustainability letter grades were derived from "Greenreportcard.org" which have been produced based on an evaluation of each school in nine main categories including: Administration, Climate Change \& Energy, Food \& Recycling, etc. In the next step, the characteristics of IHE as explanatory variables were chosen from "The Integrated Postsecondary Education Data System" (IPEDS) and respective database was implemented in STATA Software. Finally, the "ordered-Probit Model" is used through STATA to analyze the impact of some IHE's factor on adopting sustainability practices on campus.

Finding - The results of this analysis indicate that variables related to "Financial support" category are the most influential factors in determining the sustainability status of the university. "The university features" with two significant variables for "Selectivity" and "Top 50 LA" can be classified as the second influential category in this table, although the "Student influence" is also eligible to be ranked as the second important factor. Finally, the "Location feature" of university was determined with the least influential impact on the sustainability of campuses.

Originality/value - Understanding the factors which influence adopting sustainability practices in IHE is an important issue to develop more effective sustainability's methods and policies.

Keywords - Institutions of higher education (IHE), Campus sustainability, Explanatory variables, Characteristics of institutions, STATA

Paper type - MS thesis 


\section{Introduction}

Sustainability is an important subject which as time passes, plays a more crucial role in solving the challenges our world faces today. Sustainability refers to a broad area of knowledge which can be determined based on different applications. Therefore, the term of "sustainability" has many different definitions based on its respective applications, but according to U.S. Environmental Protection Agency (EPA) sustainability means "Everything that is needed for our survival and wellbeing depends, either directly or indirectly, on our natural environment. Sustainability creates and maintains the conditions under which humans and nature can exist in productive harmony, that permit fulfilling the social, economic and other requirements of present and future generations." [1]

According to Capozucca and Sarni (2012), sustainability is considered as a motivator for any type of creativity which can help businesses by increasing the efficiency of their operation, decreasing cost, and limiting the environmental consequences of projects. [2] Since every decision can affect other parameters in the long and short term, it is important to promote the idea of sustainability in all choices and actions.

The concern about sustainability has emerged as a result of rapid growth of population, the economy and consumption of our natural resources. [1] Due to the fact that most natural resources are limited, they will be consumed and eventually exhausted. Some examples of limited resources include: clean water, soil nutrients, 
and energy resources. Thus, it is essential to make good present decisions in order to avoid limiting the choices of future generations.

For instance, climate change, which is the result of human activity, is going to become one of the biggest concerns in the coming decades. Green house gases which are mainly produced by human activities can cause the elevation of surface temperatures. This climate change will influence the sustainability of our water supply which can be a big threat for future generations. According to research conducted by consulting firm, Tetra Tech, for the Natural Resources Defense Council (NRDC), more than 1,100 counties in the United States will encounter the risk of water shortages in future decades (less than 40 years), due to global warming. [3]

According to Alshuwaikhat (2008), an institution's campus is called sustainable when it does not change its surrounded environment, boosts economic growth and helps toward society's progress. [4] In research conducted by Cortese (2003), he emphasized the critical role of higher education in sustainability which can help authorities to solve the respective challenges. [5] Institutions of higher education (IHE) not only can promote sustainability by adopting its features on their campuses, but they also can develop the culture of sustainability in society. That is why universities can be considered as small towns which have significant direct and indirect impact on the society and the environment, based on their size, population and activities which take place in the universities. [4]

The focus of this research is on sustainability in institutions of higher education (IHE). Although not many empirical studies and research has been done in this field, 
the "College Sustainability Report Card" is one successful example which evaluated sustainability on the campuses in U.S. institutions. The goal of the current research is to find the factors which affect sustainability in IHE to increase the efficiency of sustainability practices on campuses. Although each university has unique environmental goals and resources for achieving them, they can learn a lot from each other.

To meet the goal of this research, the sustainability letter grade, which is given to each IHE by the "College Sustainability Report Card", has been used as a sustainability scale. On the other hand, by using a comparative evaluation of the characteristic of institutions, this study tries to identify those characteristics which affect the sustainability of the campuses.

The current thesis is divided to five chapters. It begins with review of the literature on the sustainability concept and current practices in academic institutes. Chapter two is segregated into two major sections which the first part will be a general review of campus sustainability literature in higher education institutions. Following that, more details about sustainability practices and modeling effort will be explained in second part of chapter two, derived from Stafford's case study. In the third chapter, the research methodology and modeling approach will be explained in detail, including a description about model variables and the Stata (software used through the research); while in next chapter the results of the model (derived from the Stata software) will be explained in chapter four. Finally, the summary and conclusion of research as well as further research topics are explained in chapter 5 . 


\section{Literature Review}

\section{2-1- A General Review of Campus Sustainability Literature in Higher Education Institutions}

In the following section, the typical contents of several articles with emphasis on sustainability on campuses have been reviewed. The analysis of the techniques and findings provides a general view toward sustainability status on campuses and factors which affect adopting sustainability practices in institutions of higher education (IHE).

The sustainability of a campus is a new subject and still a lot of research and work needs to be done in this field. In a paper conducted by Velazquez, et al (2006), the authors focused on the fundamental rules of sustainability in higher education institutions. [6] The authors used an empirical model to depict the basic necessities which are important to maintain sustainability on campuses.

In this paper, the authors used a literature review to take advantage of other universities experience all over the world. In addition, they conducted a survey including 26 questions (open-answer format) which were specifically looking at the particular groups of experts. The model consists of four different phases which were developed based on literature review and the empirical study. Phase one develops a sustainability vision for the universities, phase two points to the mission, phase three talks about a sustainability committee, and finally sustainability strategies discusses in the fourth phase. 
These four phases present all the sustainability plans of the respective universities. Three of them including education, research, and outreach and partnership can be organized inside or outside the university campus, but the fourth one which is "implementing sustainability" is specific to the campus itself.

Two fundamental means of all these four strategies is raising awareness of sustainability and using technology that helps to reduce environmental issues at either local or global levels. According to the result of their survey, to meet sustainability initiatives, $40 \%$ of work depends on cultural awareness and 25\% depends on both awareness and technology. (According to the reference the rest of answers are not available).

To change the model to be more empirical, defining the proper tools for tracking, analyzing, and controlling the sustainability plans is crucial. One of the important problems which is quoted in this paper is lack of indicators to measure sustainability in higher education institutions. [6]

In other research conducted by Viebahn (2002), the author focused on The Global Reporting Initiative (GRI) which is one of the leading entities in the field of sustainability practices, and concentrated on the idea of sustainability reporting as a methodology to adopt more sustainable practices.

In this paper GRI was named as an organization with high level of different parameters to evaluate the sustainability performance. Although education, research, making policy and implementing sustainability is crucial toward having a sustainable 
campus, continuous effort is needed to avoid turning it to a static process and to meet the aim of improving sustainability in the higher education institutions. [7]

Velazquez et al. developed research in the field of sustainability in higher education institutions particularly in the University of Sonora, Hermosillo - Mexico, in 2005. The authors applied a literature review to study the failure and unsuccessful experience in implementing sustainability initiative on campuses around the world. In this study the researchers focused on the factors which prevent the implementation of sustainability. The goal was to develop the level of efficiency of current sustainability plans and being prepared for the United Nations Decade of Education for Sustainable Development.

The authors recognized a long list of different parameters (18 different factors) which affect effectiveness of sustainability plans in higher education institutions. [8] Some of these factors presented in their paper are mentioned as the following:

- Shortage of interest, awareness and involvement

- Organizational structure

- Shortage of budget

- $\quad$ Shortage of administrative support from university authorities

White developed research in 2014 to do a comprehensive analysis of campus sustainability planning effort that addresses operation, academic and administration aspects of university campuses in the USA. His research points out the importance of applying integrated campus sustainability plans at IHE. He also presents a basic system for evaluating the sustainability plans. In this research, 27 campus 
sustainability plans have been examined to determine the specifications of the institutions that have practiced the respective plans. These plans are important because they can be used to organize, focus and measure sustainability practices in any level of performance. [9] According to his study, higher education has significant role in progress of sustainability concepts and practices. The IHE effort can be in different methods like signing for the American College and University Presidents' Climate Commitment (ACUPCC), providing local foods, increasing recycling, and using environmental friendly materials.

On the other hand IHE nature which allows testing and exploring new ideas can educate future leaders, as well. The results of this research show that campus sustainability plans in the USA are in different manners and the most influential factor in these plans is environmental features. Also sustainability plans on campus has lack of balance in the way that it focuses on the operations, while both academic and administrative aspects may receive less attention in comparison to the operation aspects. Most campuses' sustainability plans consider both economic and equity issues besides environmental issue and it is unique to higher education and should be evaluated based on their processes. In conclusion, campus sustainability plans can help higher education institutes have greater contribution to global sustainability plans. [9]

Higher education institutions can change their campuses into models of sustainable development and serve as agent of sustainability in their communities. The University of British Columbia is one of the examples that show the success of an institution that 
has advanced its campus' academic and practical sustainability goals and developed the partnerships between campus and the community. In research conducted by Bilodeau et al, an empirical model was developed to show how the sustainability imperative can allow universities to reduce the respective climate risks, increase the efficiencies of operation and decrease daily utility costs. In this model the collaborations between academic institutes and public/private organizations have been addressed as an important factor to improve the sustainability levels in the universities and their respective communities. Several parameters, including public awareness, policy regulation, and climate issues, are among the most important criteria of their model which was developed to evaluate the sustainability across multiple sectors. In this research, Okanagan campus in The University of British Columbia has been examined as one empirical model of sustainability collaborations and future plans developed in universities. A brief overview of motivating parameters which have been involved in sustainability assessment at UBC's Okanagan campus, are summarized in the following.

The planned construction of a new academic environment provided the opportunity for future improvement through sustainability levels. Leadership support of sustainability and a new idea was a fundamental element to the campus' progress. Their plan to establish a sustainability office helped to speed the process and to develop its sustainability commitments. The influence of sustainability leaders who can establish a bilateral relationship between internal and external stakeholders was a crucial factor to advance the sustainability initiatives. [10] 
The existence of the "Provincial Government's Carbon Neutral Mandate" provided an opportunity to establish a win-win relationship between administrative and leadership entities in order to reduce the carbon emission and related costs. The opportunity to arrange new projects to check and reduce likely risks was considered for potential improvement. The ability to evolve sustainability projects from idea to practice can be profitable from financial standpoint.

In other research conducted by Alshuwaikhat and Abubakar (2008), an integrated and systematic approach toward sustainable campuses was analyzed. According to this research, universities can be considered as small cities which can affect the environment either directly or indirectly. The suggestion solution is that the environmental pollution which is caused by universities can be reduced by an efficient alternative of technical and institutional parameters. To achieve a sustainable campus and to conquer the limitation of current management, the authors proposed a framework that has been formed by integrating social responsibility and public involvement, university Environmental Management System (EMS), which promotes sustainability in the research and academic areas. The following figure shows a structure of the proposed methodology to making sustainability progress on campus. The significant feature of this framework is its integrated and systematic approach of looking at all the sustainability issues. [4] 


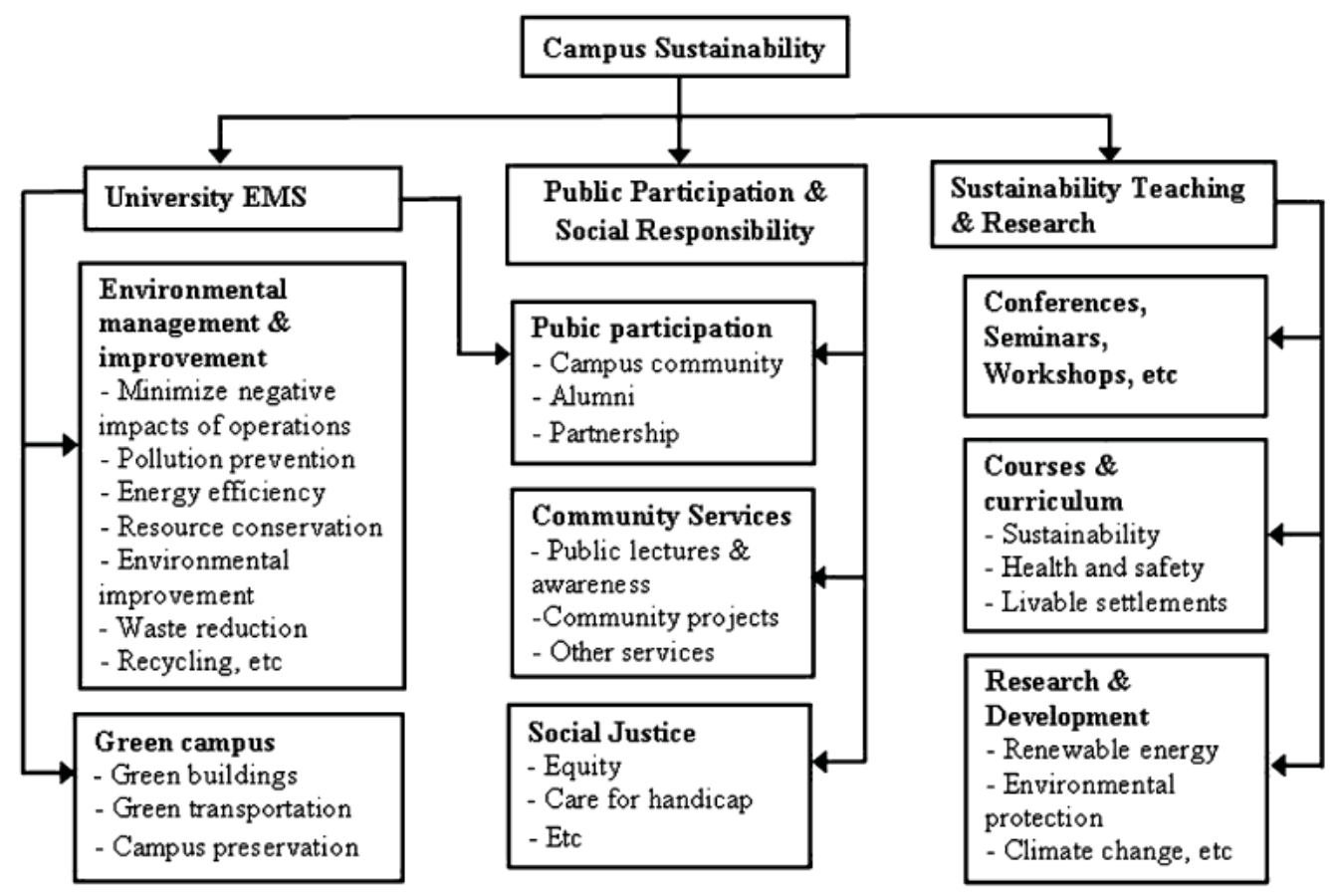

Figure 2-1- Integrated approach toward campus sustainability [4]

Since there has been limited research about construction of green buildings especially on large higher education institutions; the results of a case study of constructing green buildings in the University of Waterloo can be considered as a good resource for further sustainability construction. In a research conducted by Richardson and Lynes (2007), four areas of weakness were identified as barrier to construction of green building in the university, including: "lack of an effective leadership with decision making power", "shortage of quantifiable sustainability targets", "operational structure which does not value building design with lower energy costs", and "lack of good communication between three involving parties" (designer, facilities management and faculty). More details about these parameters are presented in table below. [11] 
Table 2-1- The Barriers, Motivators and Benefits of green buildings for IHE [11]

\begin{tabular}{|c|c|c|}
\hline Barriers & Catalysts (Motivators) & Motivations (Benefits) \\
\hline $\begin{array}{l}\text { (Perceived) higher initial } \\
\text { Capital Cost (Financial } \\
\text { Barriers) } \\
\text { Low levels of innovation } \\
\text { among designers/architects }\end{array}$ & $\begin{array}{l}\text { Pressure from } \\
\text { stakeholders } \\
\text { (students) } \\
\text { Internal environmental } \\
\text { champion with decision } \\
\text { making power }\end{array}$ & $\begin{array}{l}\text { Life-cycle operational } \\
\text { savings } \\
\text { (e.g. energy saving) } \\
\text { Better indoor work } \\
\text { environments increased } \\
\text { worker } \\
\text { Productivity, reduced } \\
\text { absenteeism, customer } \\
\text { satisfaction (e.g. students) }\end{array}$ \\
\hline $\begin{array}{l}\text { Weak Building processes and } \\
\text { policies } \\
\text { Lack of quantitative } \\
\text { Sustainability indicators }\end{array}$ & $\begin{array}{l}\text { Other IHE setting a } \\
\text { precedent } \\
\text { Long term liabilities of } \\
\text { "un" -environmental } \\
\text { buildings } \\
\text { (risk management) }\end{array}$ & $\begin{array}{l}\text { Lower environmental } \\
\text { impact } \\
\text { Positive reputation - image } \\
\text { Enhancement (students, } \\
\text { visitors, faculty recruitment, } \\
\text { community-at-large } \\
\text { Potential increase in } \\
\text { donors(due to socially } \\
\text { responsible reputation) }\end{array}$ \\
\hline $\begin{array}{l}\text { Lack of internal leadership } \\
\text { regarding sustainability issues } \\
\text { Lack of } \\
\text { collaboration/communication } \\
\text { harnessing academic } \\
\text { knowledge } \\
\text { and internal skills } \\
\text { Financial constrains of IHE } \\
\text { budget (low economic times) }\end{array}$ & & \\
\hline
\end{tabular}

Sardianou and Genoudi, (2013) developed research about evaluating different factors which may influence the user willingness to consider new sources of energy including renewable energies. According to this research, the factors which have positive effect on people's intention to adopting renewable energy sources in the resident sector are:

- being in the middle age group,

- having higher education, 
- higher income, and

- financial policy (like tax deduction)

Based on their findings both marital status and gender do not have a significant effect on people willingness to adopt sustainability in their home environment. Also, according to the empirical results of this study, financial incentives have the most significant role to adopt renewable energies in residential sector. [12]

In another paper by Posner and Stuart (2013), campus sustainability was evaluated based on using a systematic framework as an essential parameter for developing organizational change and strategically prioritizing campus sustainability work. Since the available resources to implement sustainability plans are always limited, prioritizing sustainability initiatives is important. The approach applied in this research helps the authorities to improve sustainability on campus by determining key leverage points, as identifying these parameters has an important role in evaluating different programs and most importantly to make connections between campus and the social and environmental context of its surrounding.

According to this research, the authors concluded that each university has unique and different potential for campus changes to maintain sustainability factors. Some of the factors which determine the unique capacity of each university can be named as its priorities across campus relationship and availability of resources. [13] 


\section{2-2- A Deeper Look into an Empirical Analysis: Stafford's}

\section{Case Study}

One of the empirical research that studies sustainability factors on campus has been conducted by Stafford in 2010. The result of this research has been gathered in an article entitled as "How Green is your Campus? An analysis of the factors which drives universities to embrace sustainability".[14] The author used sustainability grades of IHE to find the characteristics of institutions that were more successful in adopting sustainability on their campus. Since this paper is the most relevant reference in developing this research, the same methodology and data analysis approach has been used, as well. The following section is a summary of the methodology and the results of Stafford's research in more details.

In the introduction of Stafford's paper, it is mentioned that both IHE and corporation currently face pressure to adopt sustainability practices but for each one the environmental decision depends on different factors. The factors that affect sustainability behavior (like the option of investment in sustainability practices and the type of stakeholders who has any interest about sustainability) are different between campuses and corporations. Since most of IHE are identified as non-profit organizations, this study provides a comparison about the differences in environmental criteria between for-profit and non-profit stakeholders.

In this paper, most of the literature review is about the importance of sustainability and how it can be implemented at IHE. Also there are few studies about the factors 
which influence the success of sustainability. Sharp (2002) introduced some successful approaches to the sustainability including "effective communication, management support, partnerships with students, and continuity". [14]

On the other hand, Stafford referred to Velazquez, Munguia, and Sanchez research (2005) regarding the barriers to implementing sustainable practices on university campuses. As this research has been explained in previous section, the Munguia's research looks at the general characteristics of IHE in order to find the factors which motivate campuses to adopt sustainability. Thus, it focuses more on empirical studies on sustainable practices along corporations, rather than sustainability evaluation in IHEs.

Stafford also used Khanna and Anton (2002), Potoski and Prakash (2005) and Khanna and Brouhle (2009) regarding the empirical analysis of sustainability. According to these articles, the result of empirical analysis show that, in general, considering sustainable alternatives for corporations depends on several parameters including company's environmental responsibility in terms of its size and amount of pollution, environmental regulations, the probability of fines, the environmental preferences of consumers and community.

Stafford also explained the conceptual framework of her research which may have some similarities and differences between for-profit corporations and IHE. According to Stafford, the most significant difference between the corporations and IHE is about their goals. The main focus of for-profit corporations is to maximize their profit, while IHE try to increase the community welfare by developing high 
quality education to the students and developing research in different areas. But corporations and IHE should follow the same function of $\mathrm{R}(\mathrm{Y}, \mathrm{X})-\mathrm{C}(\mathrm{X})>0$ where $\mathrm{R}(\mathrm{y}, \mathrm{x})$ is the revenue function and $\mathrm{C}(\mathrm{x})$ is the cost function. Although in short run the sustainability practice may add some cost to both corporations and IHE, this cost brings different consequences for each of them. For example, according to Stafford, it may directly increase the revenue of IHE by adding to its value through impressing those environmental friendly students, stakeholders and community. [14]

To conduct the analysis in the model, Stafford used the College Sustainability Report Card (the sustainability grades for each IHE, the 2008 report card, issued in 2007). This data was provided by The Sustainable Endowments Institute (SEI). [15]

The letter-grades of sustainability which were assigned for each institute by SEI provided an ordinal measure for each institution's sustainability plans which has been used in the research. Since each grade stands for a specific range of numerical grades, the suitable econometrics model can be defined as ordered probit model.

To find out the factors which affect IHE decision to develop sustainable features, four categories have been selected by Stafford, including:

- Regulatory Pressures: Regulatory budget, Enforcement actions, Inspection rate, Total students (which is used as proxy for environmental exposure.)

- Financial Constraints: Tuition, Percent on financial aid, Public, Endowment, High research activity, Electricity cost

- Student Preferences: Acceptance rate, Top 50 national, Top 50 liberal arts, Percent on campus, Environmental major, Percent out of state, Percent international 
- Stakeholder Influences: Full-time faculty, Alumni giving, Size relative to county, County population, County percent with bachelor's, Environmental org. revenues, Federal land, Percent Kerry (Percent of voters in state who voted for Kerry in 2004).

In addition, there are some other factors in Satfford's paper which were considered but not in these four categories including School growth rate, Percent women, Religious, State, and Geographic zones. From the 200 institutions in the "Report Card", 15 institutions were excluded from the Stafford's analysis because their dataset was not complete, and five Canadian institutions were not included either. As result, 180 institutions were included in her analysis.

According to Stafford, the coefficients on the variables which measure the regulatory pressures show that this parameter is not a major factor on the sustainability practices in IHE, although the results of other for-profit entities are exactly in opposite to Stafford's conclusion. The coefficient on the total number of students has positive sign and is significant. Since this variable was a proxy for the size of schools it shows that larger institutes are more likely to adopt sustainability practices.

According to the Stafford results, several coefficients on financial constraints including Tuition, Percent of Financial Aid, Public, and Endowment, are significant and also have positive signs which show that institutes with better financial support are more likely to apply sustainability practices. Just two of the student preferences variables including "Percent Out of State" and "Percent International" have significant coefficients and the rest of variables in this category are not significant 
which shows that generally institutes do not practice sustainability to attract more students, unlike corporations which are trying to attract more customers by marketing sustainability.

Stafford showed that unlike the "student preferences", several variables on "Stakeholder interest" category do show the positive effect of "full time faculty" and "alumni giving" variables on sustainability practices of the institutions.

On the other hand, the negative coefficient on "County Population" variable of Stafford's analysis shows that the more population in the county, the less pressure on sustainability plans of schools. Also the positive coefficient on "Size Relative to County" shows that the more institutions embrace the county population, the more they are subject to community pressures. The Stafford's results emphasized that the counties with higher percent of bachelor degree care more about sustainability practices in institutions and put more pressure on school to adopt it. In her analysis, the coefficient on "Federal land" which is positive and significant variable, shows that institutions which are surrounded by natural resources are more likely to apply sustainability practices. Also the result shows that those institutions which have grown recently have had greater opportunity to incorporate more energy efficient measures.

According to her research results, she could show that the positive and significant coefficient on "percent women" demonstrates that the more female students in the school, the higher sustainability grades for the school. Also, the coefficient on "state system" was positive and significant which, as expected, showed those institutions 
which were evaluated according to the environmental applications of the whole state university system had higher final scores than single-campus universities. Among geographical variables "New England" had a positive sign which shows institution which were located in this area were more likely to apply sustainability patterns in comparison to Midwest institutions.

In order to consider the influence of incomplete surveys in the results, two other regressions have been run. In the first, two other variables including Campus survey and dining survey were added by Stafford to the list of the variables. The result shows that both "Campus survey" and "dining survey" have significant and positive signs. It shows that those universities which completed the survey of campus situations as well as dining survey have better sustainability grades. Although there is no major change in the sign of the other significant variables, significant coefficients for "School Growth Rate", "County Population", and "Federal Land" are not significant anymore. In the next regression only the universities which completed the "Campus Survey" have been selected. The Stafford's result is different from the first regression but most of the sign of coefficients are consistent.

The final conclusion of Stafford paper is that the result is the same in all the three regressions. Financial constraints play an important role in sustainability practices in institutions, regulatory pressures do not influence sustainability grades of institutions and the institutions do not conduct sustainability practices in order to attract students. 
In order to check for the accuracy of the institutions grade and to estimate how close the ordered-probit regression describes the grades of a given university, estimated coefficients have been used in this paper to predict each institution's sustainability grade. According to Stafford's analysis, it shows the estimated grades are very close to the real grades, the only difference is number of "C" scores which is more than they actually occur.

In order to differentiate between actions that might appear to be sustainable and ones which truly have an impact on environmental performance, another comparison was developed by Stafford. Thus, institutions that sign the "American College and University Presidents Climate Commitment" (PCC) have been examined in this research.

Those institutions that signed the PCC have committed to make their campuses to be more sustainable and to decrease the level of greenhouse gas emissions within campus environment. Therefore, a probit model was run with dependent variable equal to one, if the institutions signed for the PCC. The explanatory variables are the same as the ordered probit model in this paper.

The results of Stafford show that the coefficient on "Inspection rate" is positive and significant. It proves that institutions in the states with more policy-based enforcement are more interested to sign the PCC. On the other hand not all the institutions which signed for the PCC have good sustainability grades. For example five out of 16 institutions which signed the PCC received D- from SEI. It can be the case that regulatory pressures are enough to force universities to have a symbolic 
sustainability gesture but it is not sufficient to motivate them to follow their sustainability plans. Overall, the findings of Stafford's research can be summarized as the following:

- In the short run financial resources have significant impact on applying the sustainability plans in IHE and the affluent and larger universities are more interested to apply sustainability in comparison to small and tight budget institutions. Both size and wealth do not play a major role for applying any significant action on sustainability practices like signing for the PCC. Although surveys show that the majority of students care for sustainability practice, it does not affect their decision in choosing a college. As a result, institutions do not practice sustainability to attract student's attention. [14]

- Institutions are different from corporations in adopting sustainability practices. Regulatory pressure does not have enough power (as it does over corporations) to encourage sustainability on campuses. Alumni, stakeholders, faculty, and the community seem to have more influence in adopting sustainable practices in the universities than stakeholders have an impact for corporations. [14]

- The general result of this paper can be relevant for not only the IHE but also for all the non-profit organization. For example considering budget and financial incentives has a crucial role in embracing sustainability in all kind of non-profit institutions. [14] 


\section{Research Approach and Methodology}

The sustainability grades of IHE are used in this analysis. These letter grades which were derived from "Greenreportcard.org" have been produced based on evaluation of each school in nine main categories including: "Administration, Climate Change \& Energy, Food \& Recycling, Green Building, Student Involvement, Transportation, Endowment Transparency, Investment Priorities, and Shareholder Engagement". The selected schools in this survey are located in all 50 U.S. states and were those with the largest endowment in the United States.

The information in the "Greenreportcard.org" is based on an extensive research that is carried out for the "The college sustainability report card". Both "Greenreportcard.org" and "The college sustainability report card" are the initiative of the "Sustainable Endowments Institute" (SEI). SEI, a non-profit organization, is involved in academic and research activities to promote sustainability in terms of endowment practices as well as campus operations.

As discussed in literature review section, Stafford used the sustainability grades of 180 IHE in the 2008 report card (issued in 2007) which graded IHE in different nine categories.

The current research follows a similar method used by Stafford (2011) for modeling and analyzing the data but with larger number of observations and different tools and software (Stata). In this model, the grades which show the sustainability score of each school are derived from Report Card which covers 321 colleges in five years period (2007 to 2011). The first reference to select Schools in "The college sustainability report card" was 2007 NACUBO Endowment Study that presents 
information about university endowments. Starting from 2009 Report Card added eight schools in the U.S. as well as 11 schools in Canada to the list of schools. These new schools have the factors of holding approximately $\$ 160$ million or even more in endowment assets which was the criteria of report card for school selection. More details about "The college sustainability report card" are explained in Appendix 1. Also a list of all universities and colleges used through this research is presented in Appendix 2.

Since the letter grades of each school is an ordinal measure of a school's sustainability applications which represent an important range of numericalgrades, the econometrics model which has been used in this analysis is the Ordered Probit Model. The following table shows the sustainability grades distribution among the IHE.

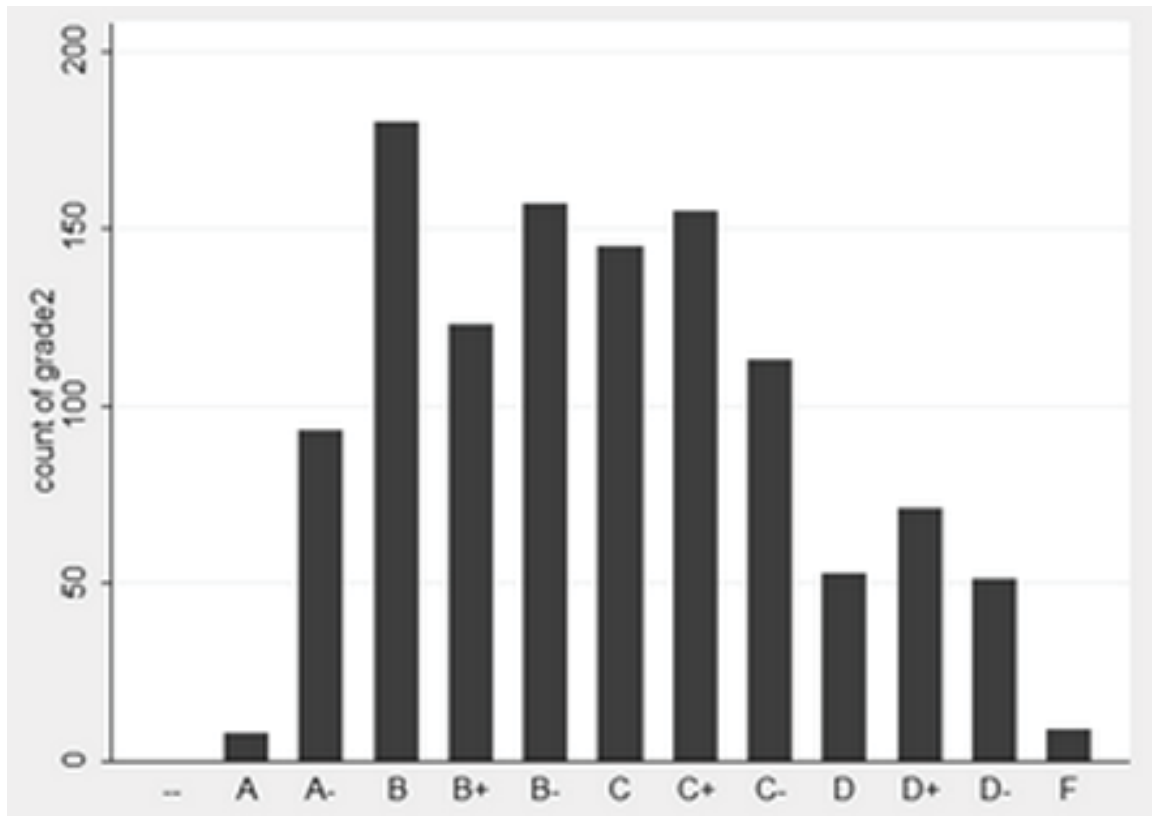

Figure 3-1- Sustainability grades distribution among the IHEs 


\section{3-1- Description of the Ordered Probit Model}

If the dependent variable has more than two possible categories and these categories are ordered it is common to use either an ordered Probit or Logit Model which have lots in common. The theoretical difference between these two approaches relates to the distribution of the error term which is logistic versus normal.

Examples of ordered outcome can be shown using a rating system (poor, fair, good and excellent) or opinion in the survey (strongly agree, agree, neutral, disagree and strongly disagree). In the current research the ordered outcome of the dependent variable is alphabetic letters including (A, A-, B, B+, B-, C, C+, C-, D, D+, D-, F).

In the ordered Probit or Logit Model the variable is treated as though it is measured on an ordinal scale, but such pattern represents an approximate level of an important interval/ratio scale. For instance, the categories of alphabetic letters are roughly measured, in which ordered Logit or Probit model can be used in this case.

In the ordered Logit model "Y" is an observed ordinal variable which is a function of an unobservable variable "Y*" that cannot be measured. The continuous latent variable "Y*" has different threshold points which determine the level (or value) of the observed ordinal variable "Y". It should be pointed out that value of "Y" depends on whether a specific threshold has been reached or not. For instance in this model the "Y" is "A" if "Y*" be above the " $\alpha \mathrm{A}$ " and the "Y" is "A-"if "Y*" be above the " $\alpha$ A-"but less than the " $\alpha$ A". 
In another words, "Y" is a collapsed version of "Y*". The "Y*" can take on an infinite range of value which will be collapsed into 11 alphabetic letter's categories of "Y".

The continuous latent variable "Y*" can be calculated by the following equation. In this equation "xi" represents independent variables and " $\beta$ " represents regression coefficients which should be estimated further. The "ci" represents random disturbance which, in the Ordered Logit or Probit model, may not be perfectly measured.

$$
Y_{i *}=\beta_{-} X i+\varepsilon i
$$

The "Ologit" or "Oprobit" commands are common to be used in Stata to estimate the order Logit or Probit models. Also if there is a sign of "i." before a variable's name in the command, Stata will turn it to a dummy variable.

Oprobit Y_ $\mathrm{Y} 1 \times 2 \times 3 \times 4 \times 5 \times 6 \times 7$

"Y" represents the dependent variable which is followed by the list of the independent variables.

If " $\mathrm{j}$ " alternatives are assumed for ordered the Logit model then there will be " $\mathrm{j}-1$ " intercepts thus multiple intercepts can be a sign of an ordered choice model.

\section{3-2- The Econometrics Model in the Current Research}

In the current model, the categories of Ordered Probit analysis for the dependent variable are numbers between zero and eleven. These numbers are equivalent to the 
sustainability's grade letters of each institution which include: A, A-, B, B+, B-, C, $\mathrm{C}+, \mathrm{C}-, \mathrm{D}, \mathrm{D}+, \mathrm{D}-$, and F.

Since the numbers show ranking, the difference between numbers is not equal. For example the difference between first and second outcome may not be the same as the second and third. In the ordered (Logit /Probit) model it is assumed that the distance between each category of the outcome is proportional. The number zero shows " $F$ " as lowest grade in the ranking and 11 shows " $\mathrm{A}$ " as highest grade in the ranking. The following tables which are derived from "Stata" illustrate both letter grades and their equivalent numerical grades with their percentage frequency in 1,160 observations. It should be mentioned that the letter grades in the following tables are not in order, but their respective values are correct and match each other. It's better to summarize dependent categorical variable by showing percent frequency, because " $\mathrm{Y}$ " is a coded variable and the mean and standard deviation doesn't mean anything here.

\begin{tabular}{|c|c|c|c|c|c|}
\hline Grade & Freq. & Percent & grade2 & Freq. & Percent \\
\hline $\begin{array}{r}-- \\
\text { A } \\
\text { A- } \\
\text { B } \\
\text { B+ } \\
\text { B- } \\
\text { C } \\
\text { C+ } \\
\text { C- } \\
\text { D } \\
\text { D+ } \\
\text { D- } \\
\text { F }\end{array}$ & $\begin{array}{r}1 \\
8 \\
93 \\
180 \\
123 \\
157 \\
145 \\
155 \\
113 \\
53 \\
71 \\
51 \\
9\end{array}$ & $\begin{array}{r}0.09 \\
0.69 \\
8.02 \\
15.53 \\
10.61 \\
13.55 \\
12.51 \\
13.37 \\
9.75 \\
4.57 \\
6.13 \\
4.40 \\
0.78\end{array}$ & $\begin{array}{r}0 \\
1 \\
2 \\
3 \\
4 \\
5 \\
6 \\
7 \\
8 \\
9 \\
10 \\
11\end{array}$ & $\begin{array}{r}9 \\
51 \\
53 \\
71 \\
113 \\
145 \\
155 \\
157 \\
180 \\
123 \\
93 \\
8\end{array}$ & $\begin{array}{r}0.78 \\
4.40 \\
4.58 \\
6.13 \\
9.76 \\
12.52 \\
13.39 \\
13.56 \\
15.54 \\
10.62 \\
8.03 \\
0.69\end{array}$ \\
\hline Total & 1,159 & 100.00 & Total & 1,158 & 100.00 \\
\hline
\end{tabular}

Figure 3-2- Letter grades and their equivalent numerical grades with their percentage frequency 
The following equation is used for ordered Probit model in the current model:

$Y_{i *}=\beta_{-} X i+\varepsilon i$

In above equation, there is a latent continuous variable which would form 12 groups with 11 thresholds which are cutoff points between 12 different categories. As discussed " $Y_{i *}$ " is unobservable and is only observed when it crosses the thresholds. This means that the true sustainability grades have not been generated; only 12 categories of letter grades have been produced which depend on the true sustainability grades. If the letter grade is presented by " $G$ ", then $G$ will be equal to following letters:

Table 3-1-Different categories of letter grades

\begin{tabular}{ll}
\hline $\mathrm{A}$ if $\mathrm{Yi} *>\mathrm{A}$ & $\mathrm{C}+$ if $\alpha \mathrm{C} \geq \mathrm{Yi} *>\alpha \mathrm{C}+$ \\
\hline $\mathrm{A}-$ if $\alpha \mathrm{A} \geq \mathrm{Yi} *>\alpha \mathrm{A}-$ & $\mathrm{C}-$ if $\alpha \mathrm{C}+\geq \mathrm{Yi} *>\alpha \mathrm{C}-$ \\
\hline $\mathrm{B}$ if $\alpha \mathrm{A}-\geq \mathrm{Yi} *>\alpha \mathrm{B}$ & $\mathrm{D}$ if $\alpha \mathrm{C}-\geq \mathrm{Yi} *>\alpha \mathrm{D}$ \\
\hline $\mathrm{B}+$ if $\alpha \mathrm{B} \geq \mathrm{Yi} *>\alpha \mathrm{B}+$ & $\mathrm{D}+$ if $\alpha \mathrm{D} \geq \mathrm{Yi} *>\alpha \mathrm{D}+$ \\
\hline B- if $\alpha \mathrm{B}+\geq \mathrm{Yi} *>\alpha \mathrm{B}-$ & $\mathrm{D}-$ if $\alpha \mathrm{D}+\geq \mathrm{Yi} *>\alpha \mathrm{D}-$ \\
\hline $\mathrm{C}$ if $\alpha \mathrm{B}-\geq \mathrm{Yi} *>\alpha \mathrm{C}$ & $\mathrm{F}$ if $\alpha \mathrm{D}-\geq \mathrm{Yi} *$ \\
\hline
\end{tabular}

\section{3-3- Description about Stata}

Stata is a complete and integrated statistical software package that was created in 1985 by Stata Corp. It is a full-featured statistical programming language which is available for Mac OS X, Windows, Unix and Linux. Stata as general purpose statistical software, helps its users with data analysis, data management, and graphics. 
The name of "Stata" is a combination of two words: statistics and data. [1] The correct pronunciation of Stata (in English) can be considered any of the "Stay-ta", "Sta-ta" or "Stah-ta". [16]

There are three major versions of Stata in the market include Stata/IC (the standard version), Stata/SE (an extended version) and Stata/MP (for multiprocessing). The number of variables that are allowed in memory is the significant difference between the Stata versions. For example the variable limitation in standard Stata/IC is 2,047 while Stata/SE or Stata/MP can analyze more variables.

Economics, sociology, political science, biomedicine and epidemiology are the most common fields of research that use Stata. A graphical user interface was added starting with version 8.0, which is equipped with menus and dialog boxes to provide access to approximately all built-in commands.

Stata can import data in formats of ASCII data (e.g. CSV or databank formats) and spreadsheet formats that includes several formats of Excel. It also can read and write SAS XPORT format datasets. Every version of Stata has the capability to read all older dataset formats, and also can write the current dataset as well as the most recent previous dataset format, by applying the "saveold" command.[4] In other words, it means that current Stata edition can open older format case studies; however older versions of Stata cannot read newer format datasets, unfortunately. [17]

One of the features of Stata is its capability to read and record written commands in a standard text file called a do-file. Creating a do-file makes the work much easier because it can execute the commands stored in thefile at any time later in the work. 
Writing a do-file and recording the steps for managing and analyzing the data has several advantages. It not only helps the user to reproduce their work later but also it makes changes much easier.

Stata journal is a publication that introduces articles about the method of using Stata and its new user-written commands. Also it publishes articles about teaching methods, data analysis, statistics and the use of Stata's language. [18]

The econometrics model which is used in Stata for this research includes 1160 observations and 59 variables. Since there is missing data and multicollinearity between some variables not all the variables in the data set have been used in the analysis.

After running the model in Stata the signs of the parameters and the significance of coefficients can be used for interpretation of the results. The signs show whether the latent "y*" increase or decrease with the regressor. For example, in this model a positive coefficient of each explanatory variable means that the likelihood of getting higher sustainability grade is increased by this variable, and similarly a negative coefficient implies that the likelihood of getting lower sustainability grade. One of the differences between Logit and Probit model is the difference in the magnitude of the coefficients.

The chi-square and degrees of freedom show the significance of the model. "Prob>chi2" is a test to check whether all the coefficients in the model are different from zero. If the number for this test is $<0.05$ then the model is ok. The " $\mathrm{Z}$ test" examines the hypothesis that each coefficient is different from " 1 " and in order to 
reject this hypothesis, the t-value should be higher than 1.96 for a $95 \%$ confidence level. In other words, the higher the coefficient, the higher the influence of explanatory variable on the dependent variable.

"P>IzI" tests the hypothesis that each coefficient is different from zero. In order to reject this hypothesis, the p-value should be lower than 0.05 which will show us that the explanatory variable has significant influence on the dependent variable "Y".

The coefficients in the order Logit and Probit model are in log-odds units and cannot be interpreted as "OLS" coefficients. In order to interpret the coefficients the predicted probability of "Y=1" should be estimated.

Also, it should be pointed out that in this research Stata has changed some of the variables name in different runs and features to fit the contents within the respective windows.

\section{3-4- Explanatory Variables}

The explanatory variables in this analysis have been chosen from "The Integrated Postsecondary Education Data System" (IPEDS). These variables have been chosen to examine the role of size, financial constraints, academic level, population, political point of view, renewable policy, school's ranking, international population, public vs. private status, geographical zone and research activity on adoption of sustainable practices by each school. 
In this analysis, to find the independent variables which are good indicators of the sustainability practices of each school, different equations with different lists of variables have been tested.

The initial list of explanatory variables which was prepared included "62" variables, which was then cut down to a smaller list including: "Share of total degrees at bachelor's level", "Education and related expenses", "Endowment", “Average amount of federal grants", "Political point of view of the state", "Research and related expenses", “Total revenue of institution", "Net tuition", “count", "selectivity of school" and "percent of internationals". To check for multicollinearity, none of the dummy variables are included in this list and they will be added to the list later individually.

There are some details about the variables in the following figure; it includes number of observations, mean, standard deviation, and minimum and maximum number for each particular variable.

The number of observation shows that there are just a couple of missing values for some variables in this list. 


\begin{tabular}{|c|c|c|c|c|c|}
\hline Variable & obs & Mean & std. Dev. & Min & $\operatorname{Max}$ \\
\hline $\begin{array}{r}\text { grade2 } \\
\text { carnegiebach } \\
\text { carnegiedoc } \\
\text { Southeast } \\
\text { west }\end{array}$ & $\begin{array}{l}1158 \\
1159 \\
1159 \\
1160 \\
1160\end{array}$ & $\begin{array}{l}6.166667 \\
.2881795 \\
.5875755 \\
.2008621 \\
.2198276\end{array}$ & $\begin{array}{l}2.515781 \\
.4531106 \\
.4924833 \\
.4008179 \\
.4143083\end{array}$ & $\begin{array}{l}0 \\
0 \\
0 \\
0 \\
0\end{array}$ & $\begin{array}{r}11 \\
1 \\
1 \\
1 \\
1\end{array}$ \\
\hline $\begin{array}{r}\text { Midwest } \\
\text { landgrnt01 } \\
\text { controlpri e } \\
\text { top501a } \\
\text { rps }\end{array}$ & $\begin{array}{l}1160 \\
1160 \\
1160 \\
1160 \\
1160\end{array}$ & $\begin{array}{l}.2293103 \\
.1491379 \\
.6448276 \\
.1655172 \\
.7232759\end{array}$ & $\begin{array}{r}.4205706 \\
.356378 \\
.4787719 \\
.371807 \\
.4475719\end{array}$ & $\begin{array}{l}0 \\
0 \\
0 \\
0 \\
0\end{array}$ & $\begin{array}{l}1 \\
1 \\
1 \\
1 \\
1\end{array}$ \\
\hline $\begin{array}{r}\text { popu1sma11 } \\
\text { popu1big } \\
\text { bach_deg_s q } \\
\text { endowment } \\
\text { fed_grant_ t }\end{array}$ & $\begin{array}{l}1160 \\
1160 \\
1149 \\
1159 \\
1149\end{array}$ & $\begin{array}{r}.1767241 \\
.4543103 \\
.6930261 \\
1332.91 \\
4967.635\end{array}$ & $\begin{array}{l}.3815996 \\
.4981228 \\
.2104382 \\
3086.434 \\
1747.816\end{array}$ & $\begin{array}{r}0 \\
0 \\
0 \\
0 \\
1529\end{array}$ & $\begin{array}{r}1 \\
1 \\
1 \\
36900 \\
38786\end{array}$ \\
\hline $\begin{array}{r}\text { obama08_sh e } \\
\text { research_r t } \\
\text { nettuition01 } \\
\text { count } \\
\text { select }\end{array}$ & $\begin{array}{l}1160 \\
1068 \\
1152 \\
1160 \\
1132\end{array}$ & $\begin{array}{l}.5448536 \\
1.82 \mathrm{e}+08 \\
1.76 \mathrm{e}+08 \\
4.043103 \\
.6909077\end{array}$ & $\begin{array}{l}.0956203 \\
2.78 \mathrm{e}+08 \\
1.79 \mathrm{e}+08 \\
.9864679 \\
.3517371\end{array}$ & $\begin{array}{r}.3254 \\
10279.29 \\
-1123339 \\
1 \\
.0530514\end{array}$ & $\begin{array}{r}.9246 \\
1.96 \mathrm{e}+09 \\
1.28 \mathrm{e}+09 \\
5 \\
5.335043\end{array}$ \\
\hline jinternations & 1153 & 6.77974 & 5.531089 & 0 & 38.5 \\
\hline
\end{tabular}

Figure 3-3- Statistical summary of variables used in the STATA

\section{3-5- Explanation of the Explanatory Variables in the Model}

The following section includes the description of each variable and the reason to include it in the model, plus predicting each variable expected sign in the result table. 
Table 3-2- List of Explanatory Variables used in the Model

\begin{tabular}{|c|c|c|}
\hline No. & Variable Name & Description \\
\hline 1 & Carnegie & $\begin{array}{l}\text { Research activity of the university based on } \\
\text { carnegie } 2005\end{array}$ \\
\hline 2 & Southeast & $\begin{array}{l}\text { Dummy equal to } 1 \text {, if university is in a Southeastern } \\
\text { state }\end{array}$ \\
\hline 3 & Midwest & Dummy equal to 1 if university is in a Midwest state \\
\hline 4 & West & Dummy equal to 1 if university is in a Western state \\
\hline 5 & landgrnt01 & $\begin{array}{l}\text { Dummy equal to } 1 \text { if university is a land grant } \\
\text { institution. }\end{array}$ \\
\hline 6 & controlprivate & $\begin{array}{l}1 \text { if the university is a private institution, } 0 \text { if the } \\
\text { university is Public institution }\end{array}$ \\
\hline 7 & top50la & $\begin{array}{l}\text { Dummy equal to } 1 \text { if the institution is a top } 50 \text { Liberal } \\
\text { Arts Institution }\end{array}$ \\
\hline 8 & rps & Renewable Portfolio Standard \\
\hline 9 & population & $\begin{array}{l}1 \text { if the university is located in small town, } 2 \text { if the } \\
\text { university located in medium size city, and } 3 \text { if the } \\
\text { university located in large city. }\end{array}$ \\
\hline 10 & bach_deg_share_of_tot_deg & Share of total degrees at bachelor's level \\
\hline 11 & endowment & funds donated to institutions \\
\hline 12 & fed_grant_avg_amount & $\begin{array}{l}\text { Average amount of federal grants received by full-time } \\
\text { first-time degree/certificate }\end{array}$ \\
\hline 13 & obama08_share & Percent of voters who voted for Obama in 2008 \\
\hline 14 & research_related_cost & Research and related expenses \\
\hline 15 & nettuition01 & Net tuition and fees revenue of each institution \\
\hline 16 & count & $\begin{array}{l}\text { The number of times that the institution contribute to the } \\
\text { survey }\end{array}$ \\
\hline 17 & select & the percent of selectivity of each institution \\
\hline 18 & internationals & The percent of international student in each institution \\
\hline
\end{tabular}




\section{3-5-1- Carnegie Classification}

The basic categories of Carnegie classification include: "Associate's Colleges, Doctorate-granting Universities, Master's Colleges and Universities, Baccalaureate Colleges, Special Focus Institutions, and Tribal Colleges". This classification has been used in U.S. higher education for the past forty years ago. The Carnegie Classification started in 1973 and it was updated in 2010 in order to continue the classification structure and its comparison through different years. [19]

The Carnegie classification is the leading feature for the study of higher education not only in representing institutional differences, but also in research studies to assure enough representation of sampled universities, students, or faculty.

The research activity of each school which is based on the Carnegie classification has been considered as one of explanatory variable. It is expected that there will be a positive relationship between research activity and sustainability performance of institutions. Those institutions with higher rate of research activity are more likely to receive grants; therefore they are expected to be more capable of investing in sustainability projects.

\section{3-5-2- Geographical Zone}

Three variables, including Southeast, West and Midwest, were selected for this research to see if there is any relationship between the geographical zone of a school and its sustainability practice. A dummy variable is used for each of Southeast, West and Midwest geographical zones and there is no expectation as to whether sustainability will be more or less successful in each of these geographic zones. 


\section{3-5-3- Land Grant Institution}

This variable indicates if a school is a land grant college. The land-grant schools or colleges have been selected by their state legislature or Congress to take advantages of the Morrill Acts of 1862 and 1890. According to Morrill Act, land grant Institutions should teach "agriculture, military tactics, the mechanic arts, and classical studies, in a way that the members of those working-classs society could obtain a liberal, practical education. It is expected to have a positive relationship for this variable, because the land grant institutions' mission is to expand practical developments and it may inspire more sustainability practice. The data for land grant institutions is based on IPED.

\section{3-5-4- Control}

This variable measures whether a university is run by those authorities who are publicly-elected or is operated by privately-elected officials. Public schools may receive state funding beside their tuition revenue, while private schools derive their major financial sources from the private sector, therefore it can be a reason for public schools to invest more on sustainability than private schools. Community pressure is another reason that may push public schools to adopt sustainability practices which is stronger in public schools than private schools. [14]

\section{3-5-5- Top 50 Liberal Art}

"Top 50 Liberal Art" schools is another explanatory variable in the list and it is different from "top 50 national" schools, with an emphasis on undergraduate education and plans at least half of their degrees in the liberal arts fields of study. 
"Top 50 Liberal Art" as a representative of top-ranked schools examines the impact of being a top-ranked school on sustainability practice. Also the "top 50 national schools" variable was included in the variables list which was dropped because of multicollinearity. It is expected that there will be a positive relationship between this explanatory variable and the school's sustainability grade, because top-ranked schools are concerned in keeping their ranking and therefore they may be more interested in achieving higher grades in the sustainability practices to keep their ranking.

\section{3-5-6- Renewable Portfolio Standard (RPS)}

Renewable portfolio standards (RPS) are policies with the goal of increasing the amount of electricity generated by renewable resources. These policies are based on encouraging electricity producers to provide a certain minimum level of generated electricity from renewable resources. Renewable resources include "wind, solar, geothermal, biomass, and some types of hydroelectricity". Sometimes other resources such as "landfill gas, municipal solid waste, and tidal energy" are also considered as renewable resources.

Both federal tax incentives and RPS policies have caused a major increase in energy generation out of renewable resources through the past years. Since the goal of the RPS policy is to motivate the applications which are based on renewable energy, it is assumed that there is a positive relationship between sustainability practice and RPS policy. The data which includes states with RPS policy are derived from the U.S. Energy Information Administration. [20] 


\section{3-5-7- Population}

This explanatory variable has been included in the model to indicate the population of the city or town where each school is located. These data are based on publicly available census report. [21]

It is assumed that the schools that are located in the more populated cities are more likely to apply sustainability practices because they are associated with more people and they may receive more pressure from outside the school for practicing sustainability. It is assumed that the school's sustainability plan has higher impact on the environment with higher population. It is expected to see a positive relationship between sustainability practices in the school and the population of county where the school is located.

\section{3-5-8- Share of Total Degrees at Bachelor's Level}

"Share of total degrees at bachelor's level" is an explanatory variable that shows the proportion of all degrees that are conferred at the bachelor's level. There is expected to be a negative relationship for this variable, because it is assumed that there is positive relationship between sustainability practice and academic level. Considering bachelor's degree as the first level in the ranking of academic levels, it is assumed that the schools with more focus on bachelor's degree are less likely to practice sustainability on their campus. In other words, it is assumed those schools with higher percent of graduate degree are more likely to practice sustainability on 
their campus because more sustainability projects can be done by graduate students. The data for this variable came from IPED.

\section{3-5-9- Endowment}

"Endowment", which is expected to behave as a strong explanatory variable, can be considered as proxy for financial strength. The prediction sign for this variable is positive because when a school has more endowments it will be more capable of allocating money for sustainability projects on its campus .The data for endowment is based on "the College Sustainability Report Card".

\section{3-5-10- Average Amount of Federal Grants}

"Average amount of federal grants" as a proxy for financial capability, is another explanatory variable that has been chosen to explain the relationship between financial condition and sustainability performance for a school. It is assumed that the more the number of students who receive federal grants, the less the number of students who need scholarship. As a result these schools will have a larger budget to spend on other projects. "Average amount of federal grants" is expected to have a positive relationship because it is assumed that as federal grants increase a school's budget will be more likely to be used for sustainable-related activities. This variable shows the average amount of federal grants awarded to full-time and first-time degree-seeking (or certificate-seeking) undergraduates; and the data for this variable has been collected from IPED. 


\section{3-5-11- Political Point of View of the State}

It might be possible that the political view of a given state has an impact on the status of the sustainability practices at a given school or college located in that state. Thus, the percent of votes for president Obama in 2008 was picked as an explanatory variable. It is expected to provide a positive relationship between this variable and sustainability practice, because the Democratic Party's platform is more inclined to support sustainability plans. The data for this variable is based on Federal Election results from 2008. [22]

\section{3-5-12- Research and Related Expenses}

"Research and related expenses" is an explanatory variable that shows the total expenditure on research and its related costs in each school or college. Those schools which have higher spending on research should have more capability to work on sustainability practices on their respective campus and it is expected that there will be a positive relationship between this variable and sustainability scores. The data for this variable has been collected from IPED.

\section{3-5-13- Net Tuition}

Net tuition is the revenue that comes directly from students and it does not include Pell, Federal, State, and Local grants. This variable was included to examine the relationship between sustainability practice of the schools and their revenue that come 
from net tuition. Those schools with a higher rate of tuition may have less financial constraint to allow a larger budget for sustainability practices on their campuses. Thus, it is expected to see a positive relation between net tuition and adoption of sustainability in schools. The data for net tuition are derived from IPED.

\section{3-5-14- Count}

This variable represents the number of times that each school contributes to the survey process and it is expected to see a positive sign for this variable's coefficient. It is expected that those schools that were more involved in the Green Report Card's survey and were more consistent in reporting the data for sustainability on their campus will get better sustainability grades.

\section{3-5-15- Selectivity}

This variable was calculated by dividing the total number of undergrad admissions by the total number of fall undergrad students who have registered in the school. The value of this variable is around "1", however, if the value is much higher than "1", it demonstrates a low selectivity level of that given institution. It is expected to observe a positive relationship between the selectivity and sustainability development in each institution because most of the high-ranking schools are selective. As discussed before high-ranking schools are expected to be more interested to sustainability practices in order to keep their ranking. 


\section{3-5-16- Internationals}

This variable which measures the influence of international students on sustainability practice is expected to have positive effect. Because studying abroad can provide this opportunity for students to develop a broader perspective of the world, it is expected they will be more concerned about sustainability practices in the school. The data type for this variable which is the result of dividing the number of students enrolled in the fall semester by the number of non-resident students in the same institution, in percentage.

\section{3-6- Test for Multicollinearity}

Multicollinearity is a statistical phenomenon in which predictor variables have a perfect or exact relationship. To check for multicollinearity a simple correlation matrix of all the (non-dummy) variables against predictor variable has been conducted.

The correlation coefficient determines whether two paired sets of data are related or not and is a number between " -1 and 1". There will be a positive linear correlation When it close to 1 and negative linear correlation when it close to "- 1 ". It shows there is no evidence of any relationship when the correlation coefficient is close to zero. [23]

The following figure shows the correlation matrix of all the (non-dummy) variables against each other. 


\begin{tabular}{|c|c|c|c|c|c|c|c|c|}
\hline & bach_d g & eandr & endowm $t$ & fed_gr $\sim t$ & obama0re & resear t & tot_renm & nettu 01 \\
\hline $\begin{array}{r}\text { bach_deg_s q } \\
\text { eandr } \\
\text { endowment } \\
\text { fed_grant_ } \\
\text { obama08_shre } \\
\text { research_r } \sim t \\
\text { tot_rev_w_ m } \\
\text { nettuition01 } \\
\text { count } \\
\text { select } \\
\text { internatious }\end{array}$ & $\begin{array}{r}1.0000 \\
-0.4715 \\
-0.3381 \\
-0.0532 \\
-0.1330 \\
-0.4317 \\
-0.3833 \\
-0.4563 \\
-0.2220 \\
0.1415 \\
-0.4928\end{array}$ & $\begin{array}{r}1.0000 \\
0.6231 \\
-0.0307 \\
0.0307 \\
0.8417 \\
0.7843 \\
0.8078 \\
0.3808 \\
-0.3680 \\
0.3571\end{array}$ & $\begin{array}{r}1.0000 \\
0.0788 \\
0.0605 \\
0.5757 \\
0.5104 \\
0.3076 \\
0.3353 \\
-0.2285 \\
0.4266\end{array}$ & $\begin{array}{r}1.0000 \\
0.1583 \\
-0.0298 \\
-0.0260 \\
-0.0118 \\
0.0388 \\
0.2127 \\
0.1598\end{array}$ & $\begin{array}{r}1.0000 \\
-0.0039 \\
-0.0217 \\
0.1144 \\
-0.0095 \\
0.2420 \\
0.2128\end{array}$ & $\begin{array}{r}1.0000 \\
0.7726 \\
0.6346 \\
0.3820 \\
-0.3662 \\
0.4083\end{array}$ & $\begin{array}{r}1.0000 \\
0.6524 \\
0.3395 \\
-0.3366 \\
0.3112\end{array}$ & $\begin{array}{r}1.0000 \\
0.3470 \\
-0.2609 \\
0.2615\end{array}$ \\
\hline & count & select & interms & & & & & \\
\hline $\begin{array}{r}\text { count } \\
\text { select } \\
\text { internations }\end{array}$ & $\begin{array}{r}1.0000 \\
-0.1707 \\
0.3938\end{array}$ & $\begin{array}{r}1.0000 \\
-0.0587\end{array}$ & 1.0000 & & & & & \\
\hline
\end{tabular}

Figure 3-4- Correlation matrix of all the (non-dummy) variables against each other

To determine which pair of variables in "correlation matrix table" has a high correlation, "T-test" can be used here. The first step to do the "T-test" is to find the related critical $\mathrm{t}$-value (t) from the $\mathrm{t}$-table. In this case the critical $\mathrm{t}$-value $(\mathrm{t})$ is 2.576 which is derived from t-table for $1 \%$ level of significance and 1042 degree of freedom $(\mathrm{n}-2)$.

Next " $\mathrm{r}$ max" is required which can be calculated according to the following equation:

$$
\mathrm{r} \max =\mathrm{t} \text { divided by the square root of }(\mathrm{n}-2+\mathrm{t} \text { squared })
$$

By using the "r max" and " $r$ ", which is the simple correlation coefficient between any two pairs of variables and is shown in figure 3-4, significant correlation between any pair of variables can be detected. If " $r$ " is greater than " $r$ max", then there is statistically significant correlation between that pair of variables. 
In this case "r max" is 0.08 which is a small number and means that "statistically significant" correlation is easy to achieve between these variables.

In the following table " $\mathbf{X}$ " shows the pair of variables which their "correlation coefficient" is greater than "r max". The highlighted cells in gray color show those pair of variables that their correlation is higher than 0.5 in the table.

Table 3-3- Table of correlation status between all non-dummy variables of the model

\begin{tabular}{|l|l|l|l|l|l|l|l|l|l|l|l|}
\hline $\begin{array}{l}\text { Non-dummy } \\
\text { variables }\end{array}$ & -1 & -2 & -3 & -4 & -5 & -6 & -7 & -8 & -9 & -10 & -11 \\
\hline Bachelor degree (1) & & & & & & & & & & & \\
\hline $\begin{array}{l}\text { Education and related } \\
\text { expenses (2) }\end{array}$ & $\times$ & & & & & & & & & & \\
\hline Endowment (3) & $\times$ & $\times$ & & & & & & & & & \\
\hline Federal grants (4) & & & & & & & & & & & \\
\hline Obama08 (5) & $\times$ & & & $\times$ & & & & & & & \\
\hline Research activity (6) & $\times$ & $\times$ & $\times$ & & & & & & & & \\
\hline Total revenue (7) & $\times$ & $\times$ & $\times$ & & & $\times$ & & & & & \\
\hline Net tuition (8) & $\times$ & $\times$ & $\times$ & & $\times$ & $\times$ & $\times$ & & & & \\
\hline Count (9) & $\times$ & $\times$ & $\times$ & & & $\times$ & $\times$ & $\times$ & & & \\
\hline Selectivity (10) & $\times$ & $\times$ & $\times$ & $\times$ & $\times$ & $\times$ & $\times$ & $\times$ & $\times$ & & \\
\hline International (11) & $\times$ & $\times$ & $\times$ & $\times$ & $\times$ & $\times$ & $\times$ & $\times$ & $\times$ & & \\
\hline
\end{tabular}

Testing for "variance inflation factor" (VIF) is another way to check for multicollinearity. The VIF command in Stata can be used after the regression. A variable whose VIF value is greater than "5" often indicates multicollinearity. Tolerance, which is calculated by $1 / \mathrm{VIF}$, also can show the degree of collinearity. When tolerance value is lower than 0.1 , it is equivalent to a VIF of 10 and it shows that the variable may be a linear combination of other independent variables. 
According to "VIF" table "carnegiebach" has 5.73 "VIF" value which indicates multicollinearity. (Figure 3-5)

\begin{tabular}{|r|rr|}
\hline variable & VIF & $1 /$ VIF \\
\hline eandr & 9.01 & 0.110956 \\
carnegiebach & 5.75 & 0.173800 \\
research_r t & 4.73 & 0.211245 \\
nettuition01 & 4.45 & 0.224679 \\
bach_deg_s g & 4.32 & 0.231221 \\
carnegiedoc & 4.03 & 0.247862 \\
controlpri i e & 3.47 & 0.288022 \\
top501a & 3.09 & 0.323655 \\
tot_rev_w_ m & 3.02 & 0.330968 \\
Southeast & 2.91 & 0.343617 \\
endowment & 2.47 & 0.404108 \\
rps & 2.35 & 0.424732 \\
obama08_sh e & 1.99 & 0.502328 \\
internatio s & 1.95 & 0.511633 \\
count & 1.83 & 0.545712 \\
west & 1.77 & 0.564172 \\
select & 1.75 & 0.571059 \\
Midwest & 1.66 & 0.601657 \\
1andgrnt01 & 1.66 & 0.604228 \\
populbig & 1.46 & 0.686849 \\
populsma11 & 1.40 & 0.715963 \\
fed_grant_ t & 1.17 & 0.853542 \\
\hline Mean vIF & 3.01 & \\
\hline
\end{tabular}

Figure 3-5- Variance inflation factor (VIF) to check for multicollinearity

The information from "T-test" along with "VIF" test can be used to decide if there is multicollinearity that is causing problems in this model.

According to the "T-test", there is a high correlation in the model between "Education and related expenses" and four other variables as "Endowment", "Research and related cost", "Total revenue" and "Net tuition". Also according to 
Figure 3-5 "VIF" for this variable is 9.01. Thus, it might be convincing to remove "Education and related expenses" variable from the model.

Also "Total revenue of institution" is considered to be subtracted from the model based on the same reason mentioned above. According to the "T-test", there is high correlation between this variable and four other variables in the model including: "Education and related expenses", "Endowment", "Research and related cost" and "Net tuition".

According to the results of "multicollinearity test" two variables "Education and related expenses" and "Total revenue of institution" will be excluded from the list of variables and the rest of variables remain in the model because it is a sound approach to keep the rest of variables in the model from theoretical stand point. 


\section{Review of Model Results}

To evaluate the significance of the coefficients the ordered probit model was conducted. The selected dummy variables are not included in this list. The result from Stata shows that except for "Education and related expenses" and "Total revenue of institution" the rest of the variables have a probability value less than ".05" and $\mathrm{z}$ score higher than " 2 " which is a satisfactory result.

\begin{tabular}{|c|c|c|c|c|c|c|}
\hline \multicolumn{4}{|c|}{ ordered probit regression } & \multicolumn{2}{|c|}{$\begin{array}{l}\text { Number of obs } \\
\text { LR chi2 (7) } \\
\text { Prob }>\text { chi2 } \\
\text { Pseudo R2 }\end{array}$} & $\begin{array}{r}1044 \\
236.56 \\
0.0000 \\
0.0503\end{array}$ \\
\hline grade 2 & coef. & std. Err. & z & $P>|z|$ & [95\% conf. & Interval] \\
\hline $\begin{array}{r}\text { bach_deg_s g } \\
\text { eandr } \\
\text { endowment } \\
\text { fed_grant_ t } \\
\text { obama08_shwe } \\
\text { research_r } \sim t \\
\text { tot_rev_w_ m } \\
\text { nettuition01 } \\
\text { count } \\
\text { select } \\
\text { internations }\end{array}$ & $\begin{array}{r}1.584034 \\
-1.48 \mathrm{e}-10 \\
.0000407 \\
.0000785 \\
.9072637 \\
1.14 \mathrm{e}-09 \\
-6.08 \mathrm{e}-11 \\
9.48 \mathrm{e}-10 \\
.0843059 \\
.2048803 \\
.0356788\end{array}$ & $\begin{array}{r}.1975561 \\
2.18 \mathrm{e}-10 \\
.000015 \\
.0000184 \\
.351976 \\
2.33 \mathrm{e}-10 \\
4.28 \mathrm{e}-11 \\
3.44 \mathrm{e}-10 \\
.0393326 \\
.1044872 \\
.0076221\end{array}$ & $\begin{array}{r}8.02 \\
-0.68 \\
2.72 \\
4.27 \\
2.58 \\
4.90 \\
-1.42 \\
2.75 \\
2.14 \\
1.96 \\
4.68\end{array}$ & $\begin{array}{l}0.000 \\
0.495 \\
0.007 \\
0.000 \\
0.010 \\
0.000 \\
0.155 \\
0.006 \\
0.032 \\
0.050 \\
0.000\end{array}$ & $\begin{array}{r}1.196831 \\
-5.75 \mathrm{e}-10 \\
.0000113 \\
.0000425 \\
.2174034 \\
6.85 \mathrm{e}-10 \\
-1.45 \mathrm{e}-10 \\
2.73 \mathrm{e}-10 \\
.0072155 \\
.0000891 \\
.0207397\end{array}$ & $\begin{array}{r}1.971237 \\
2.78 \mathrm{e}-10 \\
.00007 \\
.0001145 \\
1.597124 \\
1.60 \mathrm{e}-09 \\
2.31 \mathrm{e}-11 \\
1.62 \mathrm{e}-09 \\
.1613963 \\
.4096716 \\
.0506179\end{array}$ \\
\hline
\end{tabular}

Figure 4-1- Snapshot of STATA results excluding the "Dummy Variables"

To avoid multicollinearity, the model was redone without the two variables "Education and related expenses" and "Total revenue of institution" which had low coefficients in the previous regression. 


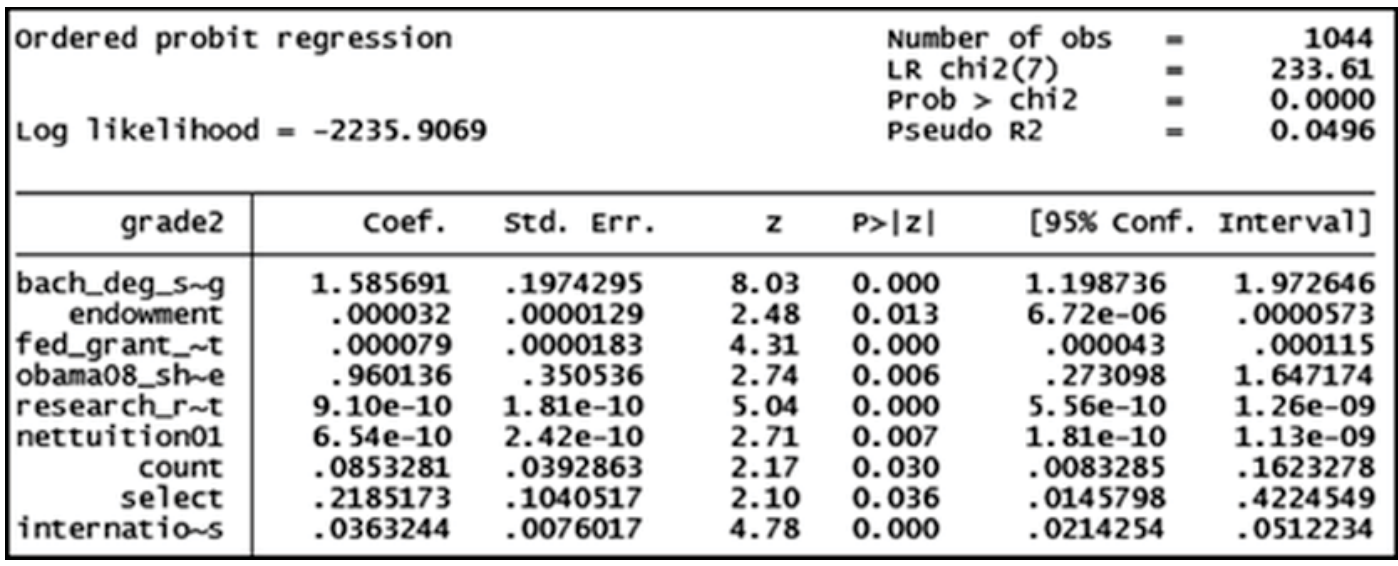

Figure 4-2- STATA results excluding “Education and related expenses" and "Total revenue of institution"

There is no change in the sign of the variables, but the significance of the coefficients have been raised a small amount from the previous regression.

\section{4-1- Four Part Specification Test over Dummy Variables}

"Four Part Specification Test" is consisted of four valid criteria to decide whether a given variable belongs to the model or not. [24] Following conditions will be considered in this test:

1. "Theory": Is the variable theoretically important to be included in the model?

2."T-test" or "F-test": Is the variable statistically significant?

3. " $\bar{R}^{2}$ ": Does the overall fit of the equation improve when the variable is added to in the model?

4."Bias": Do the coefficients of the other variables change significantly when the variable is added?

In this section, each dummy variable will be added to the variables list individually. By considering four mentioned criteria which have been discussed 
above, the influence of each dummy variable is expected to be seen on other variables in the list. After "Four Part Specification Test" it will be mentioned that the variable will be included or dropped from the model. More details about "F Test" are explained in Appendix 3.

"Population" which is the name of the first dummy variable was added to the variable list shows the population of the county where each institution is located. This factor (categorical) variable has three indicators including " 3 " which represents the big size cities (over 500,000 population), "2" represents the mid-size cities (between 60,000-120,000 population), and "1" represents the small towns (under 10,000 population). These three categories for population of states is a rough estimation.

\begin{tabular}{|r|rrr|}
\hline population & Freq. & Percent & Cum. \\
\hline 1 & 205 & 17.67 & 17.67 \\
2 & 428 & 36.90 & 54.57 \\
3 & 527 & 45.43 & 100.00 \\
\hline Tota1 & 1,160 & 100.00 & \\
\hline
\end{tabular}

Figure 4-3- Population indicators used in the STATA model

According to the table, majority of institutions are located in the cities with high population.

Two dummy variables "Populsmall" and "Populbig" are used in Stata to analyze the impact of "Population" on the dependent variable. The dummy variable which indicates big-size cities is statistically significant and has a negative sign. Other dummy variable which indicates small towns is not statistically significant and has a 
negative sign. According to the signs, as population goes up the likelihood of high sustainability scores goes down.

The following snapshot of Stata shows the result of "F-test" for "Population" variables which is a large "F-statistic" and small "P-value". Therefore it is possible to reject the null hypothesis which at the same time both coefficients of population variables are equal to zero. The negative sign for "populbig" means that the likelihood of high sustainability scores does decrease with population.

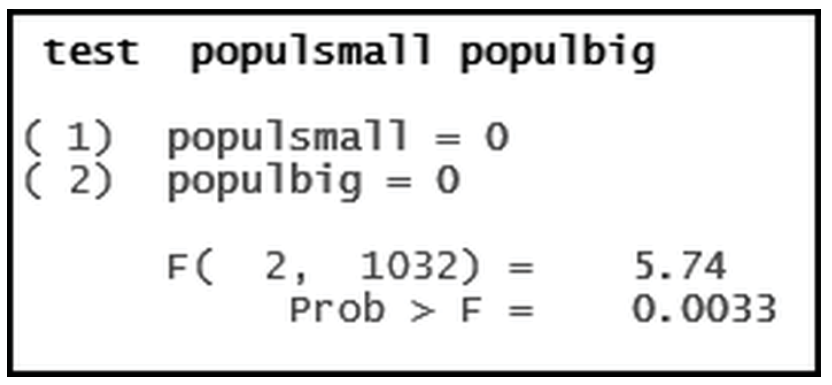

\section{Figure 4-4- Snapshot of F-test for "Populsmall" and "Populbig" variables, derived from Stata}

The "Pseudo R2" in "ordered Probit Model" which evaluates the goodness-of-fit of the model is similar to R-squared in "OLS" and has the similar scale ranging from 0 to 1 . The result shows that "Pseudo R2" improves from 0.0496 to 0.0518 when the "Population" variables are added to the list of the variables, but there is not a noticeable change in the regression coefficients.

To see the relationship between sustainability practices in the school and the population of county where the school is located, these two dummy variables including: "Populsmall" and "Populbig" are important and included in the model. 
The second dummy variable which was added to the list of variables "RPS" stands for "renewable Portfolio Standard". The positive coefficient for "RPS" implies that those institutions that are located in counties with RPS-type mechanisms are more likely to have higher sustainability score. The coefficient for this variable is not significant. According to the following figure "RPS" has a small F-statistic and small P-value.

$$
\begin{array}{ll}
\text { (1) } \operatorname{rps}=0 \\
\mathrm{~F}(1, \quad 1031)= & 0.71 \\
\text { Prob }>\mathrm{F}= & 0.3991
\end{array}
$$

Figure 4-5- Snapshot of F-test for "RPS" variable, derived from Stata

The inclusion of "RPS" does not change the signs of the other variables, but it slightly decreases the coefficient of "obama08_share". The result shows that the inclusion of "RPS" improves "Pseudo R2" slightly from 0.0518 to 0.0520 .

To find the relationship between sustainability practices in the school and "RPS" it is sound to keep this variable in the model.

The third factor (categorical) variable shows the ranking of the institution. This variable which indicates top 50 liberal art schools has been shown as "top501a" in the figure below. The coefficient for this variable is statistically significant and the positive sign shows to be considered in the list of top 50 liberal art institutions increase the likelihood of having a high sustainability grade. The following figure shows a very high F-statistic and low probability of "top501a". 


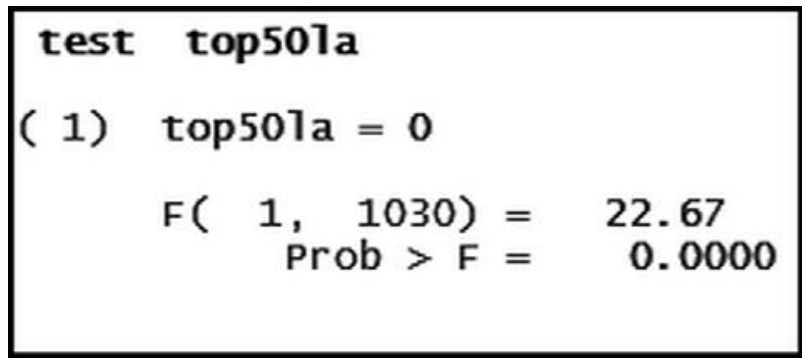

Figure 4-6- Snapshot of F-test for "Top50LA" variable, derived from Stata

After adding"top50la" to the list of variables "Pseudo R2" increases from 0.0520 to 0.0564 . There is no change in the sign or the coefficients of other variables regarding to inclusion of "top50la".

As a result of "Four Part Specification Test" this variable "top501a", is included in the model.

"Controlprivate" is the name of the forth dummy variable which distinguishes between public and private institutions. For this variable the dummy variable is equal to " 1 " if the university is private and is equal to " 0 " if it is a public institution. The result shows that "Controlprivate" has a significant coefficient and the negative sign which means that the public schools are more likely to apply sustainability practice. The following figure shows a very high "F-statistic" and zero "P-value" of this variable. 


\section{test controlprivate \\ (1) controlprivate $=0$ \\ $F(1,1029)=45.78$ \\ Prob $>F=0.0000$}

Figure 4-7- Snapshot of F-test for "Controlprivate" variable, derived from Stata

The inclusion of "Controlprivate" to the list of variables increases "Pseudo R2" from 0.0564 to 0.0657 . The result shows that after adding this variable the signs of other variables remain the same but the coefficient for "Research_related_cost" has a small change.

As a result of "Four Part Specification Test" this variable "Controlprivate", is included in the model.

"landgrnt01" is a name for fifth factor variable which shows the land grant institutions. This category which involves small number of institutions, indicating that a selected school takes advantages of the "Morrill Acts of 1862 and 1890". The coefficient for this variable has positive sign and is not significant.

The positive sign here means that land grant institutions are more likely to have high sustainability score. The following figure shows that "landgrnt01" has a low "Fstatistic" and low "P-value". 


\begin{tabular}{|lll|}
\hline test & 1andgrnt01 \\
(1) & 1andgrnt01 $=0$ \\
& $F(1,1028)=$ & 1.68 \\
& Prob $>F=$ & 0.1957 \\
\end{tabular}

Figure 4-8-Snapshot of F-test for "Landgrant01" variable, derived from Stata

After adding "landgrnt01" there is no change in the coefficients of other variables but "Pseudo R2" improves from 0.0657 to 0.0661 .

As a result of "Four Part Specification Test" this variable "landgrnt01", is included in the model.

Next, those variables which determine the geography zone of the institutions are added to the analysis. These zones include Southeast, West and Midwest which are recognizable with the same name in the result table and the signs for these variables are negative, positive and negative respectively. In general, the relevant coefficient for Midwest is better than the coefficients for both Southeast and West, but none of them is statistically significant. The following figure shows a high F-statistic and low P-value for this variable, which means it is likely to reject the null hypothesis that at the same time all the coefficients of "geography zone" are equal to zero. 


\begin{tabular}{|lll|}
\hline test & Southeast west Midwest \\
(1) & Southeast $=0$ \\
$($ 2) & West $=0$ \\
( 3) & Midwest $=0$ \\
& $F(\quad 3, \quad 1025)=$ & \\
& Prob $>F=$ & 0.0089 \\
&
\end{tabular}

Figure 4-9- Snapshot of F-test for "Geography zone" variables, derived from Stata

As a result of adding "geography zone" variables to the rest of explanatory variables in the model, "Pseudo R2" improves from 0.0661 to 0.0683 and the coefficients for "RPS" and "Nettuition01" slightly change.

As a result of "Four Part Specification Test" the geography zone variables including: Southeast, West and Midwest are included in the model.

The last variable which was added to the model was "Carnegie123" which determines the research activity of each institution by classifying them to three groups. The following table shows this classification. The "1" includes institutions where most of the degrees are at the bachelor's level and " 2 ' include institutions that most of degrees are at master level and " 3 " shows the universities which awarded at least 20 research related to the doctoral degrees. 


\begin{tabular}{|r|rrr|}
\hline carnegie12 & Freq. & Percent & Cum. \\
\hline 1 & 334 & 28.82 & 28.82 \\
2 & 144 & 12.42 & 41.24 \\
3 & 681 & 58.76 & 100.00 \\
\hline Tota1 & 1,159 & 100.00 & \\
\hline
\end{tabular}

Figure 4-10- The research activity indicators used in the STATA model

Stata considers this variable as two dummy variables which are entitled as "Carnegiebach" and "Carnegiedoc". The result shows that neither coefficient is significant. The negative sign of "Carnegiedoc" and positive sign of "Carnegiebach" imply that the number of bachelor degree students has positive impact on sustainability practices at schools. In another words those institutions with higher percent of bachelor's degree are more likely to get high sustainability grade. The following figure shows the result of F-statistic which is not significant and P-value which is not low.

$$
\begin{aligned}
& \text { test carnegiebach carnegiedoc } \\
& \text { (1) carnegiebach }=0 \\
& \text { (2) carnegiedoc }=0 \\
& \begin{aligned}
F(2,1023)= & 1.77 \\
\text { Prob }>F= & 0.1715
\end{aligned}
\end{aligned}
$$

Figure 4-11- Snapshot of F-test for "Carnegiebach" and "Carnegiedoc", derived from Stata 
As a result of adding "research activity" variables "Pseudo R2" improves from 0.0683 to 0.0690 and the coefficient of "Bach_deg_share_of_tot_deg" changes from 0.3691 to 0.0550 .

As a result of "Four Part Specification Test" two variables "Carnegiebach" and "Carnegiedoc" are included in the model.

It is theoretically a sound approach to keep most of the variables in the model, because the variety of variables can help to evaluate sustainability from different aspects. The following figure summarizes all the variables which have been selected to remain in the model at this stage.

\begin{tabular}{|c|c|c|c|c|c|c|}
\hline \multicolumn{4}{|c|}{$\begin{array}{l}\text { Ordered probit regression } \\
\text { Log likelihood }=-2190.3446\end{array}$} & \multicolumn{2}{|c|}{$\begin{array}{l}\text { Number of obs } \\
\text { LR chi2 } 18) \\
\text { Prob > Chi2 } \\
\text { Pseudo R2 }\end{array}$} & \multirow{2}{*}{$\begin{array}{r}1044 \\
324.73 \\
0.0000 \\
0.0690 \\
\text { Interva1] }\end{array}$} \\
\hline grade2 & coef. & std. Err. & $\mathbf{z}$ & $P>|z|$ & [95\% conf. & \\
\hline $\begin{array}{r}\text { carnegiebach } \\
\text { carnegiedoc } \\
\text { Southeast } \\
\text { west } \\
\text { midwest } \\
\text { landgrnt01 } \\
\text { controlpri i } \\
\text { top501a } \\
\text { rps } \\
\text { populsma11 } \\
\text { populbig } \\
\text { bach_deg_s g } \\
\text { endowment } \\
\text { fed_grant_wt } \\
\text { obama08_sh e } \\
\text { research_r t } \\
\text { nettuition01 } \\
\text { count } \\
\text { select } \\
\text { internatio s }\end{array}$ & $\begin{array}{r}.2777139 \\
-.023114 \\
-.0546879 \\
.1172182 \\
-.2064573 \\
.1526615 \\
-.7329522 \\
.6794025 \\
.2066307 \\
.0110887 \\
-.1946828 \\
.0550769 \\
.0000559 \\
.0001018 \\
.6374342 \\
5.09 \mathrm{e}-10 \\
8.07 \mathrm{e}-10 \\
.0676763 \\
.6044163 \\
.038207\end{array}$ & $\begin{array}{r}.1716821 \\
.131558 \\
.1355973 \\
.0994544 \\
.0975254 \\
.1081428 \\
.1221893 \\
.1466713 \\
.1085038 \\
.1038318 \\
.0756352 \\
.3215589 \\
.0000137 \\
.000019 \\
.4553586 \\
1.97 e-10 \\
2.55 \mathrm{e}-10 \\
.045804 \\
.1211183 \\
.0080731\end{array}$ & $\begin{array}{r}1.62 \\
-0.18 \\
-0.40 \\
1.18 \\
-2.12 \\
1.41 \\
-6.00 \\
4.63 \\
1.90 \\
0.11 \\
-2.57 \\
0.17 \\
4.06 \\
5.36 \\
1.40 \\
2.58 \\
3.16 \\
1.48 \\
4.99 \\
4.73\end{array}$ & $\begin{array}{l}0.106 \\
0.861 \\
0.687 \\
0.239 \\
0.034 \\
0.158 \\
0.000 \\
0.000 \\
0.057 \\
0.915 \\
0.010 \\
0.864 \\
0.000 \\
0.000 \\
0.162 \\
0.010 \\
0.002 \\
0.140 \\
0.000 \\
0.000\end{array}$ & $\begin{array}{r}-.0587768 \\
-.280963 \\
-.3204538 \\
-.0777087 \\
-.3976035 \\
-.0592945 \\
-.9724388 \\
.3919321 \\
-.0060329 \\
-.192418 \\
-.3429251 \\
-.575167 \\
.0000289 \\
.0000646 \\
-.2550521 \\
1.23 \mathrm{e}-10 \\
3.06 \mathrm{e}-10 \\
-.0220978 \\
.3670289 \\
.022384\end{array}$ & $\begin{array}{r}.6142045 \\
.234735 \\
.211078 \\
.3121452 \\
-.0153111 \\
.3646174 \\
-.4934656 \\
.9668729 \\
.4192942 \\
.2145954 \\
-.0464404 \\
.6853207 \\
.0000828 \\
.000139 \\
1.529921 \\
8.95 \mathrm{e}-10 \\
1.31 \mathrm{e}-09 \\
.1574504 \\
.8418038 \\
.0540299\end{array}$ \\
\hline
\end{tabular}

Figure 4-12- Snapshot of STATA variables including the "dummy variables"

Note: Due to saving space, the level indicators of factor variables are not created by STATA in the results. 


\section{4-2- “Four Parts Specification Test” over Categorical}

\section{Variables}

Following the analysis over dummy variables, in this section each of the categorical variables is evaluated to decide whether they belong to the model or not, "Four Parts Specification Test" is considered through the analysis. Thus, each categorical variable is subtracted from the model to see its impact on other coefficients and the overall fit of the model.

"Bach_deg_share_of_tot_deg" is the name of the variable which shows the Share of total degrees at bachelor's level. The coefficient for this variable is not significant but it can be inferred from the positive sign of this variable that there is a direct relationship between the number of degree in bachelor's level and sustainability grades in IHE. It means those institutions with higher number of bachelor's level are more likely to have higher sustainability grades. The following figure shows the low "F-statistic" and high "P-value" for this variable.

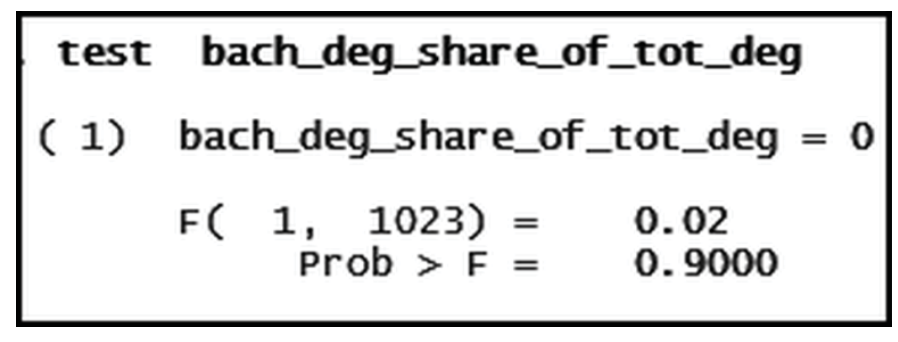

Figure 4-13-Snapshot of F-test for "Bach_deg_share_of_tot_deg" variable, derived from Stata 
After subtracting "Bach_deg_share_of_tot_deg" from the list of variables there is a change in coefficients of other variables, but "Pseudo R2" remains the same 0.0690 in the new regression.

To find the relationship between the "Share of total degrees at bachelor's level" and sustainability practice in the university, this is an important variable and is included in the model.

The result of analysis shows that "Endowment" is a significant factor that contributes to the sustainability grades in IHEs. The positive sign of this variable implies that those institutions that receive higher amount of endowment are more likely to receive a higher sustainability grades. Following figure shows high "Fstatistic" and low "P-value" for "Endowment".

$$
\begin{array}{|lcl}
\hline \text { test endowment } & \\
\text { (1) endowment }=0 & \\
\mathrm{~F}(1,1023)= & 12.90 \\
\text { Prob }>\mathrm{F}= & 0.0003
\end{array}
$$

Figure 4-14- Snapshot of F-test for "Endowment" variable, derived from Stata

Subtracting "Endowment" from the list of variables changes the coefficient of "Research_related_cost" from 5.79e-10. to 8.79e-10. Also subtracting "Endowment" decreases "Pseudo R2" from 0.0690 to 0.0655 in the new regression.

As a result of "Four Parts Specification Test", this variable "Endowment" is included in the model. 
Average amount of federal grants with the name of "Fed_grant_avg_amount" in the result table is a statistically significant factor. The "P-value" of zero and "z score" of 5.36 shows the low probability that its effect would have occurred due to the chance. The positive sign conveys that the institutions that receive higher amount of federal grants are more likely to adopt sustainability practice on their campus.

The following figure shows a very high "F-statistic" and zero "P-value" for this variable.

$$
\begin{array}{ccc}
\text { test } & \text { fed_grant_avg_amount } \\
\text { (1) fed_grant_avg_amount }=0 \\
F(1,1023)=c & 25.79 \\
\text { Prob }>F= & 0.0000
\end{array}
$$

\section{Figure 4-15-Snapshot of F-test for "Fed_grant_avg_amount" variable, derived from Stata}

As a result of subtracting "Fed_grant_avg_amount" from the list of variables "Pseudo R2" decreases from 0.0690 to 0.0629 in the new regression, and there are some changes in majority of the other coefficients.

As a result of "Four Parts Specification Test", this variable "Fed_grant_ avg_amount" is included in the model.

Although the coefficient of "Obama08_share" which indicate the majority of political views of the population in each state is not significant, the positive sign indicates that those states, which had higher percent of voters for Obama in 2008, are 
more dedicated to sustainability practices. The following figure shows "F-statistic" and "P-value" of "Obama08_share".

\begin{tabular}{|ccl|}
\hline test & obama08_share & \\
(1) & obama08_share $=$ & \\
& \\
& $F(1, \quad 1023)=$ & 2.07 \\
Prob $>F=$ & 0.1504 \\
\hline
\end{tabular}

Figure 4-16-Snapshot of F-test for "Obama08_share" variable, derived from Stata

The result shows that subtracting "Obama08_share" affect "geography zone" coefficients: "Southeast" change from -0.05 to -0.10 , "West" change from 0.11 to 0.06 and "Midwest" change from -0.21 to -0.25 . Also it will slightly reduce "Pseudo R2" from 0.0690 to 0.0686 .

Since this variable "Obama08_share" in comparison to the rest of variables provides a different aspect to evaluate sustainability relationship, it is a sound approach to keep it in the model.

"Research_related_cost" as one of the explanatory variables includes the total sum of expenses for research education, public service, scholarships and fellowships in each institution. It has a significant coefficient which shows those IHE with higher amount of expenses on research are more likely to adopt sustainability than institution with low expenses on research. The following figure shows the result of "F-test" for 
this variable. Stata could not read the data for this variable. It should be pointed out that the Stata drops constraints when they are either nonbinding or contradictory.

\begin{tabular}{|cl|}
\hline test & research_related_cost \\
(1) & $\begin{array}{l}\text { research_related_cost }=0 \\
\text { Constraint } 1 \text { dropped }\end{array}$ \\
& $F\left(\begin{array}{c}0,1023)= \\
\text { Prob }>F=\end{array}\right.$
\end{tabular}

\section{Figure 4-17-Snapshot of F-test for "Research_related_cost" variable, derived from Stata}

If the "Research_related_cost" is dropped from the list of variables "Pseudo R2" will increase from 0.0690 to 0.0710 . It also impacts the coefficient of "nettuition01" and changes it from $8.07 \mathrm{e}-10$ to $1.13 \mathrm{e}-09$.

As a result of "Four Parts Specification Test", this variable "Research_related_ cost" is included in the model.

"Nettuition01" as one of the variables which represent the direct revenue from students is statistically significant. The positive sign on this variable suggests the higher likelihood of developing sustainability in institutions with higher amount of revenue from tuition. The following figure shows the result of " $\mathrm{F}$ test" for "Nettuition01", while Stata could not read its data, either. 


\section{test nettuition01 \\ ( 1 ) nettuition01 $=0$ Constraint 1 dropped \\ $F(0,1023)=$ Prob $>\mathrm{F}=$}

Figure 4-18- Snapshot of F-test for “Nettuition01" variable, derived from Stata

Exclusion of "Nettuition01" from the list of variables has impact on "Research_related_cost"coefficient and changes it from 5.09e-10 to 7.85e-10, also it reduces "Pseudo R2" from 0.0690 to 0.0669.

As a result of "Four Parts Specification Test", this variable "Nettuition01" is included in the model.

"Count" which as an independent variable points to the number of times each institution contributed to the survey does not have a significant coefficient. Although the positive sign on this variable can be interpret as the direct relationship between the sustainability grades and number of times which each institution contribute to the survey. Following figure shows the result of "F-test" for "count" variable which has a low "F-statistic" and a high "P-value". 


$$
\begin{aligned}
& \text { test count } \\
& \text { (1) count }=0 \\
& F(1,1023)=2.47 \\
& \text { Prob }>F=0.1161
\end{aligned}
$$

Figure 4-19- Snapshot of F-test for "Count” variable, derived from Stata

The exclusion of "Count" from the list of variables changes other variables' coefficient slightly, and it reduces the "Pseudo R2" from 0.0690 to 0.0685 .

As a result of "Four Parts Specification Test", this variable "Count" is dropped from the model.

Another significant coefficient in this list belongs to "Select" which shows the selectivity of each institution. A selective institution is simply an institution which does not admit everyone. This variable with high statistical significance and positive sign imply that the higher the percent of selectivity of institution, the higher the probability of a good sustainability score. The following figure shows that this variable has a very high "F-statistic" and zero "P-value".

\begin{tabular}{|clc|}
\hline test & select \\
(1) & select $=0$ \\
& $F(1, \quad 1023)=$ & 25.05 \\
& Prob $>F=$ & 0.0000 \\
\hline
\end{tabular}

Figure 4-20- Snapshot of F-test for "Select" variable, derived from Stata 
According to the result when "Select" is dropped from the list of variables, there will be some changes in majority of other variables' coefficient, and "Pseudo R2" will be reduced from 0.0690 to 0.0652 .

As a result of "Four Parts Specification Test", this variable "Select" is included in the model.

The variable which measures the influence of international student on sustainability status of institution has positive and significant coefficient. It demonstrates the positive effect of international student in developing sustainability in institution. In another words, institution with higher percent of international student are more likely to look after sustainability practice on their campus. According to the following figure "Internationals" has a very high "F-statistic" and zero "P-value" which shows its significant effect in the model.

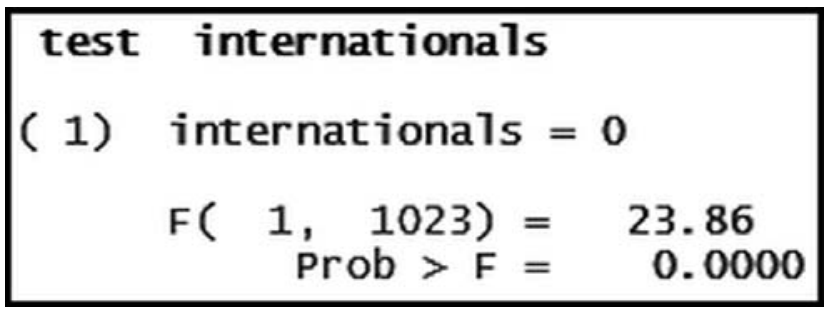

Figure 4-21- Snapshot of F-test for "International" variable, derived from Stata

According to the result after excluding "Internationals" from the model there is some changes in other variables' coefficients. For example "nettuition01" changes from 8.07e-10 to 6.00e-10. Also "Pseudo R2" will reduce from 0.0690 to 0.0643. 
As a result of "Four Parts Specification Test", this variable "Internationals" is included in the model.

\begin{tabular}{|c|c|c|c|c|c|c|}
\hline \multicolumn{4}{|c|}{ ordered probit regression } & \multicolumn{2}{|c|}{$\begin{array}{l}\text { Number of obs } \\
\text { LR chi2 }(17) \\
\text { Prob }>\text { chi2 } \\
\text { Pseudo R2 }\end{array}$} & \multirow{2}{*}{$\begin{array}{r}1044 \\
322.55 \\
0.0000 \\
0.0685 \\
\text { Interva1] }\end{array}$} \\
\hline grade2 & coef. & std. Err. & z & $P>|z|$ & [95\% conf. & \\
\hline carnegiebach & .2920859 & .171408 & 1.70 & 0.088 & -.0438676 & .6280395 \\
\hline carnegiedoc & .0434454 & .1235975 & 0.35 & 0.725 & -.1988012 & .285692 \\
\hline Southeast & -.0403344 & .1352423 & -0.30 & 0.766 & -.3054045 & .2247356 \\
\hline West & .1123012 & .0993966 & 1.13 & 0.259 & -.0825126 & .307115 \\
\hline Midwest & -.1989275 & .097389 & -2.04 & 0.041 & -.3898064 & -.0080486 \\
\hline 1andgrnt01 & .176382 & .1069434 & 1.65 & 0.099 & -.0332232 & .3859871 \\
\hline controlpri e e & -.6837836 & .1175515 & -5.82 & 0.000 & -.9141803 & -.453387 \\
\hline top501a & .7403355 & .1407524 & 5.26 & 0.000 & .4644659 & 1.016205 \\
\hline rps & .2101187 & .1084714 & 1.94 & 0.053 & -.0024814 & .4227187 \\
\hline populsma11 & .0075606 & .1038013 & 0.07 & 0.942 & -.1958861 & .2110074 \\
\hline populbig & -.1962628 & .0756249 & -2.60 & 0.009 & -.3444848 & -.0480407 \\
\hline bach_deg_s g & .0654019 & .321465 & 0.20 & 0.839 & -.5646579 & .6954616 \\
\hline endowment & .0000572 & .0000137 & 4.17 & 0.000 & .0000303 & .0000841 \\
\hline fed_grant_ t & .0001014 & .000019 & 5.34 & 0.000 & .0000642 & .0001386 \\
\hline obama08_shwe & 55087 & .4515597 & 1.22 & 0.222 & -.3341708 & 1.435911 \\
\hline research_r t & $5.35 \mathrm{e}-10$ & $1.96 \mathrm{e}-10$ & 2.73 & 0.006 & 1. $50 \mathrm{e}-10$ & $9.19 \mathrm{e}-10$ \\
\hline nettuition01 & $8.70 \mathrm{e}-10$ & $2.52 \mathrm{e}-10$ & 3.46 & 0.001 & $3.77 e-10$ & 1. $36 \mathrm{e}-09$ \\
\hline select & . 5909646 & .1207641 & 4.89 & 0.000 & .3542713 & .827658 \\
\hline internatious & .0398003 & .0080005 & 4.97 & 0.000 & .0241197 & .0554809 \\
\hline
\end{tabular}

Figure 4-22- Snapshot of STATA variables after dropping the variable "Count"

\section{Summary and Conclusion}

\section{5-1- Summary of Research Findings}

Generally speaking, every academic institute can affect its surrounding environment and society, either directly or indirectly. Thus, it can be considered as one of the best places for practicing and promoting sustainability.

Lack of an integrated and systematic sustainability plan can be referred as the shortcomings of sustainability consistency. This paper has focused on the characteristics of IHE to provide insights into which factors affect on institution's 
decision to adopt sustainability practices. By reviewing other institution sustainability grades and their institution characteristics, this paper tries to provide empirical modeling and data analysis about the factors which affect sustainability in schools. Finding the common factors between institutions with high sustainability grades can provide a big picture for developing robust campus sustainability plans and practices.

In order to develop this research, sustainability grades of 321 colleges and schools have been extracted from "The College Sustainability Report Card" and analyzed alongside the characteristics of the respective schools. "The Ordered Probit Model" has been run in Stata in order to find a meaningful relationship between sustainability practices and the characteristics of each school.

The results of this analysis indicate that financial resources do have a significant role in sustainability decisions and practices on the IHE campuses, similar to Stafford findings that introduced sustainability as a luxury activity in higher education institutions where wealthier ones have more willingness to apply sustainability plans than those with lower budgets.

According to the results of the current research developed by this model, the location of institution may affect their sustainability effort. For example those IHE that are located in the western geographic zone are more likely to be successful in improving sustainability on their campuses, whereas those universities which are located in "Midwest" and "Southeast" zones are less likely to practice sustainability on their campuses. 
Although not all the population coefficients are statistically significant, it shows that the sustainability practice of the institution and the population of the respective county have contradictory effect with each other.

In this research, two variables (percentage of international student and the share of total bachelor degree) examine the student impact on applying sustainability practices in IHE. The statistically significant coefficient for international student implies that the institutions that have a higher percentage of international students are more interested to be involved in sustainability plans. Although the coefficient on "the share of the total bachelor degree" is not significant, it shows the positive effect of the number of bachelor students on sustainability status in IHE.

According to the results, institutions which are included in the top 50 liberal art institutions and those which are more selective regarding student applications, are more interested in keeping their sustainability grades at higher levels. On the other hand, positive sign on RPS variable shows that the policies which promote sustainability practices do have positive effect on adopting sustainability on campuses.

Although the political view variable is not statistically significant, its sign is as expected and shows that the percentage of voters who voted for Obama in 2008 and sustainability grades of IHEs do have positive relationship.

Also the majority of institutions in this research were private, but the result conveys that public schools are more dedicated to promoting sustainability on their 
campuses. On the other hand, some universities are categorized as a land grant institution, but this variable does not impact the sustainability status of these entities.

The coefficient which shows the number of times that each institution contributed to the survey is positive but not significant so it is dropped from the model.

To get a big picture about the variables impacting sustainability practices in IHE, and to find out which variables have the most direct or indirect influence in this analysis; all variables are classified in four major categories including: "financial support, location features, student influence and university features".

The following table shows the classification of all variables used through the research and the column entitled as "Status" indicates the rough estimation of positive or negative impact of each variable on the sustainability status in the universities. If the coefficient for each variable is statistically significant then the relevant sign has been written twice. For example two plus sign $(++)$ for "Endowment" indicates that its coefficient is statistically significant and has positive effect on sustainability status of the university. 
Table 5-1-Classification of the variables which have the most impact on sustainability

\begin{tabular}{|l|l|c|}
\hline \multicolumn{1}{|c|}{ Category } & \multicolumn{1}{|c|}{ Subcategory } & Status \\
\hline \multirow{4}{*}{ Financial Support } & Carnegie & - \\
\cline { 2 - 3 } & Endowment & ++ \\
\cline { 2 - 3 } & Research activity & ++ \\
\cline { 2 - 3 } & Federal grants & ++ \\
\cline { 2 - 3 } & Net tuition & ++ \\
\hline \multirow{4}{*}{ Location Features } & Southeast & - \\
\cline { 2 - 3 } & Midwest & +- \\
\cline { 2 - 3 } & West & +- \\
\cline { 2 - 3 } & Political view (Obama08) & + \\
\cline { 2 - 3 } & Population & + \\
\cline { 2 - 3 } & RPS & + \\
\hline \multirow{4}{*}{ Student Influence } & International & ++ \\
\cline { 2 - 3 } & Bachelor degree & + \\
\hline \multirow{4}{*}{ University Features } & Selectivity & + \\
\cline { 2 - 3 } & Top 50 LA & + \\
\cline { 2 - 3 } & Control private & + \\
\cline { 2 - 3 } & Land grant & + \\
\hline
\end{tabular}

According to the table above, five variables including "Carnegie", "Endowment", "Research activity", "Federal grant" and "Net tuition" in this analysis examine the impact of financial support on the sustainability status of the universities. The number of significant variables (4 out of 5) indicates that in this analysis "financial support" is the most influential factor in determining the sustainability status of the university.

"The university features" with two significant variables for "Selectivity" and "Top 50 LA" can be classified as the second influential category in this table, although the "student influence" is also eligible to be ranked as the second important factor. Finally, the "Location feature" of university with two negative significant variables 
can be classified in fourth place with the least influential impact on the sustainability of campus.

\section{5-2- Further Research}

As discussed before "the College Sustainability Report Card" had evaluated universities sustainability grades in five continuous years. Further research could be conducted based on the existing information and a new approach of using time series methodology to monitor sustainability grades of each university over the five years time frame. Also it will be an excellent analytical approach to look more deeply into the financial parameters of the universities and the sustainability grades since it has been hypothesized that there is a strong relationship between the financial parameters and the sustainability status of universities. 


\section{Appendix 1- The College Sustainability Report Card}

The goal of "The college sustainability report card" was to assess the environmental sustainability practices and plans at 322 schools/universities in the U.S. and Canada. At the end of these evaluations "The college sustainability report card" planned to find academic entities that are more successful in sustainability practices and may help the schools to learn from each other's performance in order to flourish the sustainability initiative on campuses.

The first reference of the "Report Card" to select respective schools was "2007 NACUBO Endowment Study" that provides information about university endowments. Starting from 2009, the "Report Card" added eight and eleven schools, respectively, to the list of the U.S. and Canada. These new schools have the criteria of approximately holding \$160 million, or even more, in endowment assets which was the criteria of "Report Card" for school selection. Schools in Canada were not taken into account for analysis in this paper.

In the procedure of selecting schools, the "Report Card" did not select the institutions that were limited to a single and particular area of graduate or professional study. Also it did not asses the universities that do not have ordinary and traditional designed facilities in the campus or those academic entities which share endowments with other primary or secondary schools.

To find relative data about potential or current sustainability initiatives of institution of higher education the "Report Card" starts to develop a research. They 
started to gather the information in 2007 by developing four surveys about sustainability performance in institutions, with concentration on "campus operations", "dining services", "endowment investment practices", and "student activities". These surveys were sent to the respective administrators and students of all 322 institutions. The full database of completed surveys of each school's sustainability initiatives is available on-line through "The Report Card" website.

Some of the most important entities and rating systems which were mentioned in the survey included "The United States Green Building Council's LEED rating system" for green building, "the EPA's Energy Star rating" for buildings and appliances, "the Fair Trade Certified Label" for items grown and processed under humane labor conditions, "the Marine Stewardship Council and Monterey Bay Aquarium Seafood Watch Standards" for sustainable seafood harvesting, etc.

It should be mentioned that the data for each year "Report Card" was collected one year earlier. For example the data for "Report Card 2011" was gathered from April through September 2010.

The focus of Report Card's research group for data gathering was on policies and approaches in nine main classes as the following:

- Administration,

- Climate Change \& Energy,

- $\quad$ Food \& Recycling,

- Green Building,

- $\quad$ Student Involvement,

- Transportation,

- Endowment Transparency,

- Investment Priorities,

- Shareholder Engagement 
"The Report Card Research Group" assigned the letter grades to each of the universities which had contributed in the surveys. These grades are calculated based on the cumulative scores awarded for 52 sustainability parameters, which were distributed through the nine categories (equally weighted) mentioned earlier.

The amount of the points which can be applied for a single parameter depends on the parameter's influence on the overall condition of campus sustainability levels and its degree of importance in comparison to the other parameters. Although these parameters include several policies and programs, they could not reflect all the university sustainability efforts like teaching, research or other aspects of sustainability.

To make it simple, only full letter grades, (A, B, C, D, and F with no plus or minus), were applied for the individual categories. The letter A in any category means the respective university accumulated at least $70 \%$ of total scores for the above mentioned parameters. Similarly, each of the letters B, C and D in any category was necessary to receive 50, 30 and 10 percent of the available points, respectively. To optimize the investment returns, no university received a grade of " $D$ " or " $F$ " in the "Investment priorities" class. Also, the overall grade for each university is a letter including minus and plus ranging from "A to F".

In order to keep the consistently for the comparison of grades, "The Report Card" have updated the particular sustainability future plans since 2007. 
Appendix 2- List of Universities Used in the Research (Extracted from Report Card)

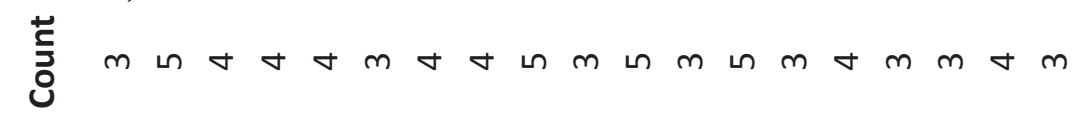

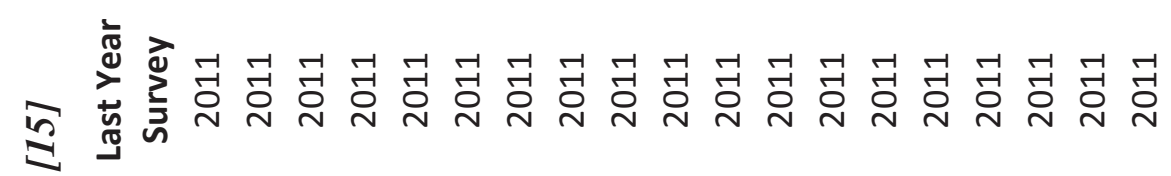

(ิ)

¿

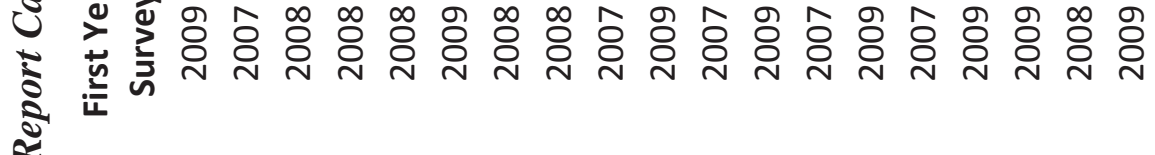

$\approx$

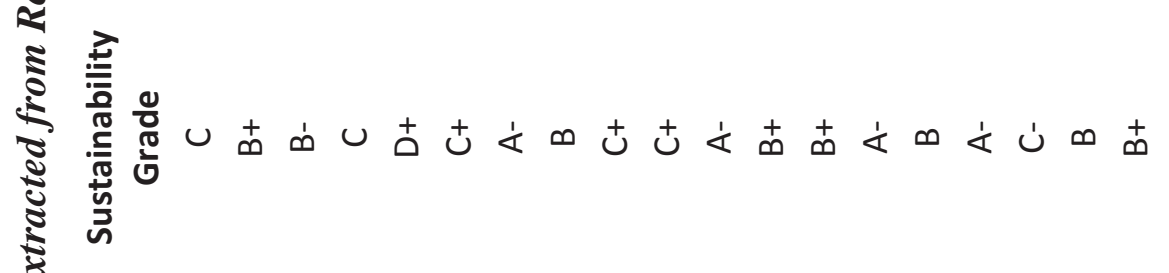

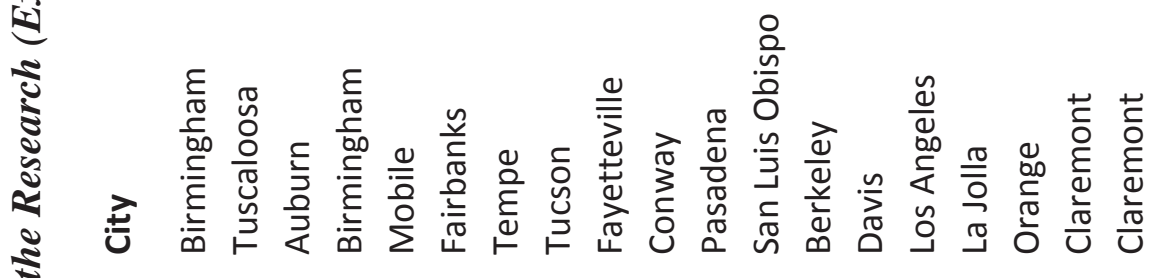

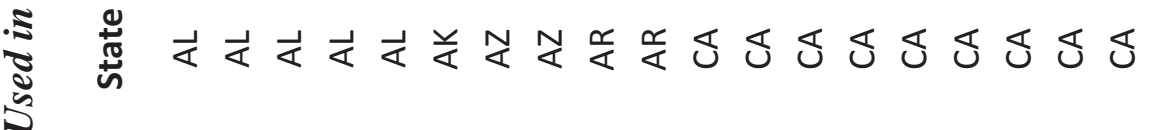

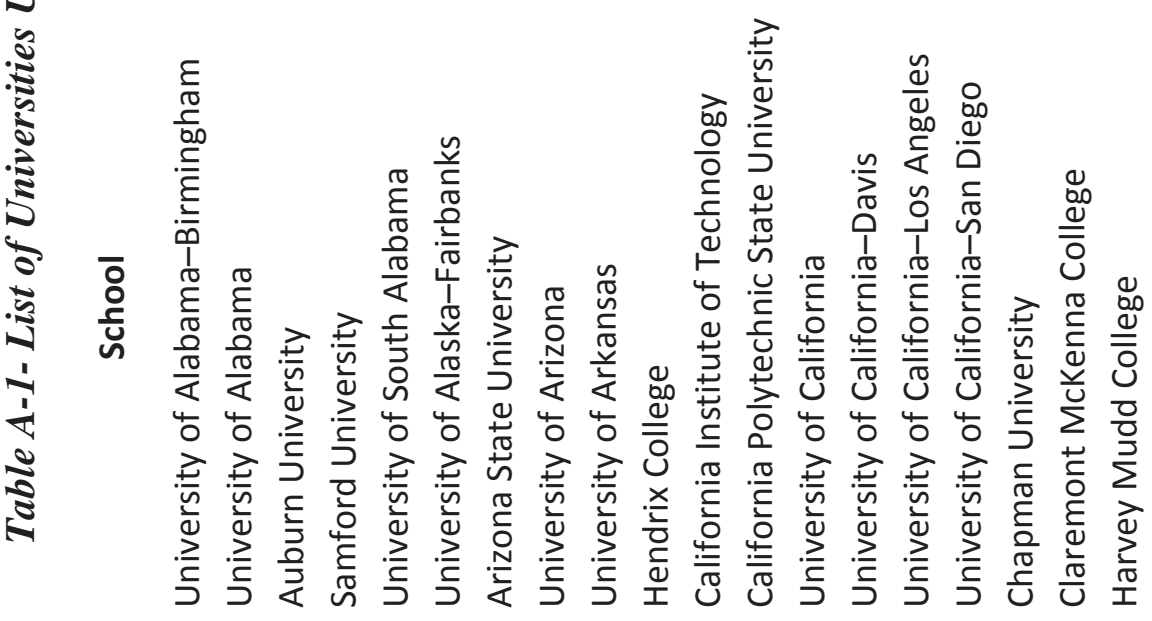

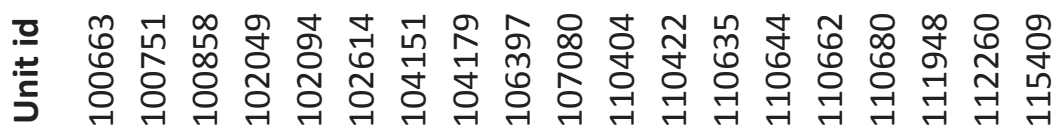


言

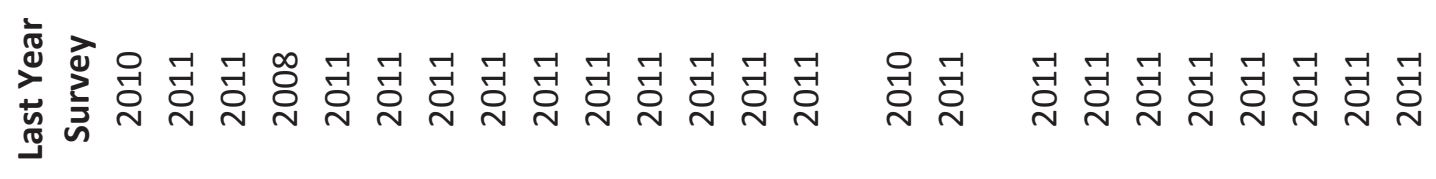

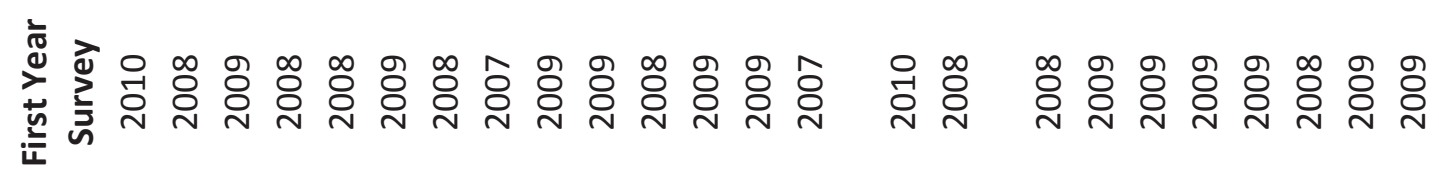

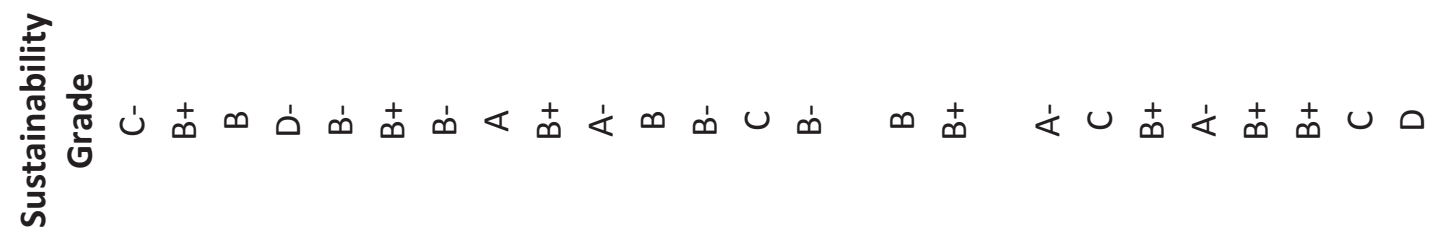

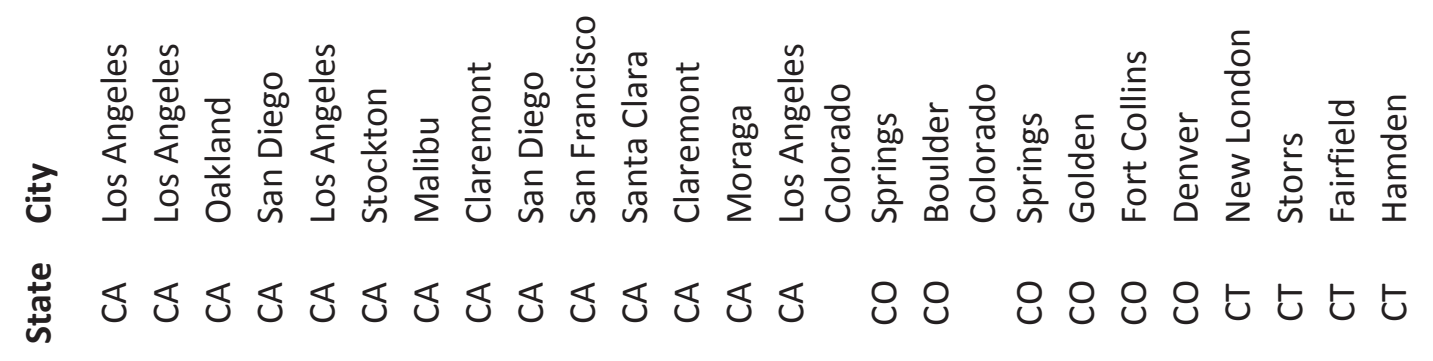

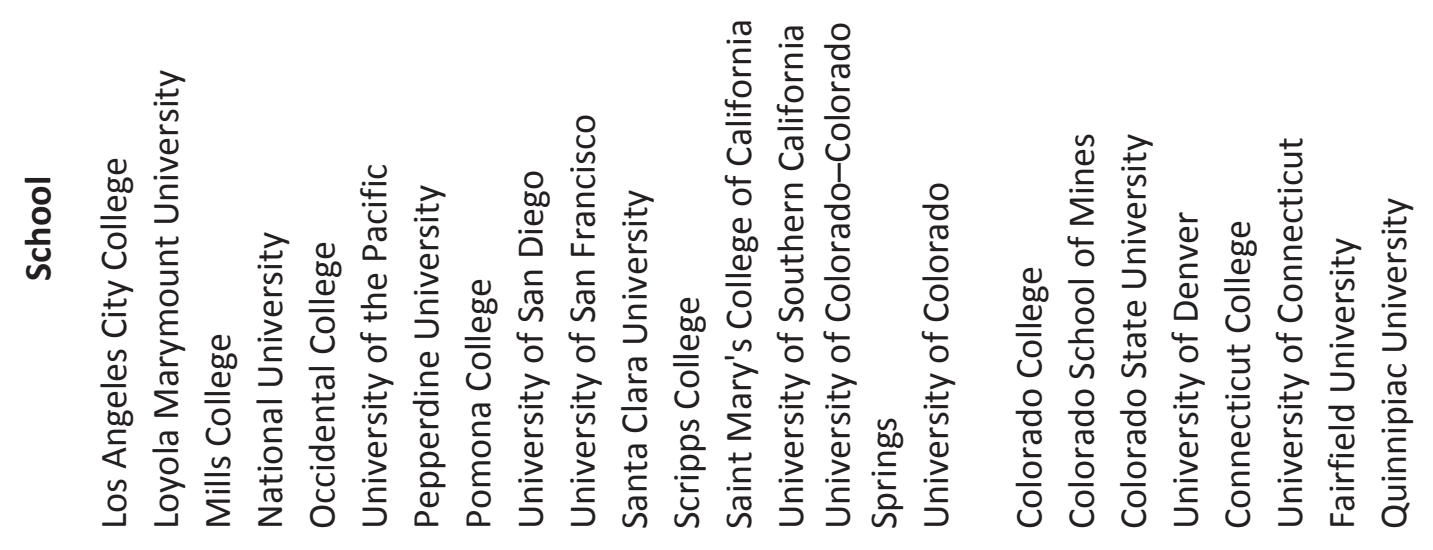

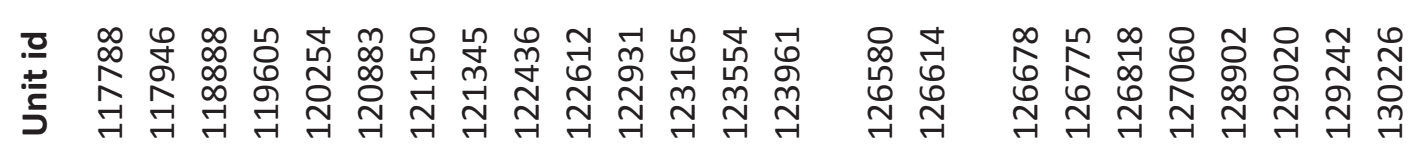




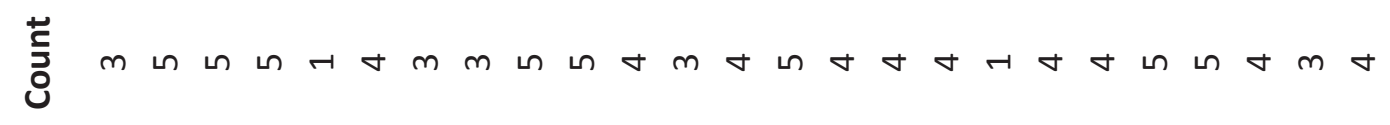

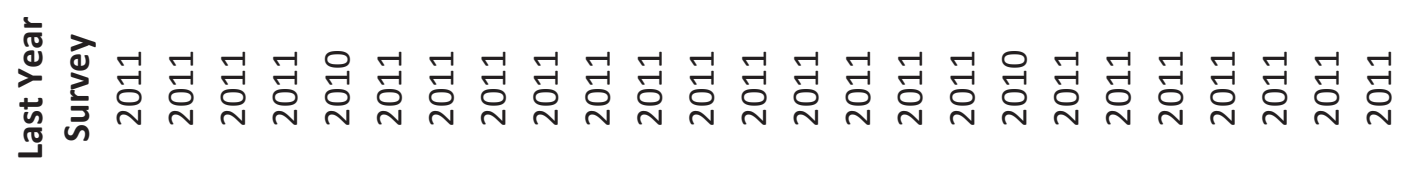

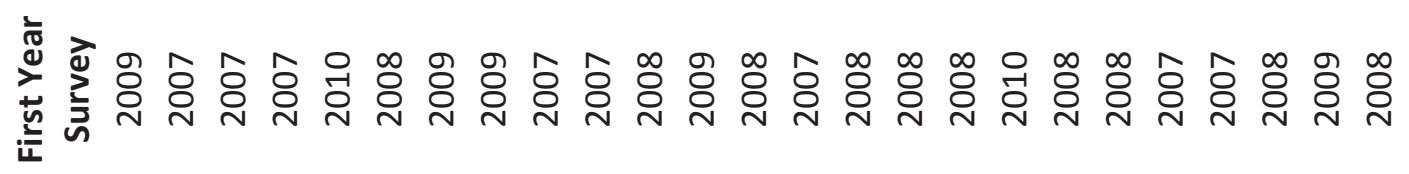

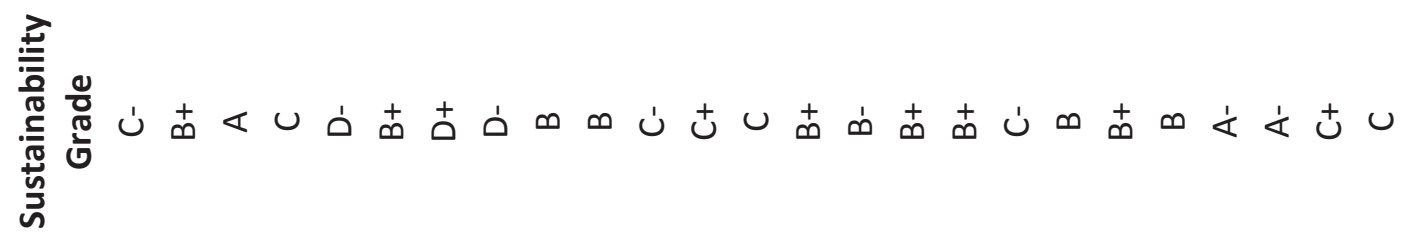

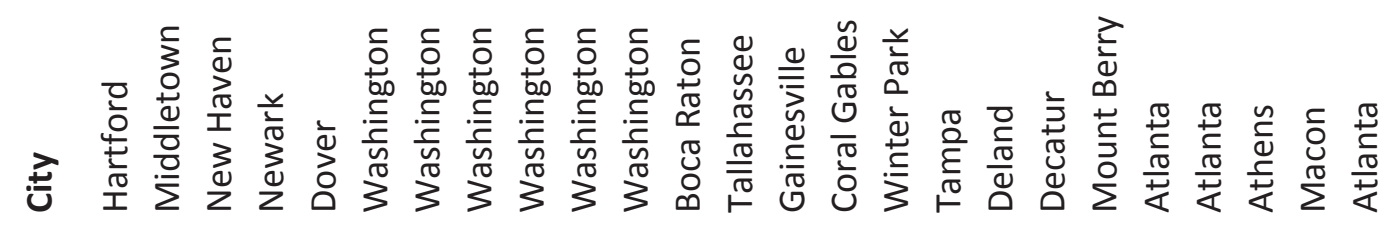

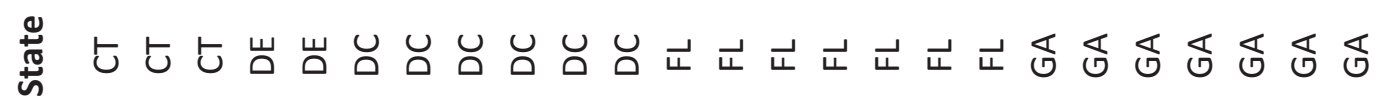

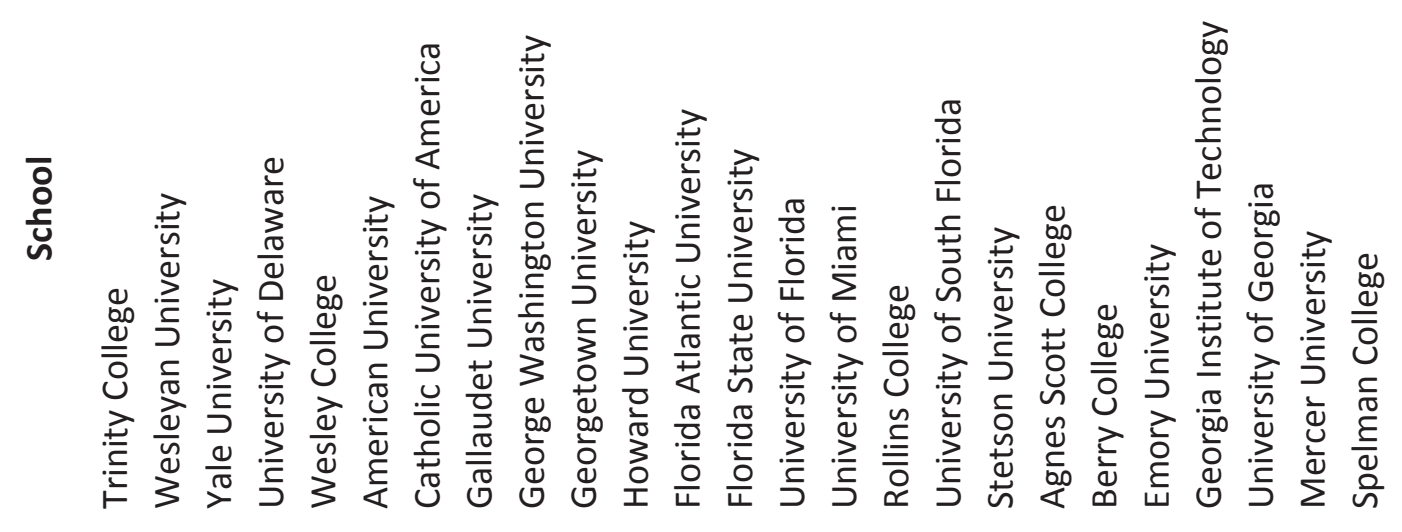

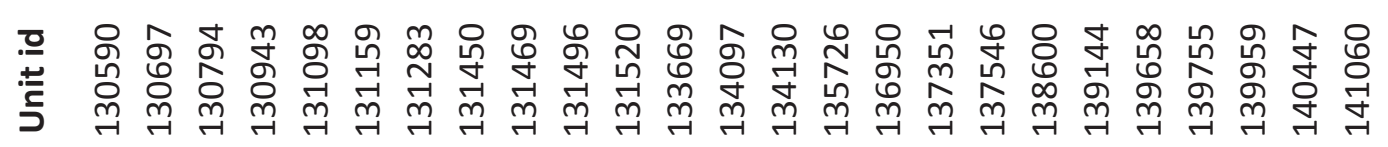




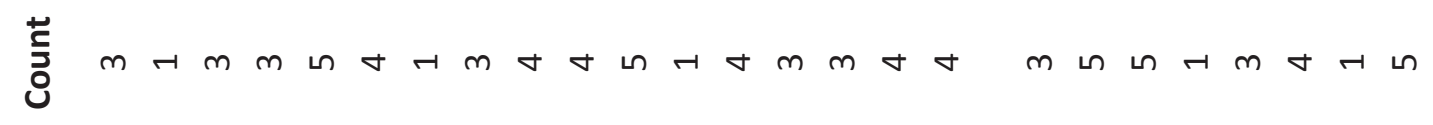

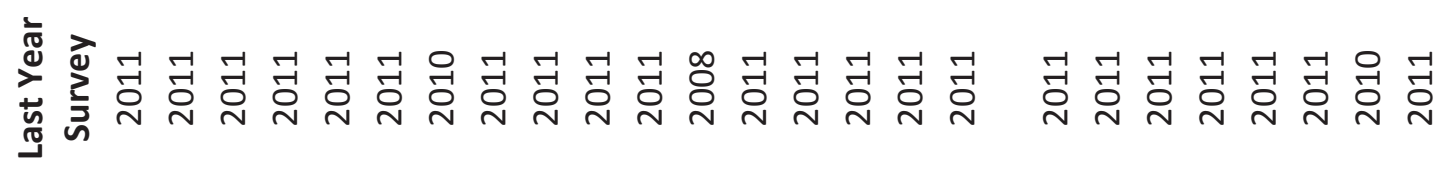

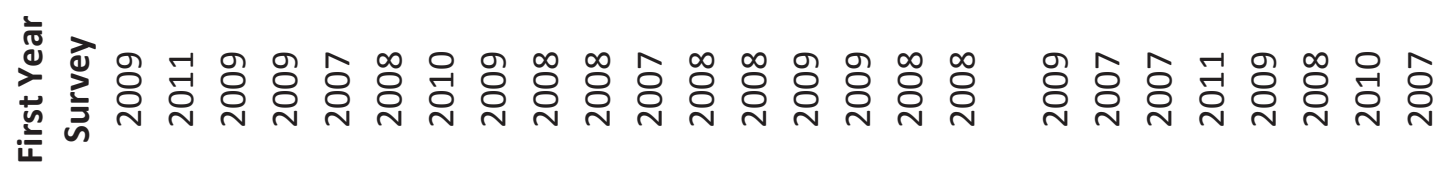

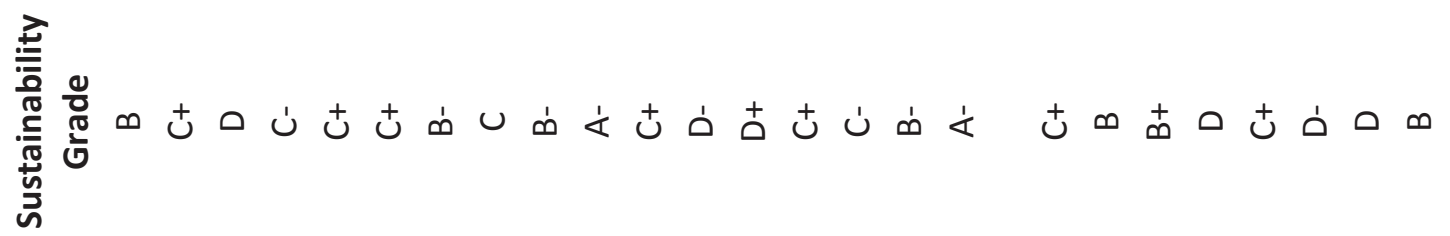

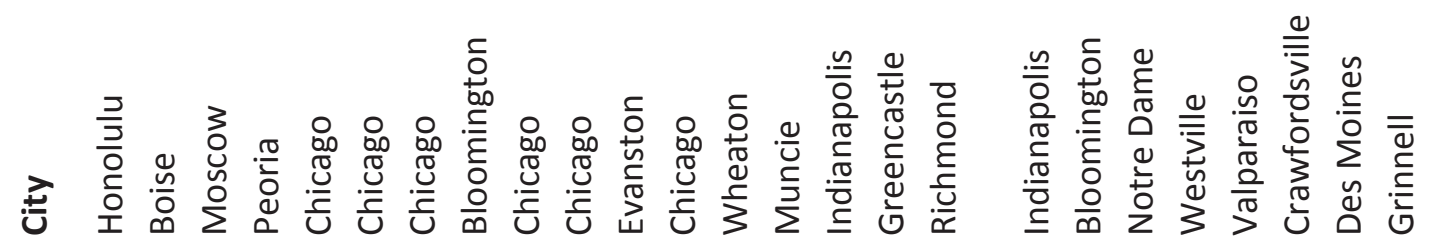

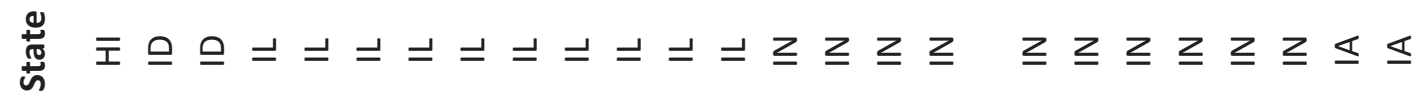

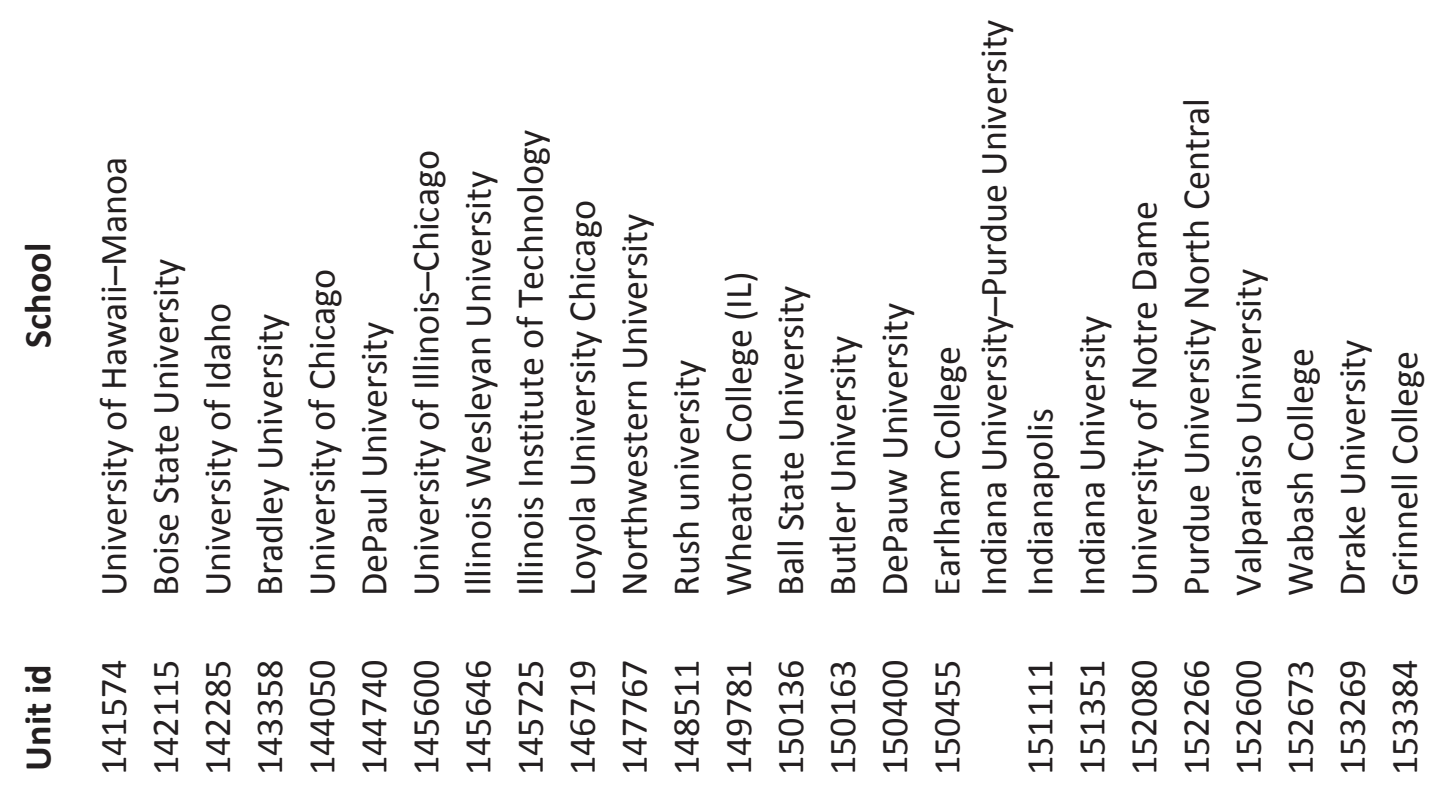




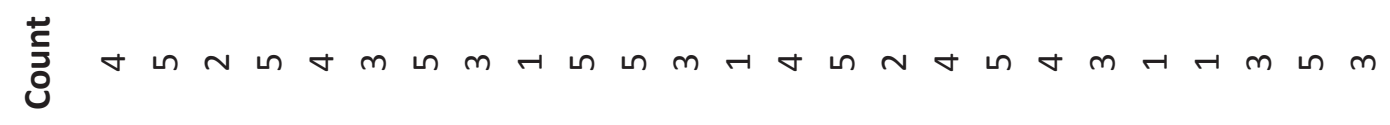

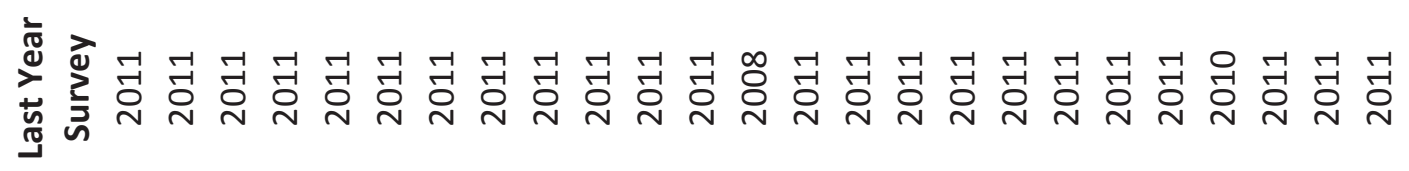

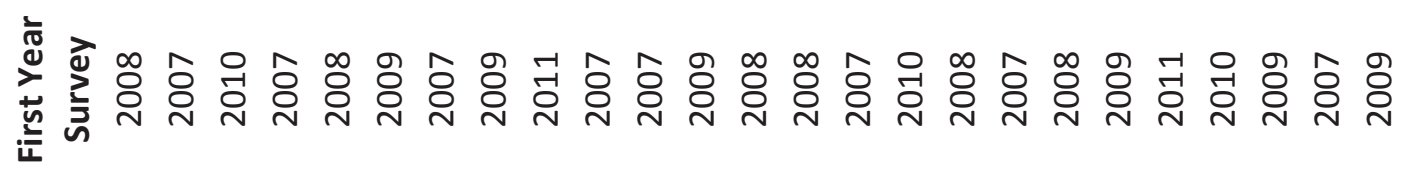
胥

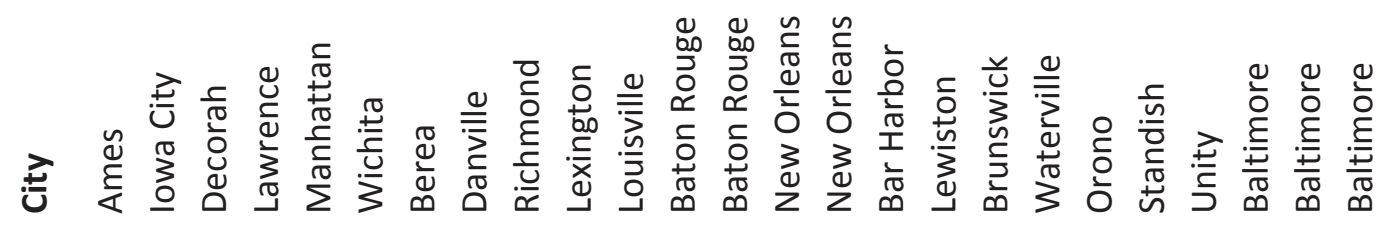

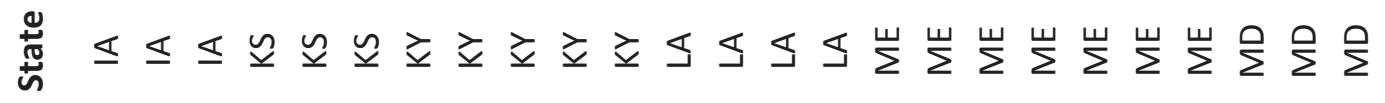

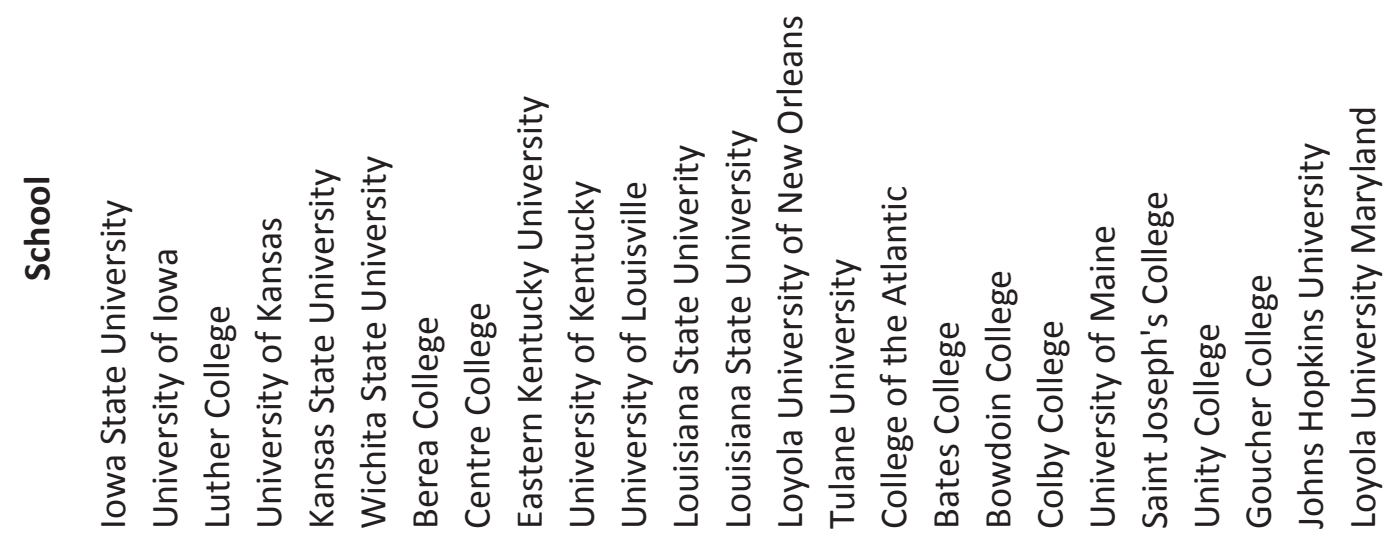

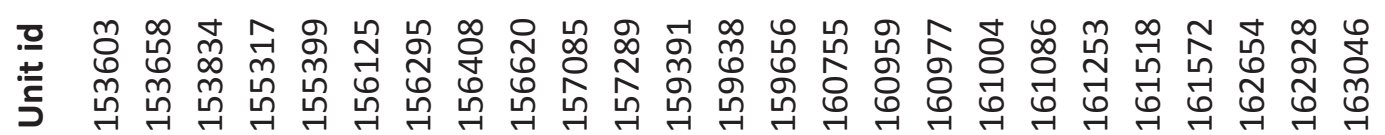




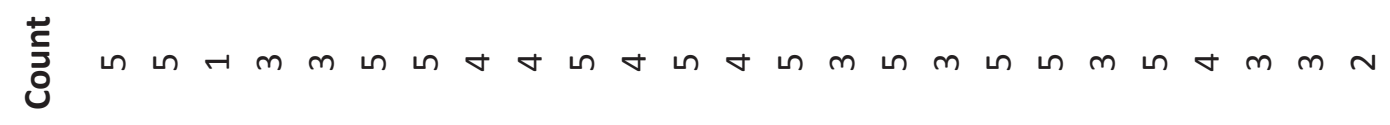

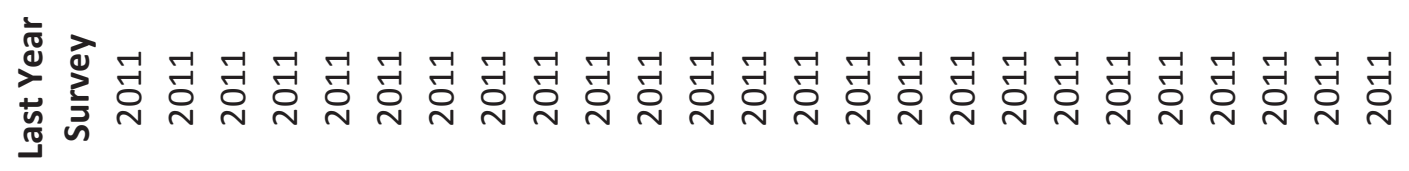

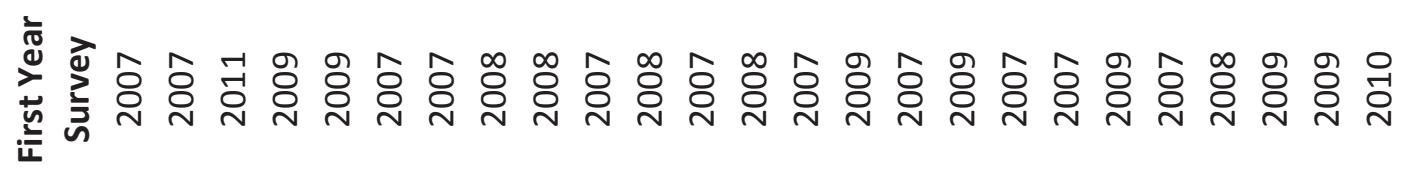

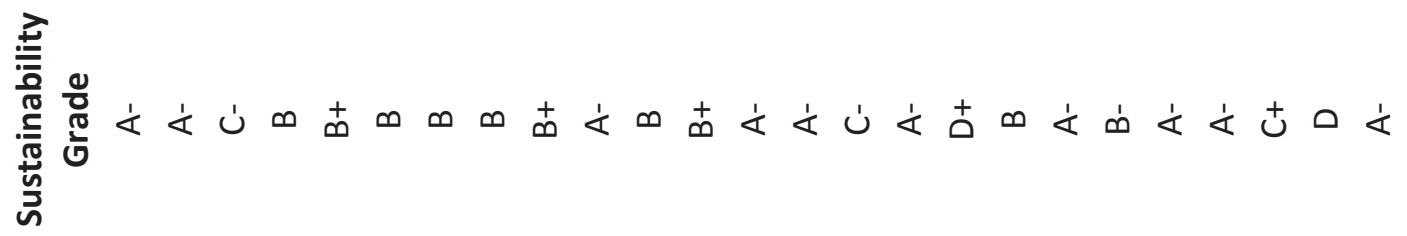

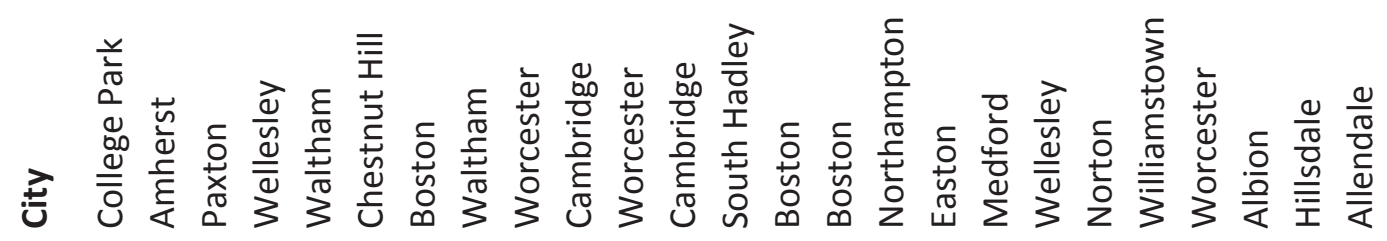

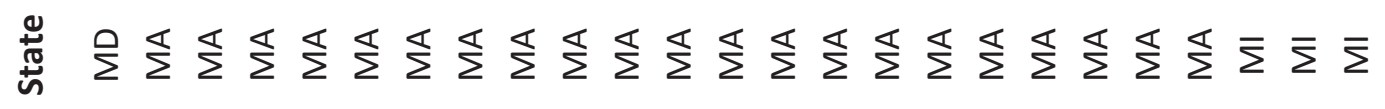

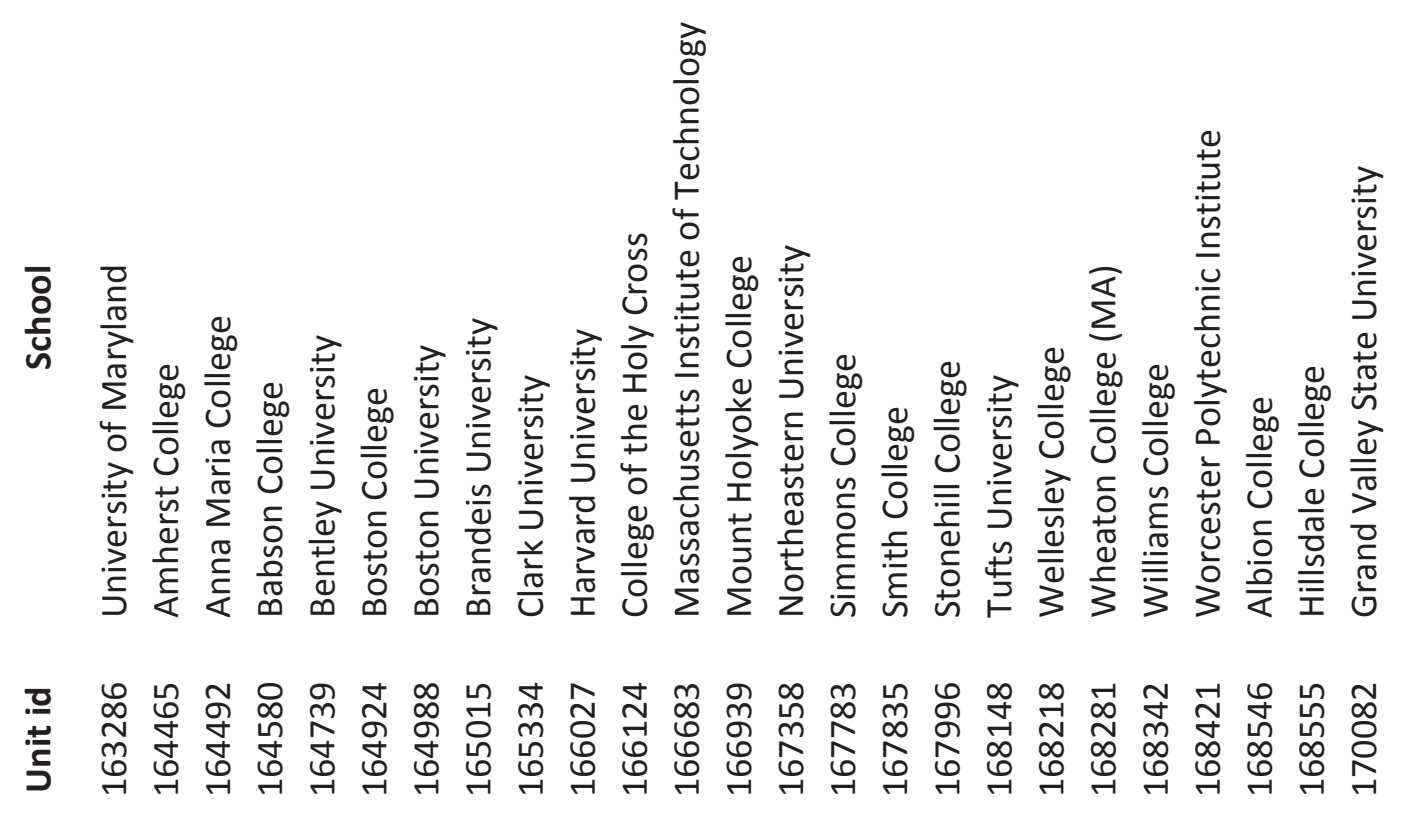




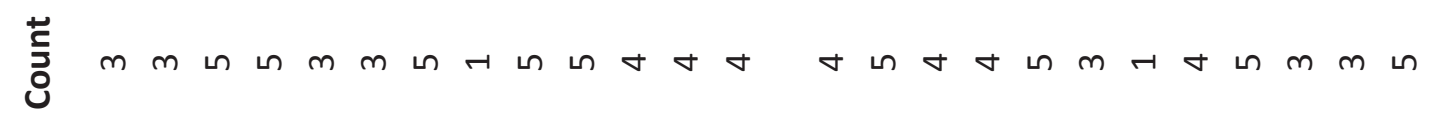

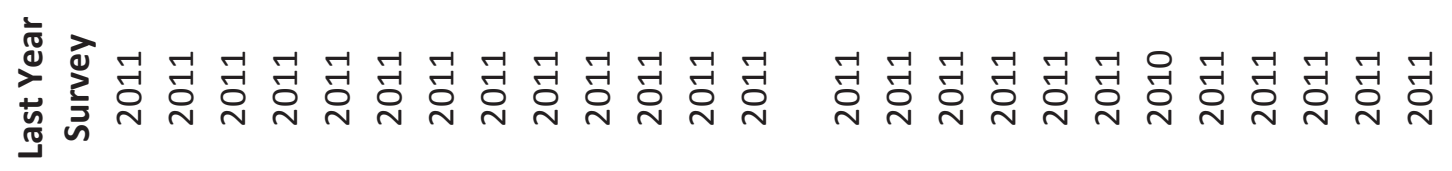

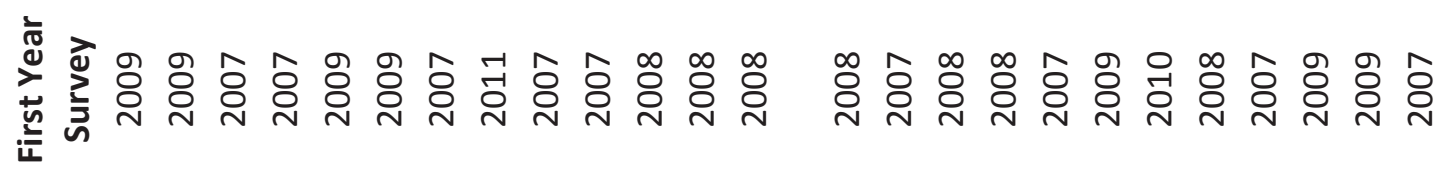

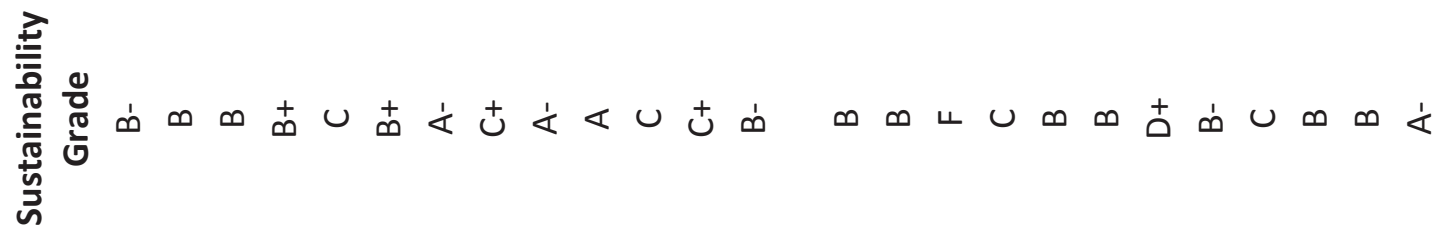

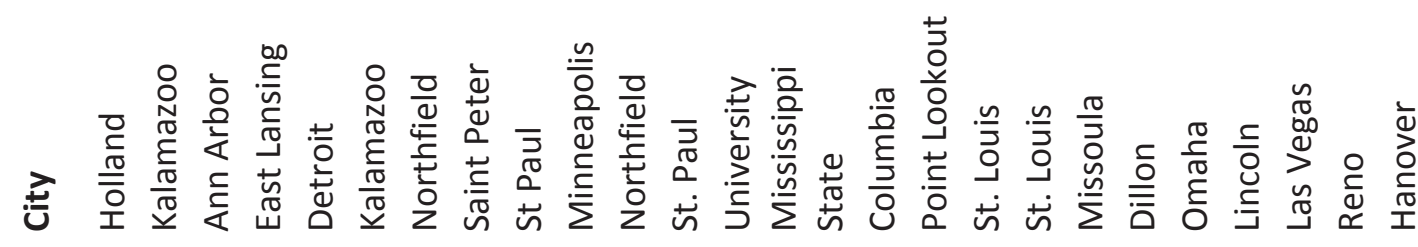

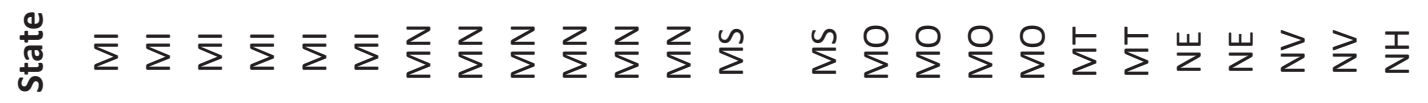

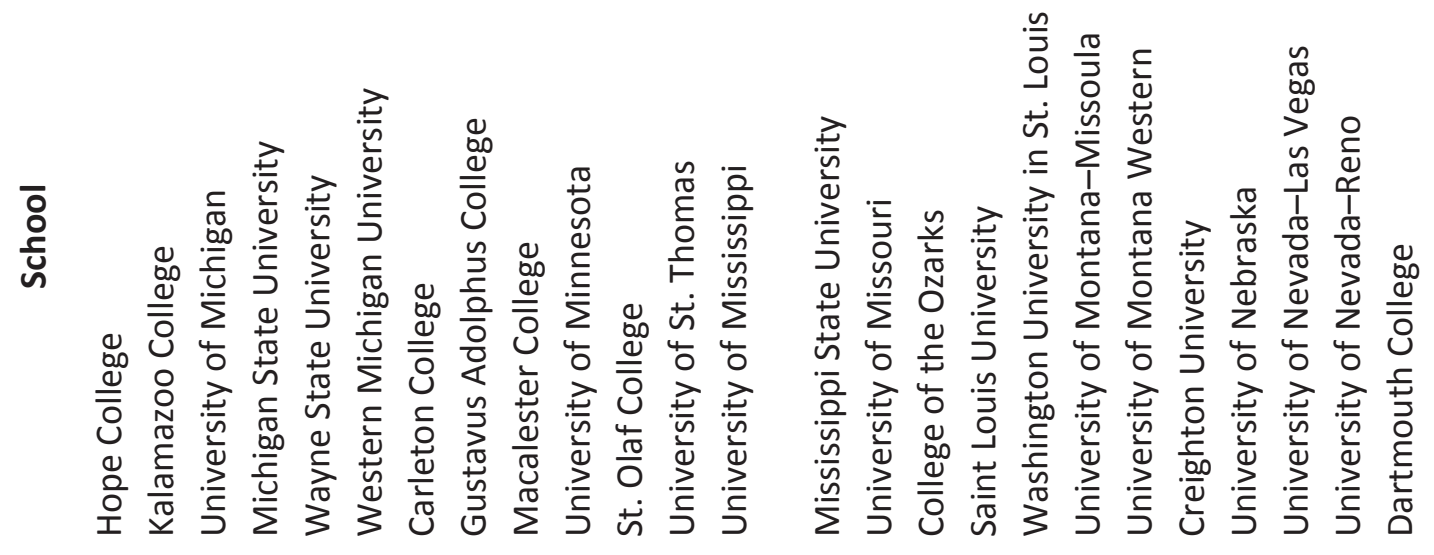

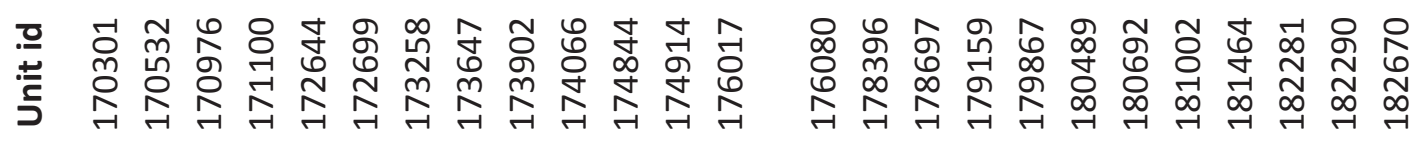




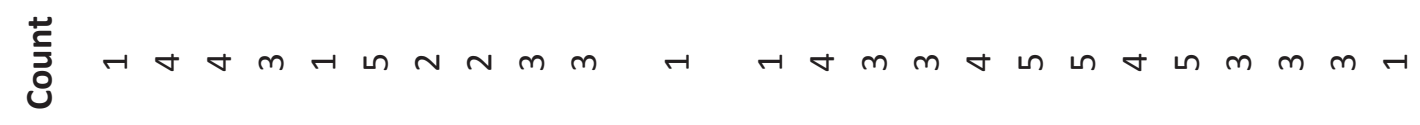

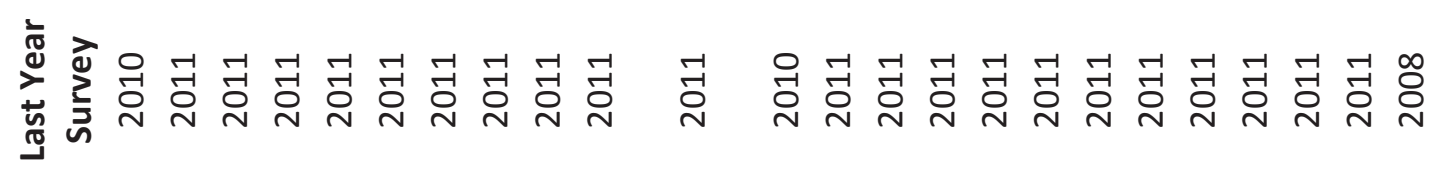

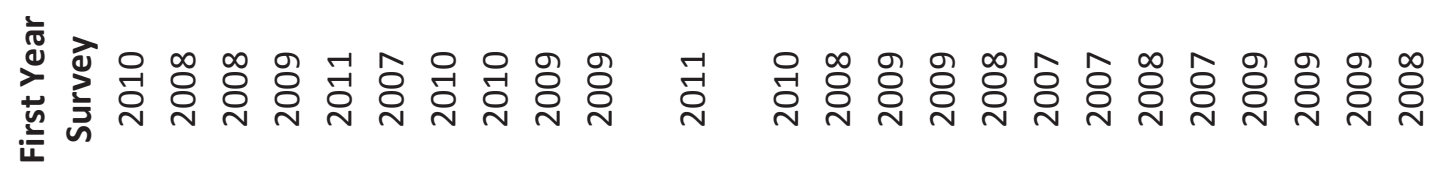

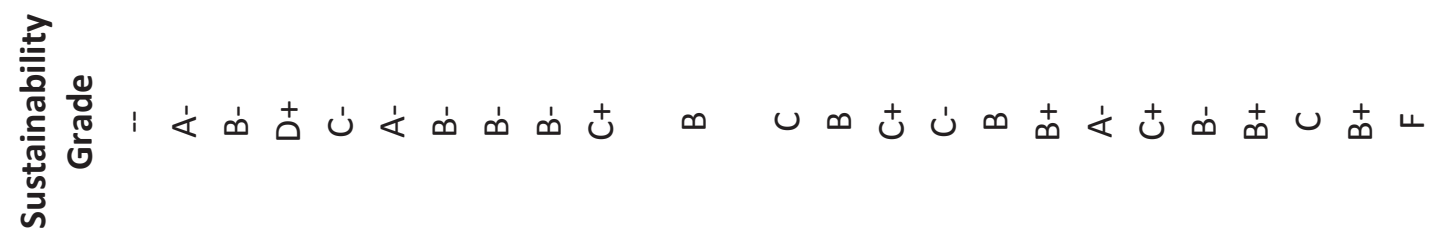

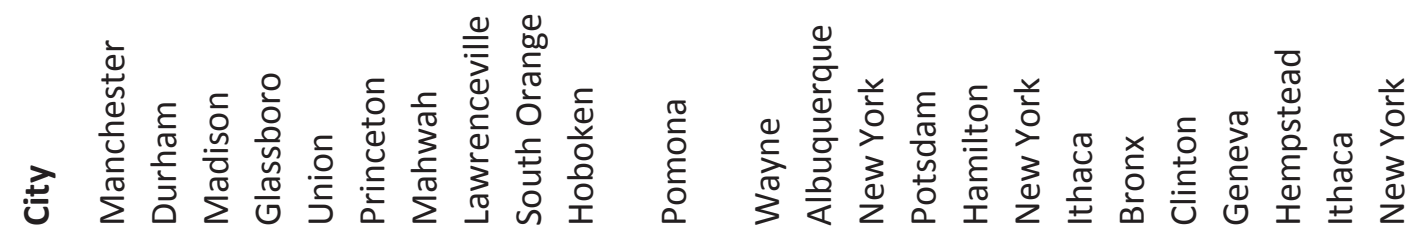

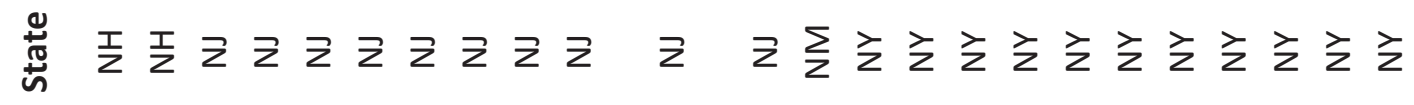
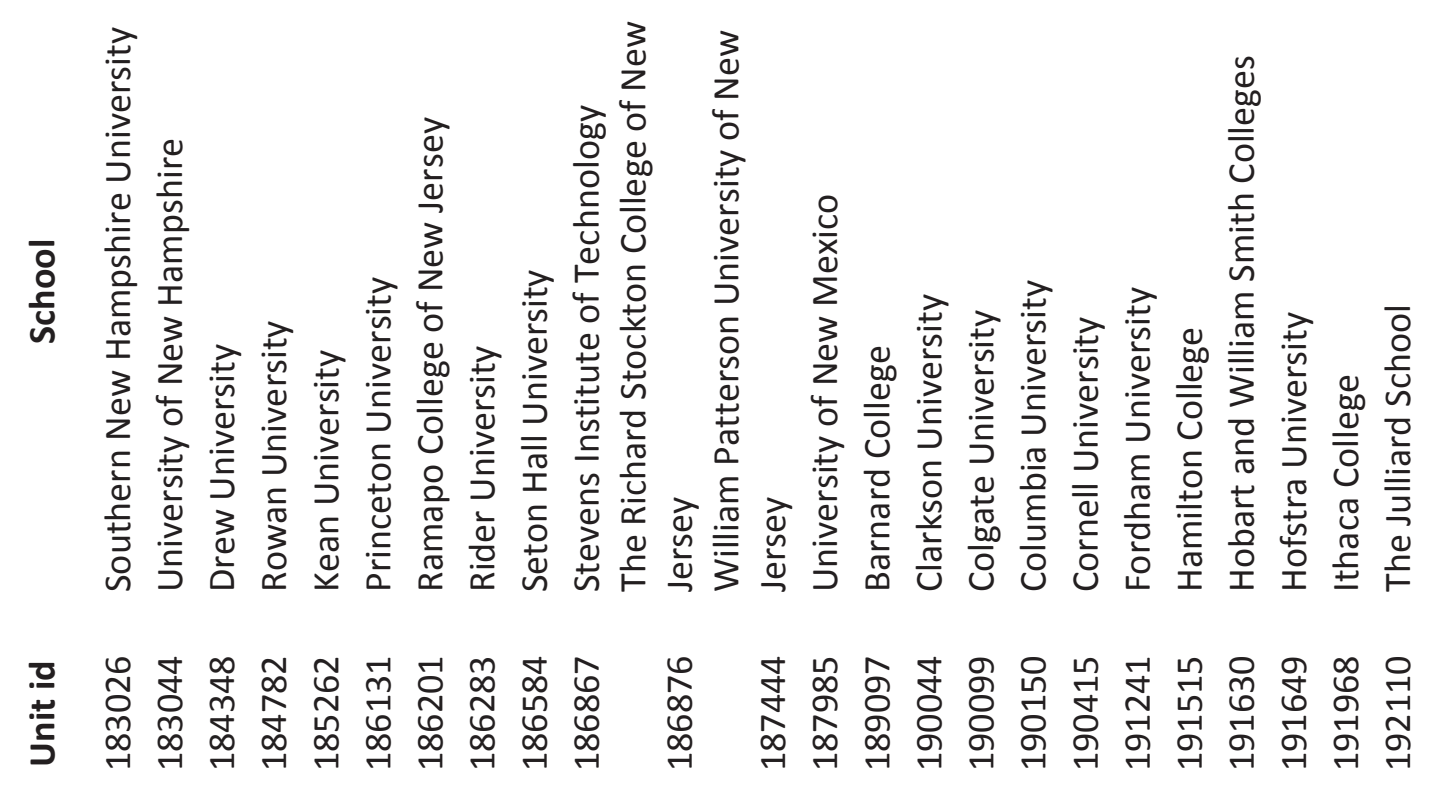


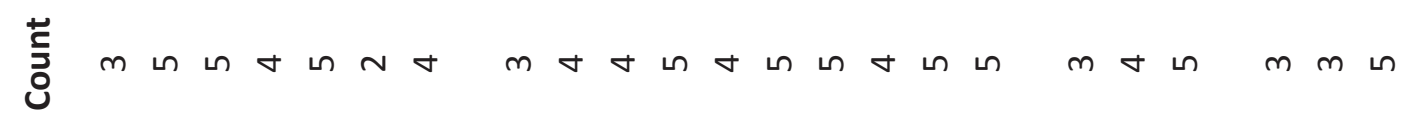

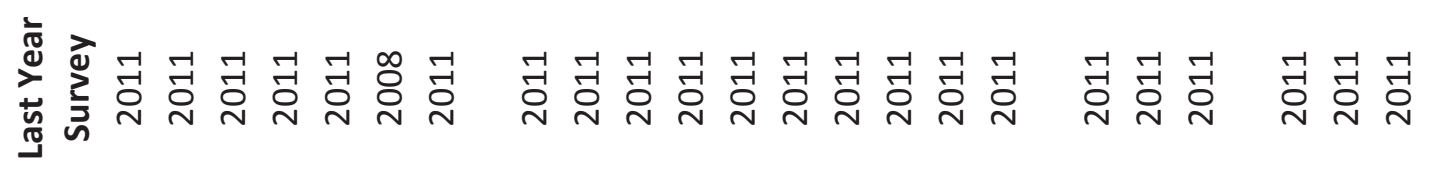

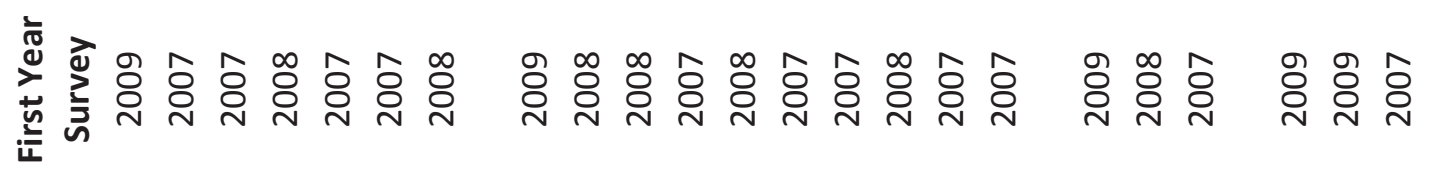

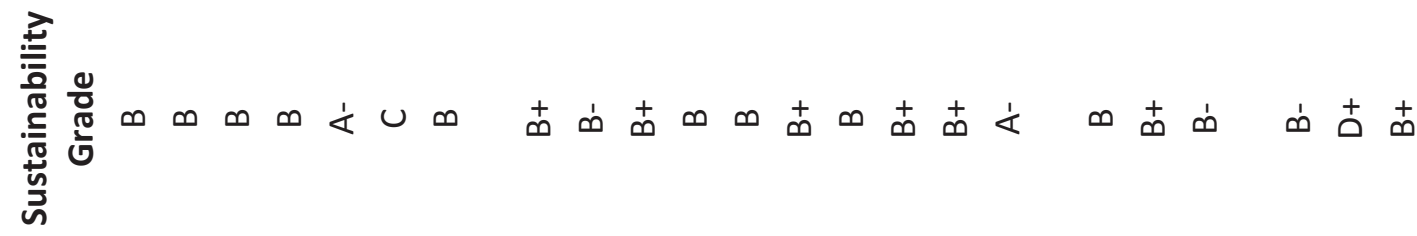

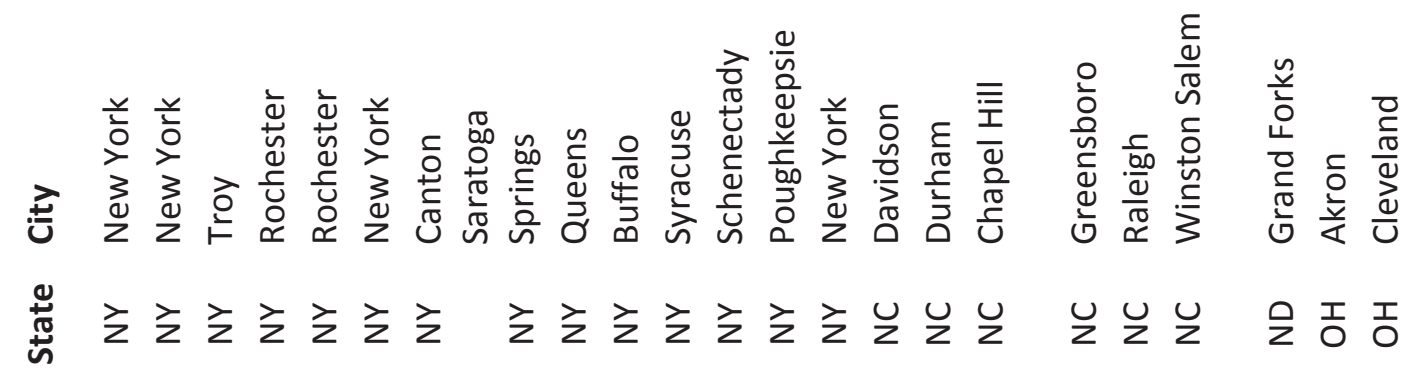

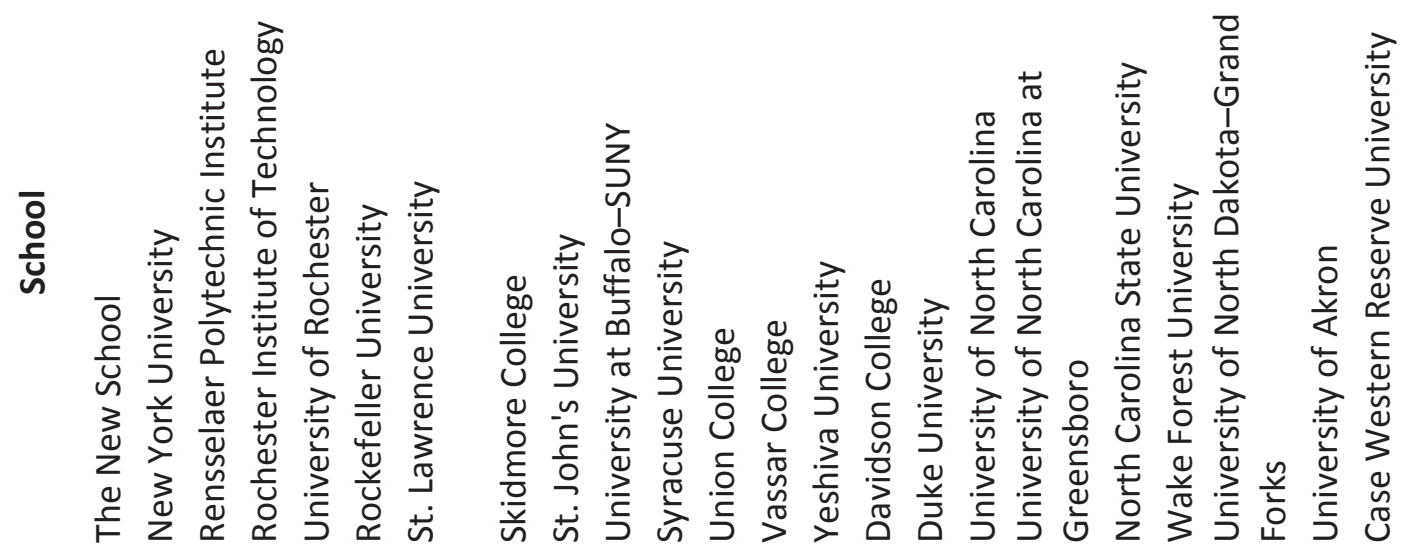

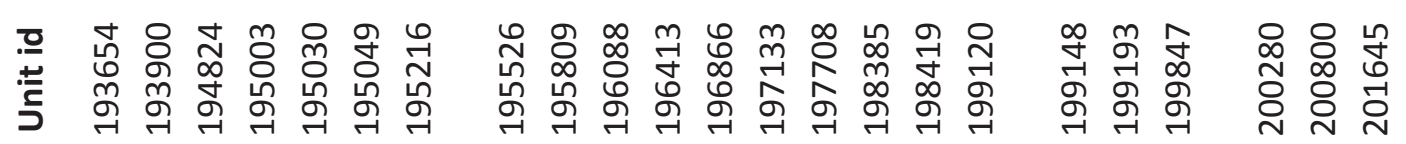




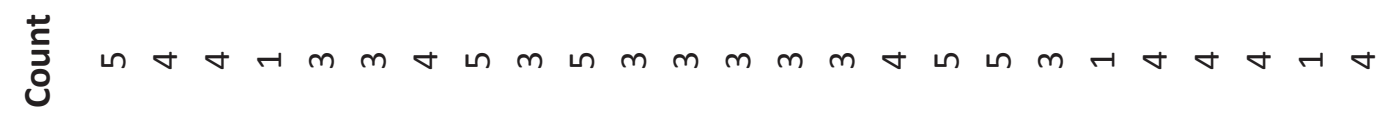

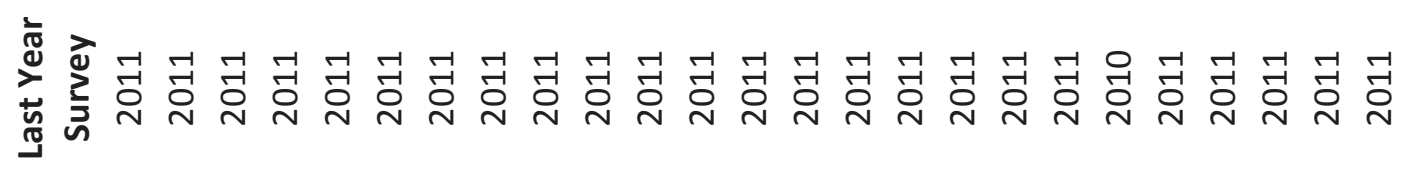

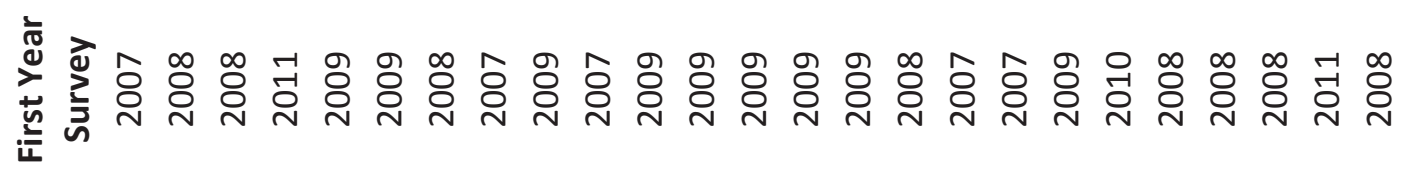

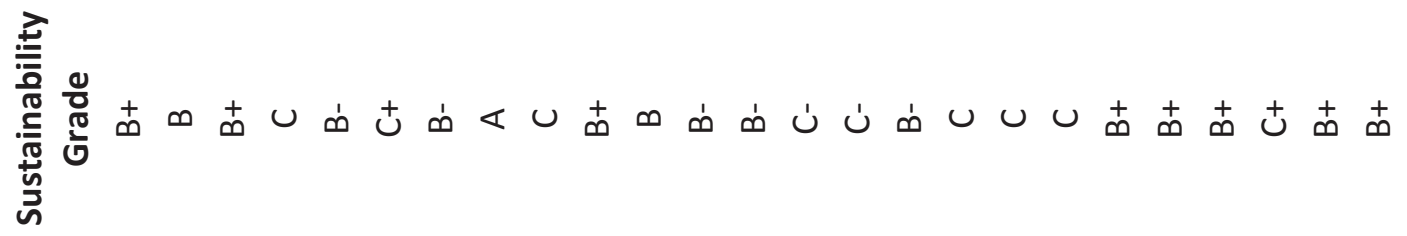

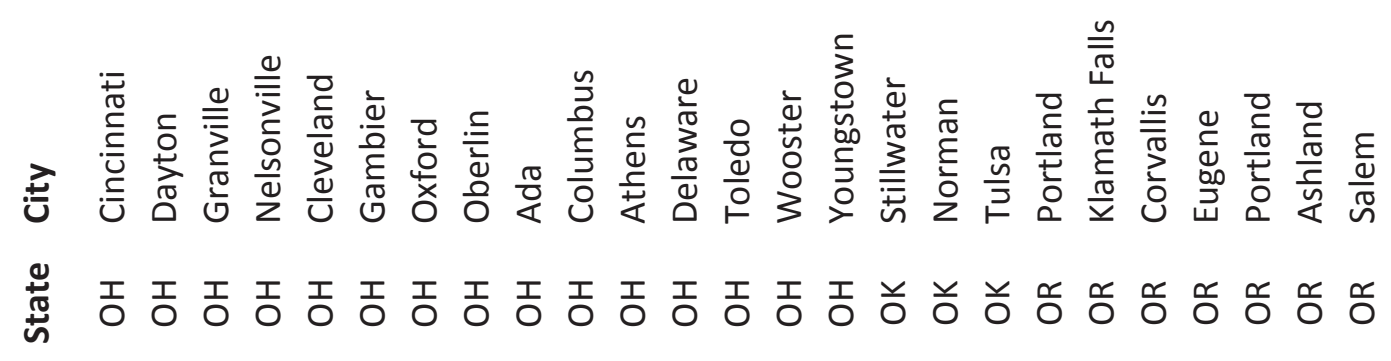

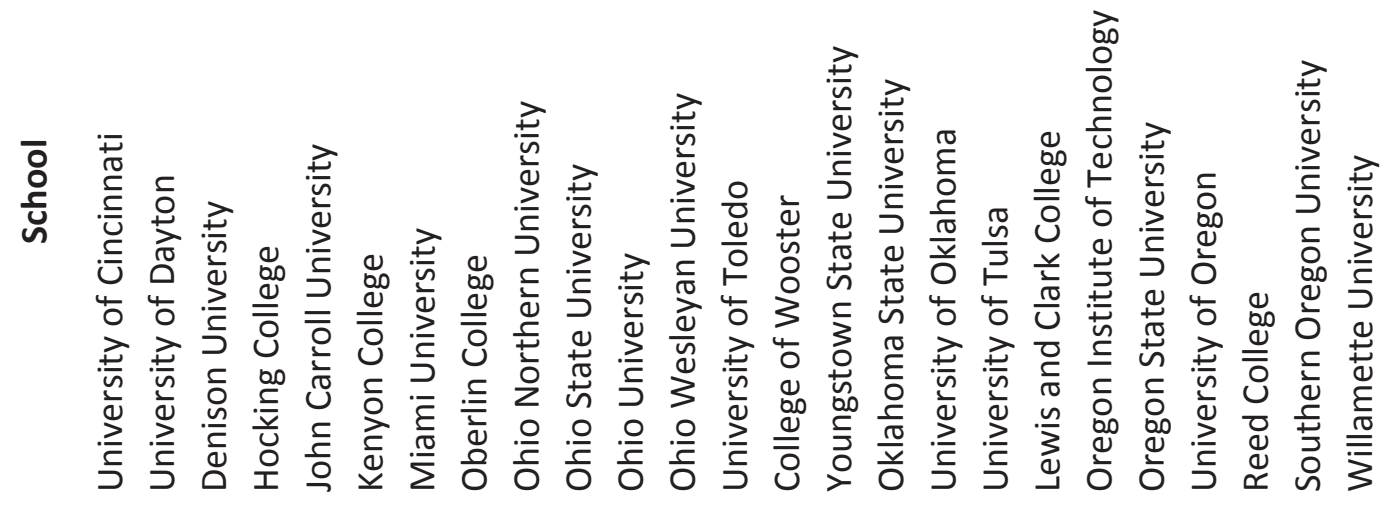

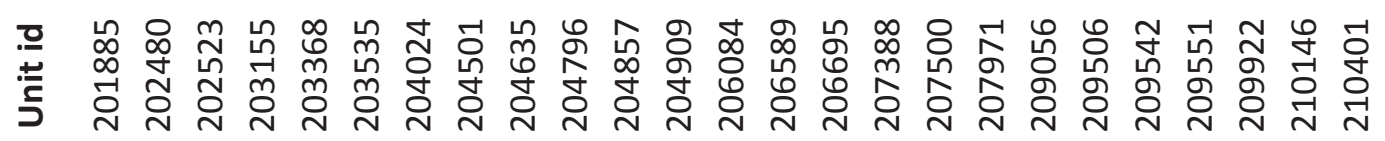


言

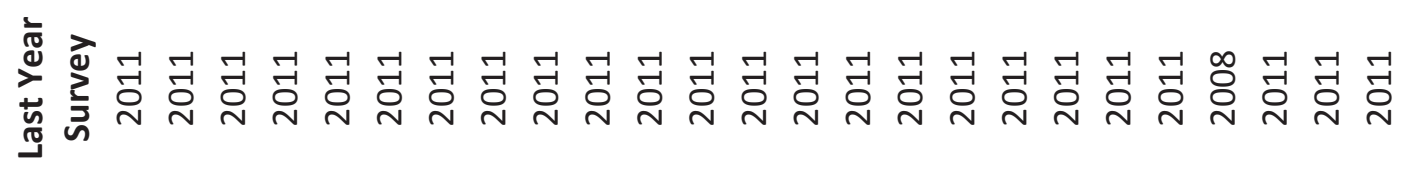

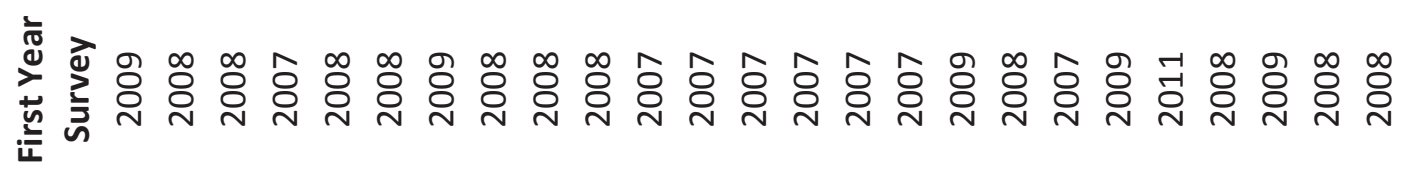

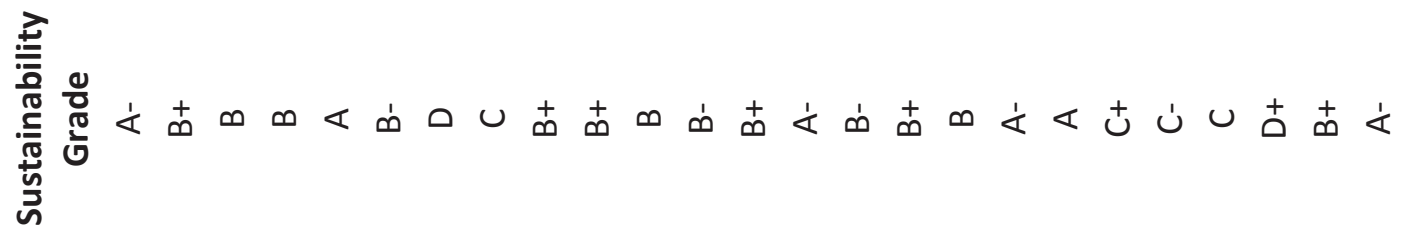

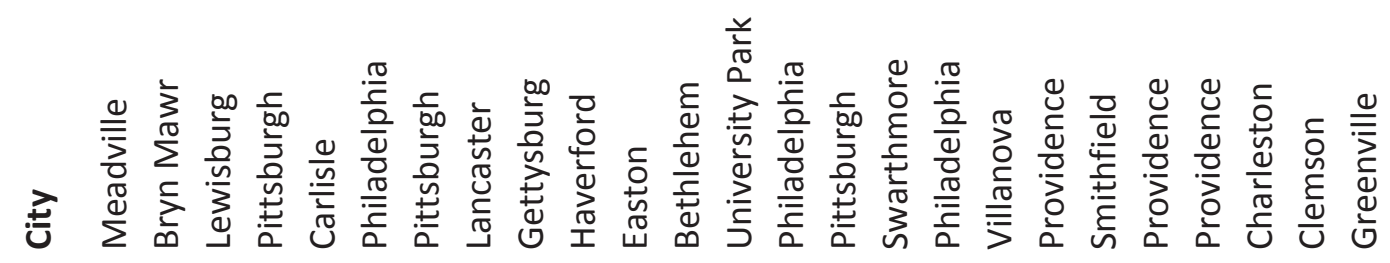

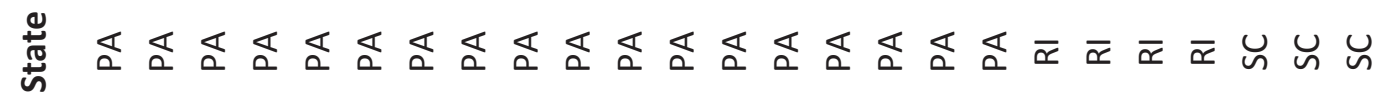

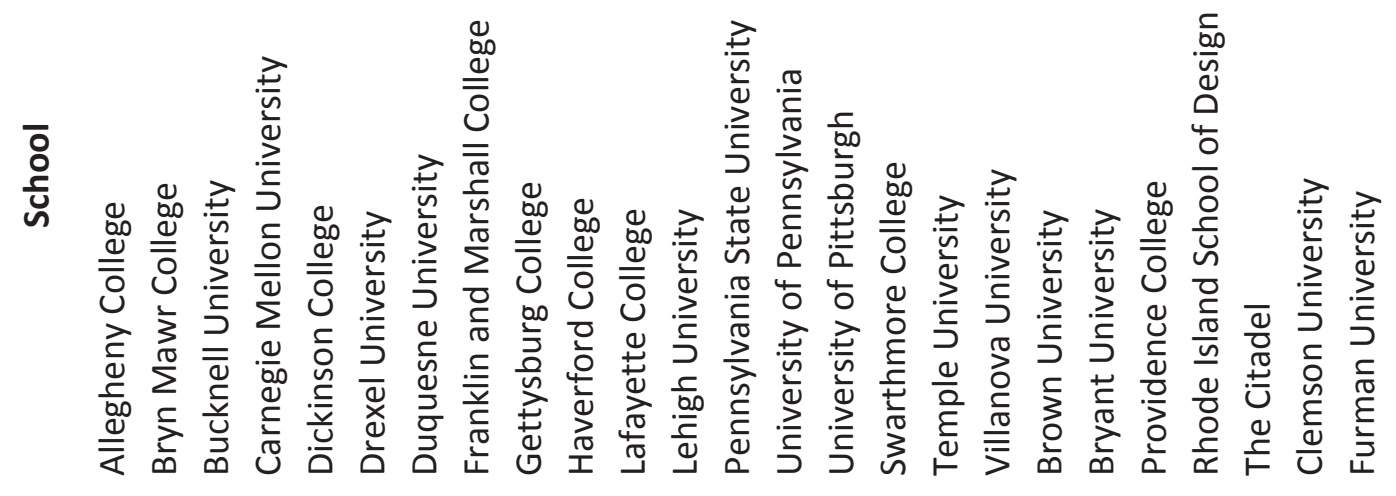

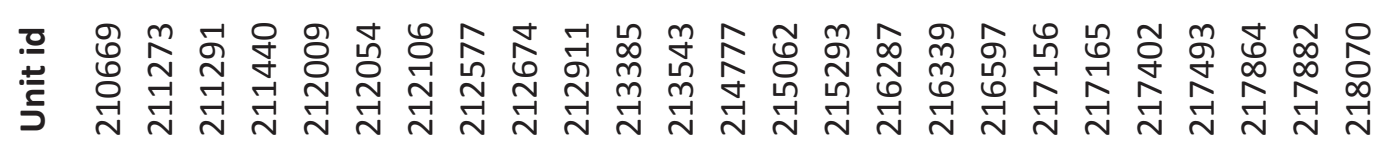




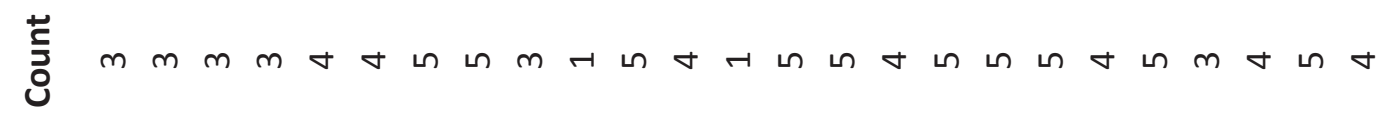

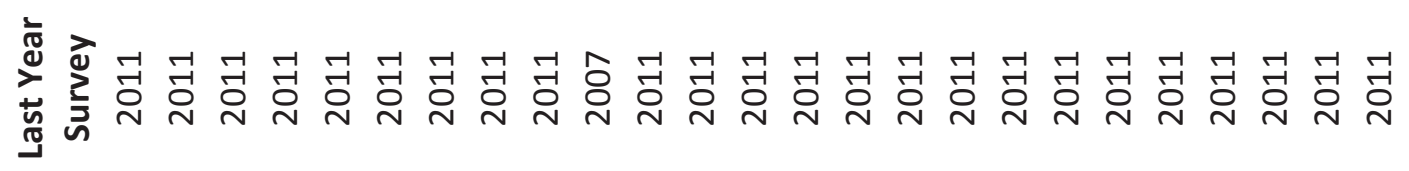

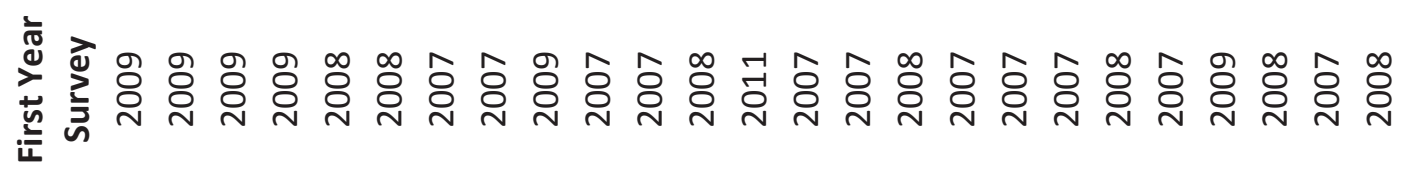

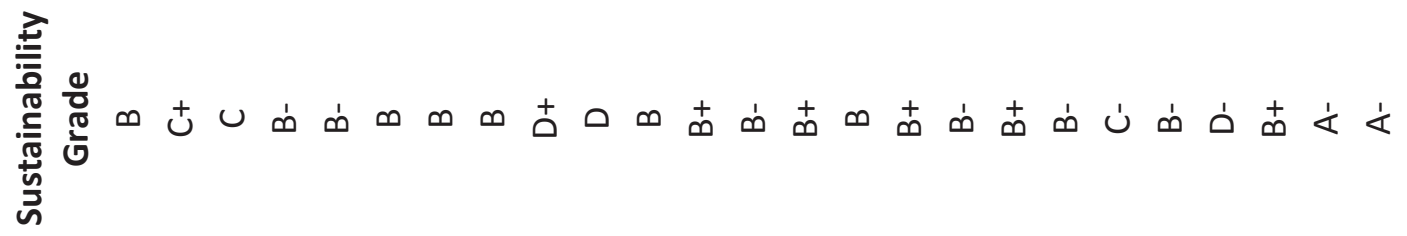

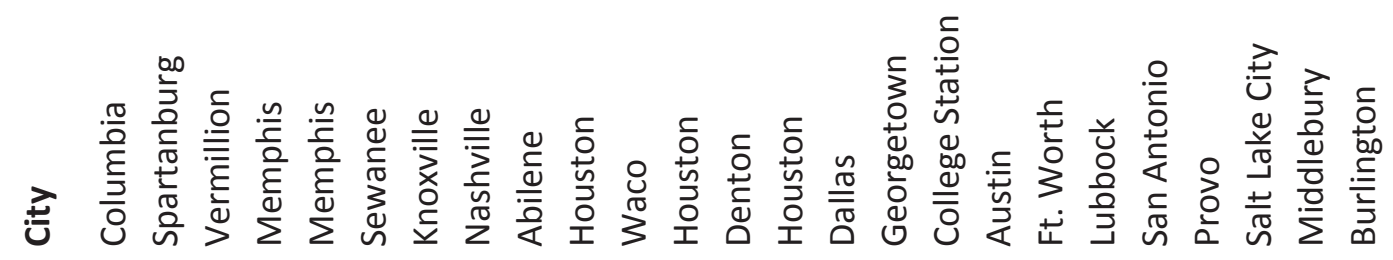
营 $u$ 心

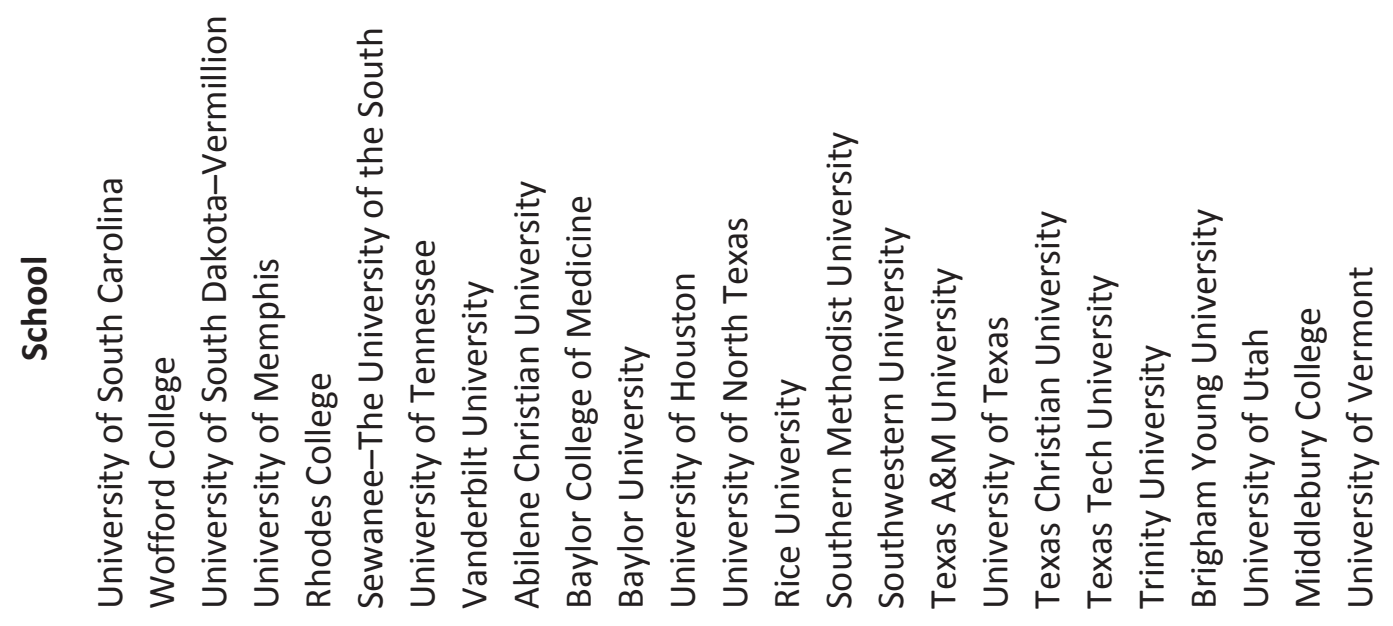

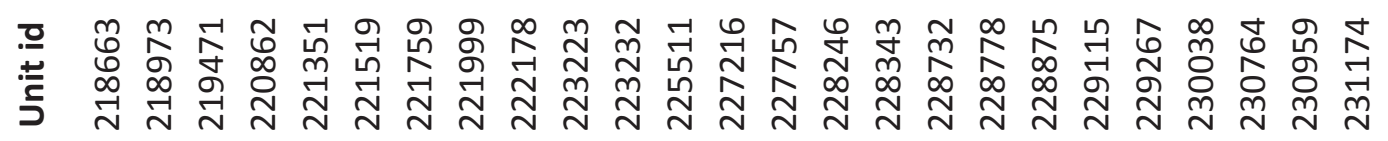




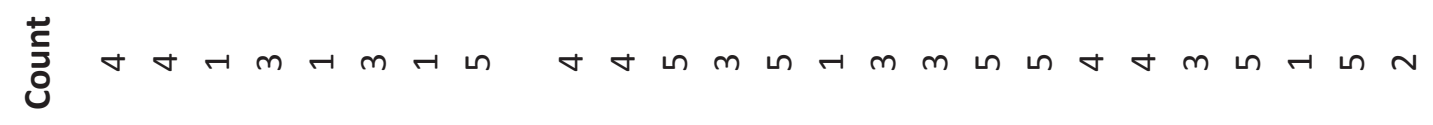

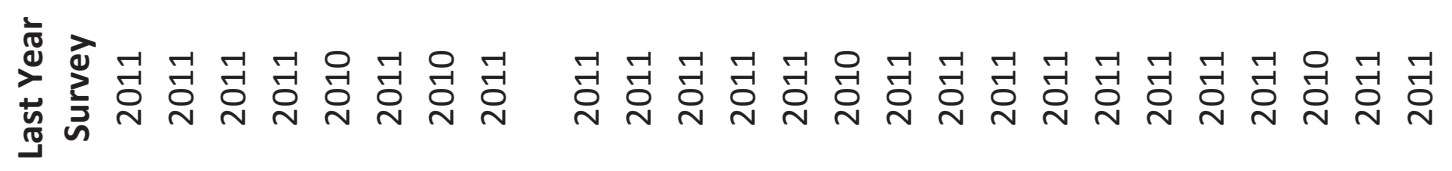

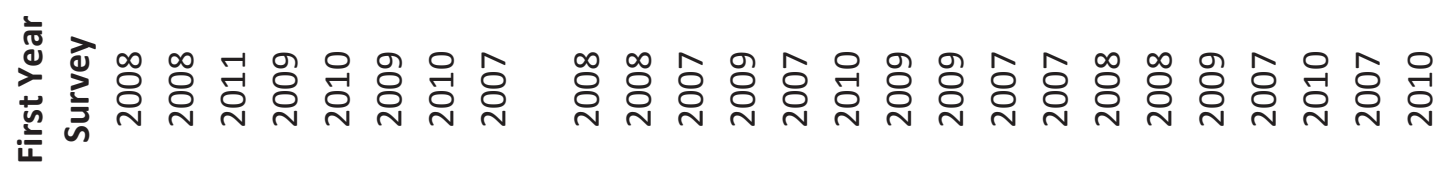

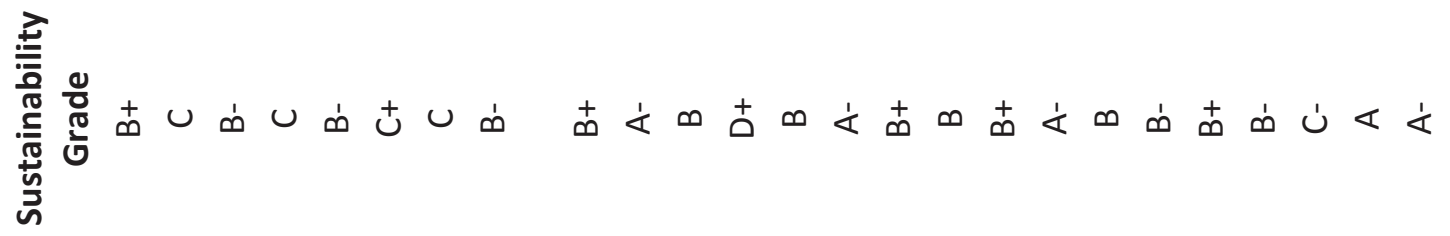

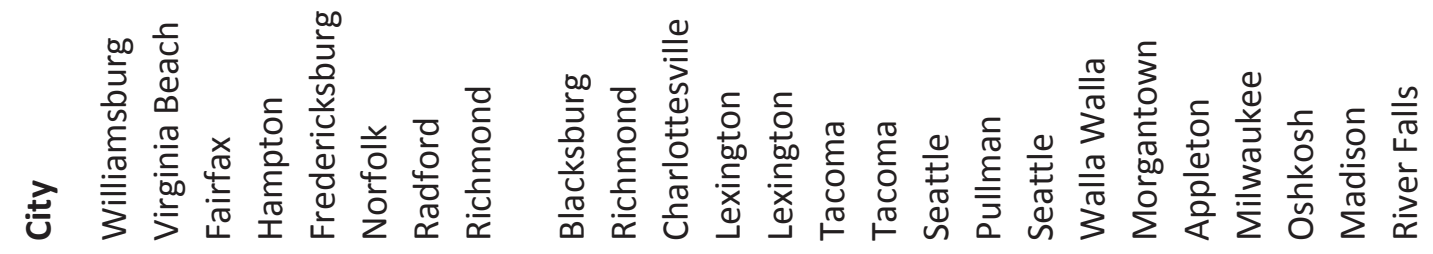
兽

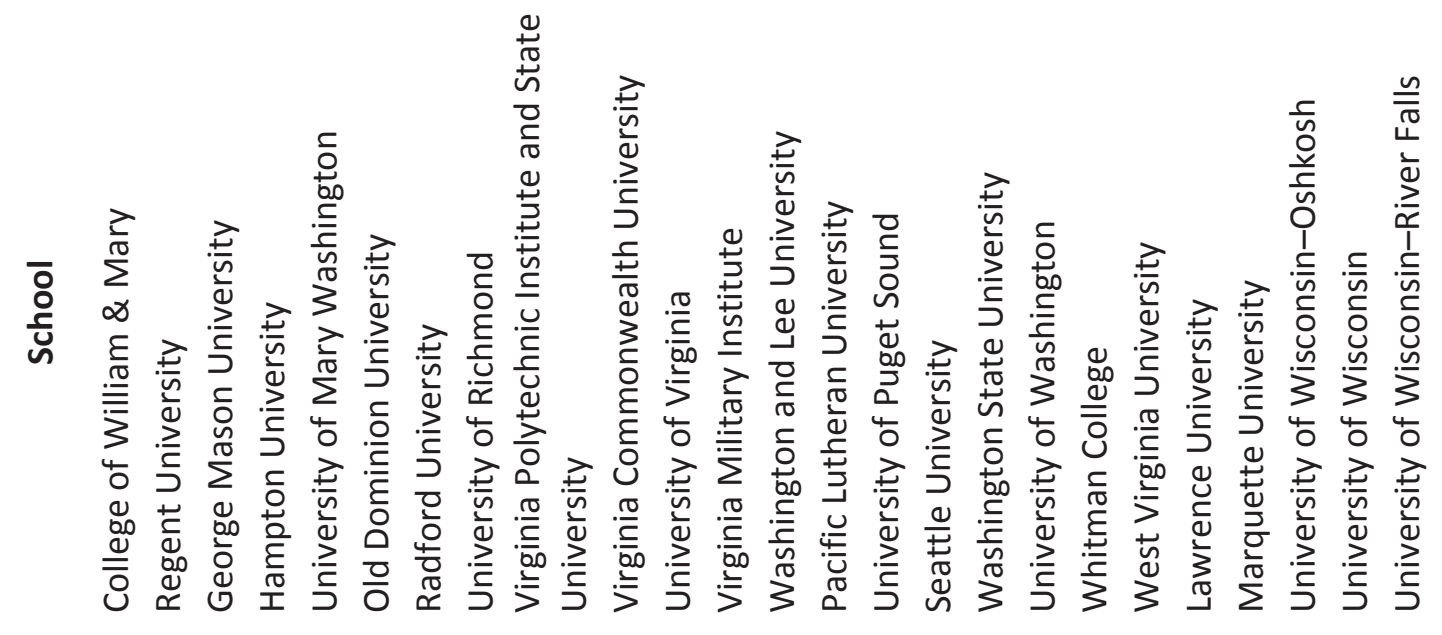

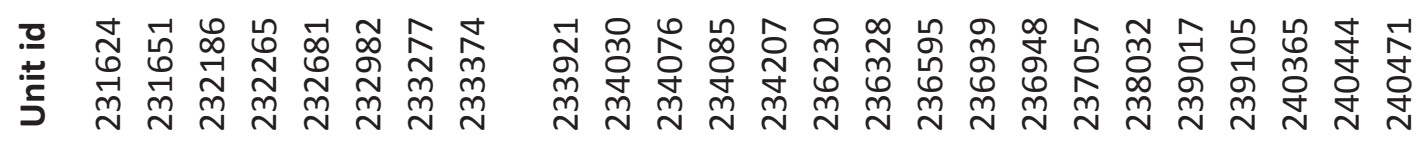



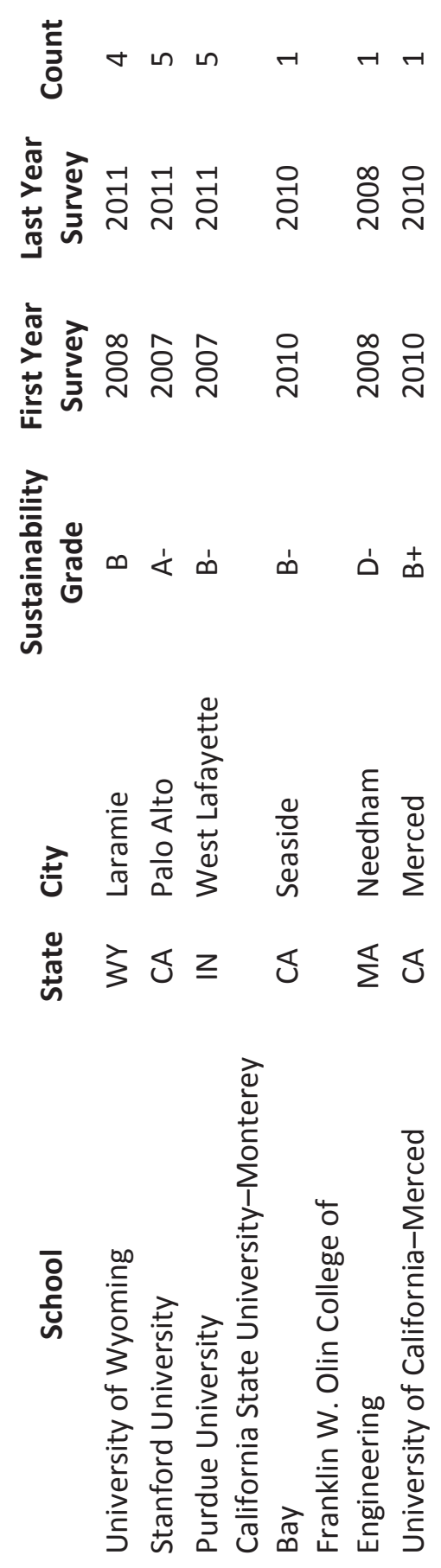

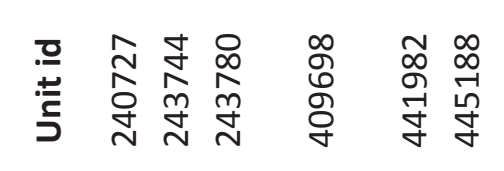




\section{Appendix 3-Testing Equality Constraints in the Model}

In this section we want to test whether "Education and related expenses" has the same effect on the sustainability grade as "Total revenue of institution" or not. The "Sustainability grades" is regressed on "Education and related expenses" and "Total revenue of institution" yielding the following result:

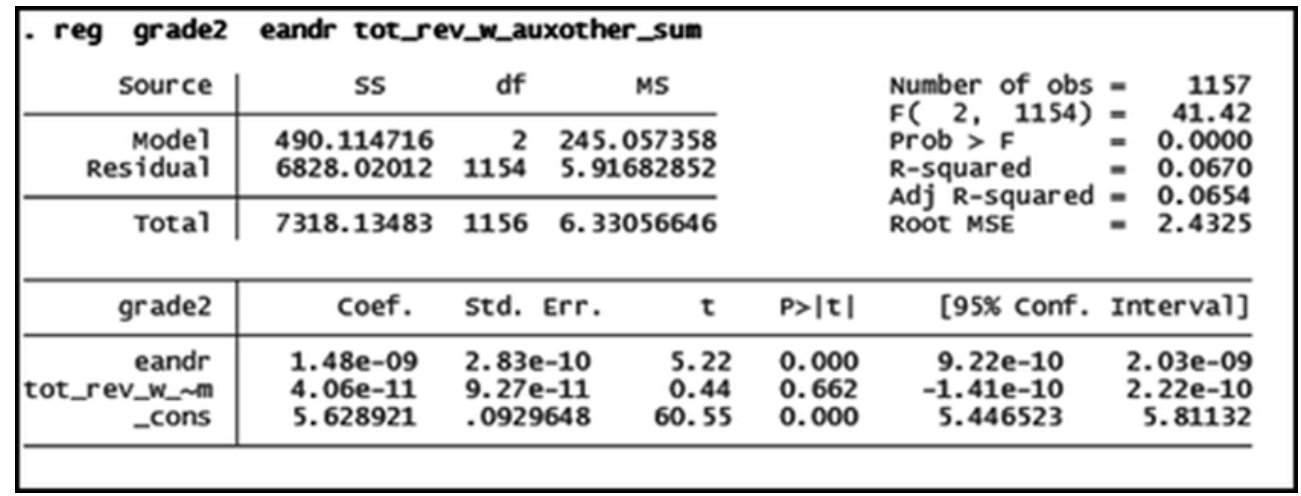

Figure A-1- Snapshot of testing equality constraint in a regression through Stata

To check for equality of parameters within the model the test is:

$\mathrm{H} 0: \beta 1=\beta 2$

$\mathrm{HA}: \beta 1 \neq \beta 2$

To make sure that these two variables do not have the same effect on the dependent variable, it is possible to reject the null hypothesis which is $\mathrm{H} 0$ : $\beta 1=\beta 2$. $[25]$ 
In this case Stata approach is using "test" command which is relatively simple and easy. The following window shows the result of "test" command in Stata. In order to reject the null hypothesis the "F statistic" should be highly significant and "Prob> F" should be quietly low. As shown in the figure below, the Stata dropped the constraint. It should be mentioned that the Stata drops constraints when they are nonbinding or contradictory. However, in this case it may represent the same effect of these two variables on the sustainability grades.

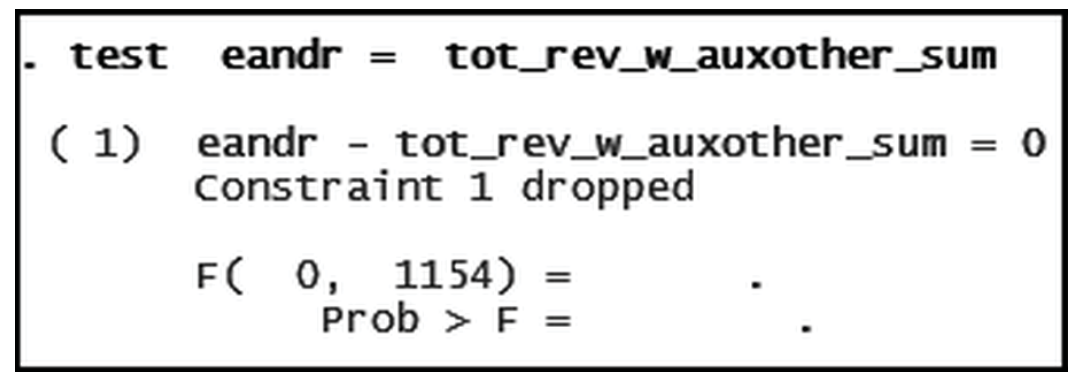

Figure A-2- The result of test command in Stata

Another approach to test whether two variables (X1 and $\mathrm{X} 2$ ) have equal effects on the dependent variable $(\mathrm{Y})$ is using the incremental F-test. For this test all the explanatory variables in the model should be included in the regression. This is called "The unconstrained model" because the effect of two variables (X1 and X2) is not constraint to be equal. [25] Thus, the "Sustainability grades" is regressed on all the explanatory variables in the Stata to estimate the unconstrained model. The following figure shows the results of unconstrained model extracted from Stata. By looking at the t-ratios for "Education and related expenses" and "Total revenue of institution" shows that neither of them is individually statistically different from "0". 


\begin{tabular}{|c|c|c|c|c|c|c|}
\hline source & SS & df & MS & & \multirow{3}{*}{$\begin{array}{l}\text { Number of obs } \\
\text { F( } 11,1032) \\
\text { Prob > F } \\
\text { R-squared } \\
\text { Adj R-squared } \\
\text { Root MSE }\end{array}$} & \multirow{3}{*}{$\begin{array}{l}=\quad 1044 \\
=23.46 \\
=0.0000 \\
=0.2000 \\
=0.1915 \\
=2.2106\end{array}$} \\
\hline $\begin{array}{r}\text { Model } \\
\text { Residual }\end{array}$ & $\begin{array}{l}1260.80615 \\
5042.98695\end{array}$ & $\begin{array}{rr}11 & 114 \\
1032 & 4.8\end{array}$ & $\begin{array}{l}18741 \\
61526\end{array}$ & & & \\
\hline Total & 6303.7931 & 10436.0 & 90518 & & & \\
\hline grade2 & coef. & std. Err. & $t$ & $P>|t|$ & [95\% conf. & Interval] \\
\hline $\begin{array}{r}\text { eandr } \\
\text { tot_rev_w_we } \\
\text { bach_deg_s } q 9 \\
\text { endowment } \\
\text { fed_grant_wt } \\
\text { obama08_shne } \\
\text { research_r } \sim t \\
\text { nettuition01 } \\
\text { count } \\
\text { select } \\
\text { internations } \\
\text { _cons }\end{array}$ & $\begin{array}{r}-2.77 \mathrm{e}-10 \\
-1.05 \mathrm{e}-10 \\
3.457403 \\
.0000685 \\
.0001577 \\
2.001243 \\
2.28 \mathrm{e}-09 \\
2.24 \mathrm{e}-09 \\
.2079346 \\
.4493002 \\
.0801442 \\
-.4384161\end{array}$ & $\begin{array}{r}4.71 \mathrm{e}-10 \\
9.08 \mathrm{e}-11 \\
.424093 \\
.0000318 \\
.0000397 \\
.7645459 \\
5.02 \mathrm{e}-10 \\
7.47 \mathrm{e}-10 \\
.0856446 \\
.2276424 \\
.0165141 \\
.6435421\end{array}$ & $\begin{array}{r}-0.59 \\
-1.16 \\
8.15 \\
2.15 \\
3.97 \\
2.62 \\
4.54 \\
3.00 \\
2.43 \\
1.97 \\
4.85 \\
-0.68\end{array}$ & $\begin{array}{l}0.557 \\
0.247 \\
0.000 \\
0.032 \\
0.000 \\
0.009 \\
0.000 \\
0.003 \\
0.015 \\
0.049 \\
0.000 \\
0.496\end{array}$ & $\begin{array}{r}-1.20 \mathrm{e}-09 \\
-2.83 \mathrm{e}-10 \\
2.62522 \\
6.02 \mathrm{e}-06 \\
.0000797 \\
.5010014 \\
1.29 \mathrm{e}-09 \\
7.78 \mathrm{e}-10 \\
.0398772 \\
.0026055 \\
.0477392 \\
-1.701216\end{array}$ & $\begin{array}{r}6.48 \mathrm{e}-10 \\
7.31 \mathrm{e}-11 \\
4.289586 \\
.0001309 \\
.0002356 \\
.3 .501485 \\
3.26 \mathrm{e}-09 \\
3.71 \mathrm{e}-09 \\
.375992 \\
.8959949 \\
.1125493 \\
.8243842\end{array}$ \\
\hline
\end{tabular}

Figure A-3- Unconstrained model extracted from Stata

In the next step the constrained model which includes a new variable will be executed in Stata. The new variable is the sum of two none-statistically significant variables including: "Education and related expenses" and "Total revenue of institution". Command below is used through the Stata:

Command: "gen Eandrtotrev $=$ eandr + tot_rev_w_auxother_sum"

The following figure shows the result of constrained model. 


\begin{tabular}{|c|c|c|c|c|c|c|}
\hline Source & SS & df & MS & & \multirow{3}{*}{$\begin{array}{l}\text { Number of obs } \\
\text { F( } 10,1033) \\
\text { Prob }>F \\
\text { R-squared } \\
\text { Adj R-squared } \\
\text { Root MSE }\end{array}$} & \multirow{3}{*}{$\begin{array}{l}=1044 \\
=\quad 25.81 \\
=0.0000 \\
=0.1999 \\
=0.1922 \\
=2.2096\end{array}$} \\
\hline $\begin{array}{r}\text { Model } \\
\text { Residual }\end{array}$ & $\begin{array}{l}1260.2194 \\
5043.5737\end{array}$ & $\begin{array}{rr}10 & 12 \\
1033 & 4.8\end{array}$ & $\begin{array}{l}2194 \\
\$ 276\end{array}$ & & & \\
\hline Total & 6303.7931 & 10436.0 & 90518 & & & \\
\hline grade2 & coef. & std. Err. & $\tau$ & $P>|\tau|$ & [95\% conf. & Interval] \\
\hline $\begin{array}{r}\text { eandrtotrev } \\
\text { bach_deg_s g } \\
\text { endowment } \\
\text { fed_grant_ t } \\
\text { obama08_shre } \\
\text { research_r t } \\
\text { nettuitiono1 } \\
\text { count } \\
\text { select } \\
\text { internations } \\
\text { cons }\end{array}$ & $\begin{array}{r}-1.16 \mathrm{e}-10 \\
3.462704 \\
.0000635 \\
.0001583 \\
2.010338 \\
2.21 \mathrm{e}-09 \\
2.09 \mathrm{e}-09 \\
.2092818 \\
.4546971 \\
.0805044 \\
-.4626125\end{array}$ & $\begin{array}{r}8.50 \mathrm{e}-11 \\
.4236364 \\
.0000284 \\
.0000397 \\
.7637698 \\
4.63 \mathrm{e}-10 \\
5.92 \mathrm{e}-10 \\
.0855198 \\
.2270122 \\
.0164743 \\
.63947\end{array}$ & $\begin{array}{r}-1.37 \\
8.17 \\
2.24 \\
3.99 \\
2.63 \\
4.78 \\
3.53 \\
2.45 \\
2.00 \\
4.89 \\
-0.72\end{array}$ & $\begin{array}{l}0.172 \\
0.000 \\
0.025 \\
0.000 \\
0.009 \\
0.000 \\
0.000 \\
0.015 \\
0.045 \\
0.000 \\
0.470\end{array}$ & $\begin{array}{r}-2.83 \mathrm{e}-10 \\
2.631418 \\
7.80 \mathrm{e}-06 \\
.0000805 \\
.511621 \\
1.30 \mathrm{e}-09 \\
9.26 \mathrm{e}-10 \\
.0414694 \\
.0092394 \\
.0481775 \\
-1.717421\end{array}$ & $\begin{array}{r}5.08 \mathrm{e}-11 \\
4.29399 \\
.0001191 \\
.0002362 \\
3.509056 \\
3.12 \mathrm{e}-09 \\
3.25 \mathrm{e}-09 \\
.3770943 \\
.9001547 \\
.1128314 \\
.7921958\end{array}$ \\
\hline
\end{tabular}

Figure A-4- Constrained model extracted from Stata

The figure below shows the result of "ftest" in Stata. This command tests whether the "R-squared" from the unconstrained model significantly vary from the "Rsquared" from the constrained model, or not.

\begin{tabular}{|l|}
\hline ftest unconstrained constrained \\
Assumption: constrained nested in unconstrained \\
F( $1, \quad$\begin{tabular}{cc}
$1032)=$ & 0.12 \\
prob $>F=$ & 0.7290 \\
\hline
\end{tabular}
\end{tabular}

Figure A-5-The result of "ftest" unconstrained against constrained

According to the results of Figure A-5, it shows that the "F statistic" is " 0.12 " which is not highly significant and the probability is " 0.73 " which is not quite low. It can be concluded that two variables of "Education and related expenses" and "Total revenue of institution" have an equal effect on the sustainability grades in the model. 


\section{References}

1. (EPA), E.P.A. What is sustainability? / What is EPA doing? / How can / help? 2014 03/2014]; Available from: http://www.epa.gov/sustainability/basicinfo.htm.

2. sarni, P.P.a.W., Using sustainability to drive business innovation and growth. 2012.

3. Altman, S.a. Climate Change, Water, and Risk: Current Water Demands Are Not Sustainable. 2010.

4. Alshuwaikhat, H.M. and I. Abubakar, An integrated approach to achieving campus sustainability: assessment of the current campus environmental management practices. Journal of Cleaner Production (Elsevier), 2008. 16: p. 1777-1785.

5. Cortese, A.D., The Critical Role of Higher Education in Creating a Sustainable Future. 2003.

6. Velazquez, L., et al., Sustainable university: what can be the matter? Journal of Cleaner Production (Elsevier), 2006. 14: p. 810-819.

7. Viebahn, P., An environmental management model for universities: from environmental guidelines to staff involvement. . Journal of Cleaner Production (Elsevier), 2002. 10: p. 3-12.

8. Velazquez, L., N. Munguia, and M. Sanchez, Deterring sustainability in higher education institutions, An appraisal of the factors which influence sustainability in higher education institutions. International Journal of Sustainability in Higher Education, 2005. 6(4): p. 383-391.

9. White, S.S., Campus sustainability plans in the United States: where, what, and how to evaluate? International Journal of Sustainability in Higher Education, 2014. 15(2): p. 228241.

10. Bilodeau, L., J. Podger, and A. Abd-El-Aziz, Advancing campus and community sustainability: strategic alliances in action. International Journal of Sustainability in Higher Education, 2014. 15(2): p. 157-168.

11. Richardson, G. and J. Lynes, Institutional Motivations and Barriers to the Construction of Green Buildings on Campus. International Journal of Sustainability in Higher Education, 2007. 8(8): p. 339-354.

12. Sardianou, E. and P. Genoudi, Which factors affect the willingness of consumers to adopt renewable energies? Renewable Energy (Elsevier), 2013. 57: p. 1-4.

13. Posner, S.M. and R. Stuart, Understanding and advancing campus sustainability using a systems framework. International Journal of Sustainability in Higher Education, 2013. 14(3): p. 264-277.

14. Stafford, S.L., How Green is Your Campus? An Analysis of the Factors that Drive Universities to Embrace Sustainability. CONTEMPORARY ECONOMIC POLICY, 2010. 29(3): p. 337-356.

15. greenreportcard.org. The College Sustainability Report Card. 2007-2011 11/20123/2013]; Available from: http://www.greenreportcard.org/.

16. statalist.org. Statalist Forums. 2013 05/2013]; Available from: http://www.statalist.org/forums/. 
17. stata.com. Stata 13 help for save. 2013 06/2013]; Available from: http://www.stata.com/help.cgi?save.

18. stata.com, Manual of Stata, Chapter 16: Do-files, 2013, www.stata.com.

19. Carnegie, F.f.t.A.o.T. Classification Description. 2005; Available from: http://classifications.carnegiefoundation.org/descriptions/basic.php.

20. eia.gov. Most states have Renewable Portfolio Standards. 2012 06/2013]; Available from: http://www.eia.gov/todayinenergy/detail.cfm?id=4850\&amp;src=email.

21. Census.gov. Metropolitan and Micropolitan Statistical Areas Main. 2010 06/2013]; Available from: http://www.census.gov/population/metro/.

22. USA.gov, FEDERAL ELECTIONS 2008; Election Results for the U.S. President, the U.S. Senate and the U.S. House of Representatives F.E. Commission, Editor 2009: Washington, D.C.

23. Fenton, N. and M. Neil, Chapter 1: Correlation coefficient and p-values: what they are and why you need to be very wary of them, in Risk Assessment and Decision Analysis with Bayesian Networks2012, CRC Press.

24. A.H.Studenmund, Using Econometrics: A Practical Guide2005: Prentice Hall. 173.

25. nd.edu, Imposing and Testing Equality Constraints in Models, 2013. 